\title{
Multidisciplinary rehabilitation for older people with hip fractures (Review)
}

\author{
Handoll HHG, Cameron ID, Mak JCS, Finnegan TP
}

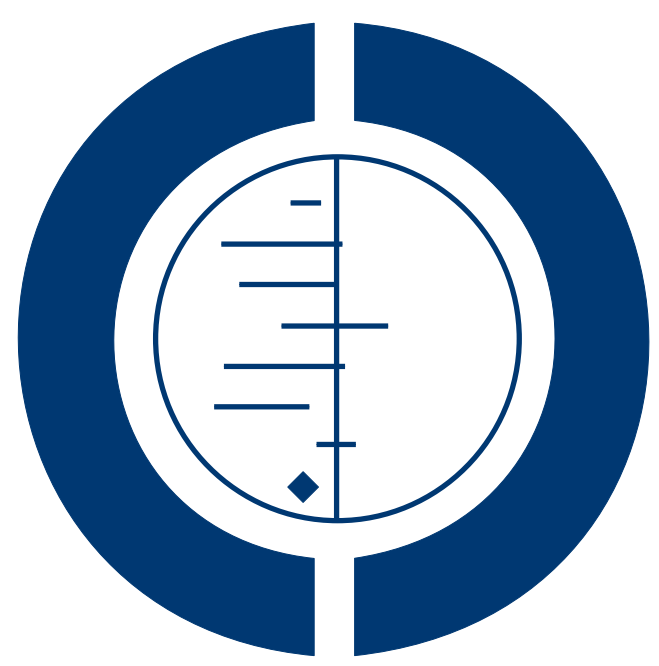

\section{THE COCHRANE COLLABORATION $^{\circledR}$}

This is a reprint of a Cochrane review, prepared and maintained by The Cochrane Collaboration and published in The Cochrane Library 2009, Issue 4

http://www.thecochranelibrary.com

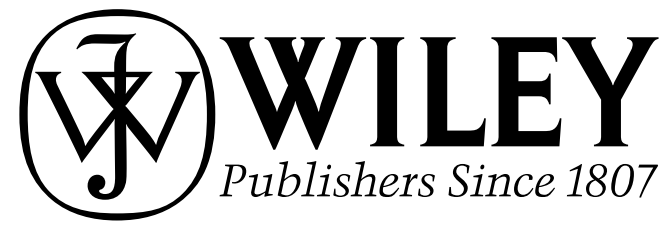

Multidisciplinary rehabilitation for older people with hip fractures (Review)

Copyright (@) 2009 The Cochrane Collaboration. Published by John Wiley \& Sons, Ltd. 
TABLE OF CONTENTS

HEADER . . . . . . . . . . . . . . . . . . . . . . . . . . . . . . . . . . . . . . . 1

ABSTRACT . . . . . . . . . . . . . . . . . . . . . . . . . . . . . . . . . . . . . . . . . . 1

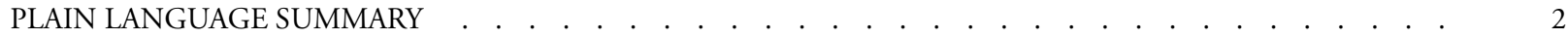

BACKGROUND . . . . . . . . . . . . . . . . . . . . . . . . . . . . . . . . . . . . . 2

OBJECTIVES . . . . . . . . . . . . . . . . . . . . . . . . . . . . . . . . . . . . . 4

METHODS . . . . . . . . . . . . . . . . . . . . . . . . . . . . . . . . . . . . . . 44

RESULTS . . . . . . . . . . . . . . . . . . . . . . . . . . . . . . . . . . . . . . . 7

Figure 1. . . . . . . . . . . . . . . . . . . . . . . . . . . . . . . . . 10

DISCUSSION . . . . . . . . . . . . . . . . . . . . . . . . . . . . . . . . 14

AUTHORS' CONCLUSIONS . . . . . . . . . . . . . . . . . . . . . . . . . . . . . . . . . . . . . 16

ACKNOWLEDGEMENTS . . . . . . . . . . . . . . . . . . . . . . . . . . . . . . . . . . . . . . . . 17

REFERENCES . . . . . . . . . . . . . . . . . . . . . . . . . . . . . . . . . . . . 17

CHARACTERISTICS OF STUDIES . . . . . . . . . . . . . . . . . . . . . . . . . . . . . 21

DATA AND ANALYSES . . . . . . . . . . . . . . . . . . . . . . . . . . . . . . . . . . . . . . . . . . . 54

Analysis 1.1. Comparison 1 Multidisciplinary inpatient rehabilitation versus usual care, Outcome 1 'Poor outcome' (longterm follow-up). . . . . . . . . . . . . . . . . . . . . . . . . . . . . . . . . . 57

Analysis 1.2. Comparison 1 Multidisciplinary inpatient rehabilitation versus usual care, Outcome 2 'Poor outcome' (longterm follow-up) - Kennie 1988.

Analysis 1.3. Comparison 1 Multidisciplinary inpatient rehabilitation versus usual care, Outcome 3 'Poor outcome' (longterm follow-up) by intervention type.

Analysis 1.4. Comparison 1 Multidisciplinary inpatient rehabilitation versus usual care, Outcome 4 'Poor outcome' (longterm follow-up) by selection bias.

Analysis 1.5. Comparison 1 Multidisciplinary inpatient rehabilitation versus usual care, Outcome 5 'Poor outcome' (at discharge).

Analysis 1.6. Comparison 1 Multidisciplinary inpatient rehabilitation versus usual care, Outcome 6 Mortality (end of scheduled follow-up).

Analysis 1.7. Comparison 1 Multidisciplinary inpatient rehabilitation versus usual care, Outcome 7 Mortality (end of scheduled follow-up) - with 12 month data for Cameron 1993. . . . . . . . . . . . . . . . . . . .

Analysis 1.8. Comparison 1 Multidisciplinary inpatient rehabilitation versus usual care, Outcome 8 Mortality (at discharge).

Analysis 1.9. Comparison 1 Multidisciplinary inpatient rehabilitation versus usual care, Outcome 9 Functional outcomes.

Analysis 1.10. Comparison 1 Multidisciplinary inpatient rehabilitation versus usual care, Outcome 10 Functional outcomes: Barthel scores at long-term follow-up.

Analysis 1.11. Comparison 1 Multidisciplinary inpatient rehabilitation versus usual care, Outcome 11 Complications.

Analysis 1.12. Comparison 1 Multidisciplinary inpatient rehabilitation versus usual care, Outcome 12 Length of hospital stay. . . . . . . . . . . . . . . . . . . . . . . . . . . . . . . . . . . . . .

Analysis 1.13. Comparison 1 Multidisciplinary inpatient rehabilitation versus usual care, Outcome 13 Readmitted to hospital during follow-up.

Analysis 1.14. Comparison 1 Multidisciplinary inpatient rehabilitation versus usual care, Outcome 14 Dead or readmitted to hospital during follow-up.

Analysis 2.1. Comparison 2 Accelerated discharge and multidisciplinary home-based rehabilitation versus usual inpatient rehabilitation, Outcome 1 'Poor outcome', mortality, institutional care and unable to walk (12 months).

Analysis 2.2. Comparison 2 Accelerated discharge and multidisciplinary home-based rehabilitation versus usual inpatient rehabilitation, Outcome 2 SF-36 scores at 12 months (0: worst to 100: best).

Analysis 2.3. Comparison 2 Accelerated discharge and multidisciplinary home-based rehabilitation versus usual inpatient rehabilitation, Outcome 3 Lengths of hospital or rehabilitation stays (days).

Analysis 2.4. Comparison 2 Accelerated discharge and multidisciplinary home-based rehabilitation versus usual inpatient rehabilitation, Outcome 4 Readmission to hospital during 4 months follow-up. . . . . . . . . . . . .

Analysis 3.1. Comparison 3 Intensive versus less intensive community rehabilitation, Outcome 1 'Poor outcome', mortality and institutional care (12 months). 
Analysis 3.2. Comparison 3 Intensive versus less intensive community rehabilitation, Outcome 2 Number of contacts over

12 weeks (for participants with hip fracture or stroke). . . . . . . . . . . . . . . . . . . . .

Analysis 4.1. Comparison 4 Exploratory analysis: all settings, Outcome 1 'Poor outcome' (long-term follow-up) by intervention type + Crotty 2003. . . . . . . . . . . . . . . . . . . . . . . . . . . . 73

APPENDICES . . . . . . . . . . . . . . . . . . . . . . . . . . . . . . . . . . . . . 73

HISTORY . . . . . . . . . . . . . . . . . . . . . . . . . . . . . . . . . . . . 75

CONTRIBUTIONS OF AUTHORS . . . . . . . . . . . . . . . . . . . . . . . . . . . . . . 75

DECLARATIONS OF INTEREST . . . . . . . . . . . . . . . . . . . . . . . . . . . . . . . . . . . . . . . 79

SOURCES OF SUPPORT . . . . . . . . . . . . . . . . . . . . . . . . . . . . . . . . . . . . . . . . . . . . . 76

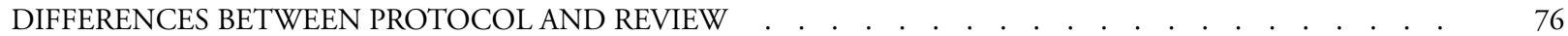

NOTES . . . . . . . . . . . . . . . . . . . . . . . . . . . . . . . . 76 


\title{
[Intervention Review]
}

\section{Multidisciplinary rehabilitation for older people with hip fractures}

\author{
Helen HG Handoll ${ }^{2}$, Ian D Cameron ${ }^{1}$, Jenson CS Mak ${ }^{3}$, Terence P Finnegan ${ }^{4}$ \\ ${ }^{1}$ Rehabilitation Studies Unit, Northern Clinical School, Sydney Medical School, The University of Sydney, Ryde, Australia. ${ }^{2}$ Centre \\ for Rehabilitation Sciences (CRS), Research Institute for Health Sciences and Social Care, University of Teesside, Middlesborough, \\ UK. ${ }^{3}$ Sacred Heart Rehabilitation Service, St Vincent's Hospital, Sydney, Australia. ${ }^{4}$ Department of Aged Care and Rehabilitation \\ Medicine, Royal North Shore Hospital of Sydney, St Leonards, Australia
}

Contact address: Ian D Cameron, Rehabilitation Studies Unit, Northern Clinical School, Sydney Medical School, The University of Sydney, PO Box 6, Ryde, NSW, 1680, Australia. ianc@mail.usyd.edu.au.

Editorial group: Cochrane Bone, Joint and Muscle Trauma Group.

Publication status and date: New, published in Issue 4, 2009.

Review content assessed as up-to-date: 31 May 2009.

Citation: Handoll HHG, Cameron ID, Mak JCS, Finnegan TP. Multidisciplinary rehabilitation for older people with hip fractures. Cochrane Database of Systematic Reviews 2009, Issue 4. Art. No.: CD007125. DOI: 10.1002/14651858.CD007125.pub2.

Copyright (C) 2009 The Cochrane Collaboration. Published by John Wiley \& Sons, Ltd.

\section{A B S T R A C T}

Background

Hip fracture is a major cause of morbidity and mortality in older people and its impact on society is substantial.

\section{Objectives}

To examine the effects of multidisciplinary rehabilitation, in either inpatient or ambulatory care settings, for older patients with hip fracture.

\section{Search strategy}

We searched the Cochrane Bone, Joint and Muscle Trauma Group Specialised Register (April 2009), The Cochrane Library (2009, Issue 2), MEDLINE and EMBASE (both to April 2009).

\section{Selection criteria}

Randomised and quasi-randomised trials of post-surgical care using multidisciplinary rehabilitation of older patients (aged 65 years or over) with hip fracture. The primary outcome, 'poor outcome' was a composite of mortality and decline in residential status at longterm (generally one year) follow-up.

Data collection and analysis

Trial selection was by consensus. Two review authors independently assessed trial quality and extracted data. Data were pooled where appropriate.

\section{Main results}

The 13 included trials involved 2498 older, usually female, patients who had undergone hip fracture surgery. Though generally well conducted, some trials were at risk of bias such as from imbalances in key baseline characteristics.

There was substantial clinical heterogeneity in the trial interventions and populations. Multidisciplinary rehabilitation was provided primarily in an inpatient setting in 11 trials. Pooled results showed no statistically significant difference between intervention and 
control groups for poor outcome (risk ratio $0.89 ; 95 \%$ confidence interval 0.78 to 1.01 ), mortality (risk ratio $0.90,95 \%$ confidence interval 0.76 to 1.07 ) or hospital readmission. Individual trials found better results, often short-term only, in the intervention group for activities of daily living and mobility. There was considerable heterogeneity in length of stay and cost data. Three trials reporting carer burden showed no evidence of detrimental effect from the intervention. Overall, the evidence indicates that multidisciplinary rehabilitation is not harmful.

The trial comparing primarily home-based multidisciplinary rehabilitation with usual inpatient care found marginally improved function and a clinically significantly lower burden for carers in the intervention group. Participants of this group had shorter hospital stays, but longer periods of rehabilitation. One trial found no significant effect from doubling the number of weekly contacts at the patient's home from a multidisciplinary rehabilitation team.

\section{Authors' conclusions}

While there was a tendency to a better overall result in patients receiving multidisciplinary inpatient rehabilitation, these results were not statistically significant.

Future trials of multidisciplinary rehabilitation should aim to establish both effectiveness and cost effectiveness of multidisciplinary rehabilitation overall, rather than evaluate its components.

\section{PLAIN LANGUAGE SUMMARY}

\section{Multidisciplinary rehabilitation of older patients with hip fractures}

Hip fracture is a serious injury in older people and can contribute to their death or loss of independence. Normally surgery is performed and followed by care in a ward under the supervision of orthopaedic staff. Additional rehabilitation within the hospital is sometimes provided by a geriatrician and other health professionals. Sometimes, the emphasis is on early discharge from hospital with multidisciplinary rehabilitation provided to the patient at home. There is enormous variety in these rehabilitation programmes.

This review included 13 trials, which involved a total of 2498 older, usually female, patients who had undergone surgery for hip fracture. Generally the trials appeared well conducted, although some were at risk of bias that could affect the reliability of their results. For example, despite randomisation, in five trials there were some important differences in patient characteristics, such as age, at the start of the trial that could have influenced trial findings. The trial interventions were very varied but all compared multidisciplinary rehabilitation with usual care. In 11 trials, care was provided either totally or mainly in an inpatient or hospital setting. While there was a tendency for a better outcome after multidisciplinary rehabilitation, the results were not statistically significant and thus cannot be considered conclusive. However, the overall evidence indicates that multidisciplinary rehabilitation is not harmful. Additionally, there was some inconclusive evidence that multidisciplinary rehabilitation did not add to the burden of carers. In one trial that compared home-based multidisciplinary rehabilitation with usual inpatient care, carers reported significantly lower burden in the long term after multidisciplinary rehabilitation. Participants in the home-based rehabilitation group of this trial had shorter hospital stays, but longer periods of rehabilitation. One other trial found no significant effect from doubling the number of weekly contacts at the patient's home by a multidisciplinary rehabilitation team.

Overall, the results of this review suggest that multidisciplinary rehabilitation may help more older people recover after a hip fracture. However, the results are not conclusive and more research is needed.

\section{B A C K G R O U N D}

This new review, preceded by a protocol (published in Issue 2, 2008), replaces a previous review (Cameron 2001), the scope of which was confined to inpatient rehabilitation.

\section{Description of the condition}

Fracture of the proximal femur, generally termed a 'hip fracture', occurs most often in frail older people and generally as a result of a simple fall from standing height or less (Norton 1997). In industrialised countries, the mean age of people sustaining a hip 
fracture is around 80 years and around $80 \%$ are female. People sustaining a hip fracture frequently have many other medical and physical problems; these often hinder their recovery and add to the challenge of managing their fracture. Cognitive impairment and dementia are also major considerations, both in terms of risk of hip fracture and recovery from hip fracture. Despite generally successful surgical treatment, hip fracture poses a major threat to life, mobility and independence (Marottoli 1992). Between 12\% and $37 \%$ of people sustaining a hip fracture die within the first year (Lyons 1997), often as a direct consequence of their fracture (Parker 1991). Most of the survivors fail to regain their former levels of mobility and activity, and many become more dependent (Magaziner 2000). About 10 to $20 \%$ of the survivors will require a change to a more dependent residential status (Rosell 2003).

The burden on society from hip fracture is immense and is increasing. An estimated 1.26 million hip fractures occurred in adults in 1990 with predictions of numbers rising to 7.3 to 21.3 million by the year 2050; the steepest increases being expected in Asia (Gullberg 1997). The resources required to provide the institutional and community care for those afflicted are already enormous (Schneider 1990). Recently, the direct costs of hip fracture were found to exceed acute myocardial infarction in Italy (Piscitelli 2007). There are data suggesting current trends in the incidence of hip fracture vary between countries, and also within countries. Overall there is an increase in incidence of hip fracture that is continuing in most countries (Cummings 2002). In developed countries, lifetime prevalence has been estimated to be one in six for Caucasian women and somewhat less than half of this for men ( Cummings 2002). Inevitably the absolute disease burden will also increase with population aging, putting further pressure on already stretched health care systems. Additionally, very large costs are generated by the additional requirement for institutional care for many people.

\section{Description of the intervention}

Most people with hip fracture have surgery (Handoll 2008), after which there are a wide range of treatments that are used to assist recovery (SIGN 2002). Some of these treatments have specific goals, such as restoring mobility (see Handoll 2007 for a systematic review of mobilisation strategies) and independence in other basic daily living functions, such as bathing, dressing and continence. The focus of this review is the delivery and provision of rehabilitation, specifically using a multidisciplinary approach.

For the purpose of this review, 'rehabilitation' is defined as services provided by a multidisciplinary team with the goal of reducing disability by improving task-oriented behaviour, for example, walking and dressing.

Care provision after hip fracture varies substantially across the world and may be determined by economic and cultural factors (personal or societal). Many strategies have been employed for the rehabilitation of hip fracture patients. Rehabilitation is generally adapted to an individual's general health, disability status and living circumstances. For instance, a small percentage of hip fracture patients are fit enough to return directly home from the surgical ward albeit, where possible, with the support of services, including home-based rehabilitation. The majority though have, or require, additional institutionally-based treatment.

Inpatient rehabilitation can be provided in an orthopaedic ward, but it often takes place in a separate rehabilitation ward, to where the patients are transferred from the acute orthopaedic ward upon recovery from their operation. The rehabilitation ward is typically designed to improve functioning by encouraging mobility and self care through practice of these activities with the support of staff in a ward environment that provides equipment, for example mobility aids and adaptations in the bathroom, and appropriate routines, for example meals in a dining room. Multiple health disciplines, for example physiotherapists, occupational therapists, social workers, nurses and doctors, work with the person with hip fracture to provide a co-ordinated rehabilitation programme. This is facilitated by formal meetings, usually weekly, and regular discussion about goals of treatment with the patient and their family. In the UK, there are a number of rehabilitation units that accommodate only geriatric orthopaedic patients (Geriatric Orthopaedic Rehabilitation Units: GORU). The more common model internationally is the Mixed Assessment and Rehabilitation Unit (MARU), where older patients from mixed diagnostic groups are accommodated.

Ideally the patient is generally discharged from a hospital-based rehabilitation programme when able to live with acceptable risk in their usual accommodation or an alternative setting. Following discharge from hospital several different types of rehabilitation programme have been described. Early Supported Discharge (ESD) is a rehabilitation programme provided in the patient's home setting. In the USA, patients are often discharged to skilled nursing facilities for rehabilitation. Other types of non inpatient rehabilitation programme are provided in some circumstances; for example, in a day hospital or in an outpatient department.

Programmes of care and rehabilitation after hip fracture surgery have been developed in which a number of the components described above are combined and co-ordinated. One such programme is the Geriatric Hip Fracture Rehabilitation Programme. These programme components and models are described in more detail in the NHS Review (Cameron 2000).

In summary, the intervention tested in this review is specialised multidisciplinary rehabilitation supervised by a geriatrician or rehabilitation physician (a medical practitioner with skill and experience in rehabilitation) compared with usual care, for older people with hip fracture, in either an inpatient rehabilitation setting, an ambulatory rehabilitation setting or both. The comparator (control) intervention is usual care. In early studies this was care in the orthopaedic surgical ward. However, in some more recent studies it is an alternative rehabilitation programme that usually starts later, and is less intensive and co-ordinated (Halbert 2007). In 
the ambulatory setting, the supervisory role may be performed by a specialist clinician in geriatrics or rehabilitation other than a physician.

\section{How the intervention might work}

The primary goal for the person with hip fracture is a return to optimal level of functioning (WHO 2003). To achieve this, specific goals are set and the therapeutic input required to achieve these is dependent on the co-ordinated skills of multiple health professionals. While the process has been described and documented by the World Health Organisation, stroke researchers have most clearly described the components of rehabilitation that are potentially associated with effectiveness (Stroke Collaboration 1997; Stroke Collaboration 2007). However, in this review, we aim to establish the effectiveness and cost effectiveness of multidisciplinary rehabilitation overall, rather than attempt to evaluate its components.

\section{Why it is important to do this review}

This review is required because of the very large number of older people who sustain hip fractures; and the substantial impact, both on the individual and to society, of these fractures. Given this, it is highly important that the effectiveness of the various strategies employed for the rehabilitation of people with these fractures is assessed. Since the previous review (Cameron 2001), which focused on co-ordinated multidisciplinary inpatient rehabilitation only, the international trend to reduction of acute hospital length of stay has intensified and encouraged the development of rehabilitation programmes that operate in a variety of settings. Thus as well as updating the evidence for the inpatient care, we have included outpatient or 'ambulatory' rehabilitation in different settings to ensure the continuing relevance.

\section{O B JE C T IVES}

This review aims to examine the effectiveness and cost effectiveness of specialised multidisciplinary rehabilitation supervised by a geriatrician or rehabilitation physician/clinician compared with usual care, for older people with hip fracture. This comparison encompasses both inpatient and post-hospital-discharge (including outpatient) care. Given the anticipated differences in types of service provision between the two settings (inpatient and ambulatory) and consequent problems in interpretation of the findings, we will pool data from both settings on an exploratory basis only. Our primary objectives are thus to examine the effectiveness and cost effectiveness of specialised multidisciplinary rehabilitation supervised by a geriatrician or rehabilitation physician compared with usual care, for older people with hip fracture, in:
- the inpatient rehabilitation setting;

- the ambulatory rehabilitation setting.

Unless predominantly ambulatory care, care spanning over both settings was intended to be included in the inpatient category.

\section{METHODS}

\section{Criteria for considering studies for this review}

\section{Types of studies}

Included were randomised trials of post-surgical care comparing specialised multidisciplinary rehabilitation with conventional care. Trials that used a quasi-randomisation technique (e.g. allocation by date of birth or days of the week) were also eligible for inclusion.

\section{Types of participants}

Older people with any type of fracture of the proximal femur which had been surgically fixed prior to entry into the care programme were included. Specific age limits were not defined but as anticipated most participants will be aged 65 years and over. Younger patients $(<65$ years) were included as the number of these was relatively small and there appeared be be adequate randomisation with unbiased distribution of this younger population between the intervention and control groups. Reports of proximal femoral fracture confined to younger populations or to people with multiple trauma including hip fracture were excluded.

\section{Types of interventions}

For this review, the type of intervention under scrutiny is treatment in a multidisciplinary rehabilitation programme (where rehabilitation is delivered by a multidisciplinary team, supervised by a geriatrician or rehabilitation physician/clinician) as opposed to "usual" care (control group). Such a programme would aim to improve the functioning of the person with hip fracture. The programme will be provided in an inpatient or ambulatory setting (or both). Here ambulatory setting covers home, outpatient department and day hospital locations. "Usual" care for the control group will be usual orthopaedic or medical care, or potentially a rehabilitation programme of lesser intensity, or with different components, to the intervention under study. 


\section{Types of outcome measures}

The primary outcome is 'poor outcome', defined as death or deterioration of functional status leading to increased dependency in the community or admission to institutional care.

Information was sought on this and its constituent outcomes, and other outcomes as listed below. These were treated as secondary outcomes.

- All cause mortality;

- Morbidity, including postoperative complications and treatment of newly recognised but pre-existing disease or illness;

- Patients' postoperative functional status including cognitive functioning, mobility and ability to perform activities of daily living;

- Resource use including length of hospital stay and subsequent admission rates to, and days spent in, institutional care;

- The level of care and extent of support required or provided on discharge;

- The patients' perceived quality of life, and wellbeing, after discharge;

- Carer burden and stress;

- Direct, indirect, hidden and opportunity costs (the cost of treatments forgone);

- Adherence to rehabilitation under examination (including changes to other types of rehabilitation).

\section{Timing of outcome assessment}

Results were collected for the final follow-up time for which these were available. We, however, took note where trial results may not have been representative of final functional status. This was based on a minimum follow-up of six months from time of injury.

\section{Search methods for identification of studies}

\section{Electronic searches}

We searched the Cochrane Bone, Joint and Muscle Trauma Group Specialised Register (April 2009), the Cochrane Central Register of Controlled Trials (The Cochrane Library, 2009, Issue 2), MEDLINE (1950 to April week 3 2009), and EMBASE (1980 to 2009 week 16). We also searched Current Controlled Trials (up to 29 April 2009) and the WHO International Clinical Trials Registry Platform (up to 23 April 2009) for ongoing and recently completed trials. No language restriction was applied.

The topic-specific MEDLINE search is combined with the first two stages of the Cochrane optimal trial search strategy (Higgins 2006). This and the Group's generic hip fracture EMBASE search strategy are shown in Appendix 1.

\section{Searching other resources}

As well as following up any reports of relevant trials presented at conferences attended in person (IC), we included the findings from handsearches of Orthopaedic Transactions, supplements of Acta Orthopaedica Scandinavica and the British Volume of the Journal of Bone and Joint Surgery (1996 to 2007). In addition, we handsearched the final programmes of SICOT (1996, 1999 and 2007), the British Orthopaedic Association Congress (2000, 2001, 2002, 2003, 2005 and 2006), and abstracts of the American Orthopaedic Trauma Association annual meetings (1996 to 2006). We scrutinised weekly downloads of "Fracture" articles in new issues of 15 journals (Acta Orthop Scand; Am J Orthop; Arch Orthop Trauma Surg; Clin J Sport Med; Clin Orthop; Foot Ankle Int; Injury; J Am Acad Orthop Surg; J Arthroplasty; J Bone Joint Surg Am; J Bone Joint Surg Br; J Foot Ankle Surg; J Orthop Trauma; J Trauma; Orthopedics) and of "Rehabilitation Medicine" in a further 10 journals (Am J Phys Med Rehabil; Arch Phys Med Rehabil; BMJ; Clin Rehabil; J Am Geriatr Soc; J Rehabil Med; JAMA; Lancet; Phys There; Scand J Rehabil Med) from AMEDEO.

Results from a comprehensive search for trials (up to August 1998) for a non-Cochrane review on rehabilitation following fractures in older people (Cameron 2000) were screened as well as those from a more recent non-Cochrane review on multidisciplinary rehabilitation (Halbert 2007).

\section{Data collection and analysis}

\section{Selection of studies}

After initial screening by two authors (IC and $\mathrm{HH}$ ), all four review authors independently assessed potentially eligible trials identified via the search for inclusion using a pre-piloted form. Any disagreement was resolved by discussion. It was not found necessary to seek further information about study methods and interventions from trialists to determine eligibility.

\section{Data extraction and management}

Using a pre-piloted data extraction form, pairs of review authors independently extracted trial details and data for the five trials not included in Cameron 2001; and four trials, one of which was the basis of the pilot, reviewed in Cameron 2001. Data extraction for all of the trials was done by $\mathrm{HH}$, who checked these against data extraction forms provided by the other authors and, where appropriate, data presented in Cameron 2000, Cameron 2001 and Halbert 2007. Key additional information was sought from trialists, including the method of randomisation. There was no need to extract results from graphs in trial reports, although this would have been considered where data were not otherwise available. Decisions for data aggregation for calculating 'poor' outcome, the 
designated primary outcome of this review, from mortality and functional data presented in individual trials were by consensus (IC and $\mathrm{HH}$ ).

Results were collected for the final follow-up time for which these are available. We intended, however, to note instances where a marked and important difference between groups in the pattern of functional recovery had been found at an intermediate assessment.

\section{Assessment of risk of bias in included studies}

Risk of bias was independently assessed, without masking of the source and authorship of the trial reports, by pairs of review authors for nine trials, and by $\mathrm{HH}$ alone for four other trials that had been assessed in previous reviews. Consistency in assessment was checked by $\mathrm{HH}$ at data entry. We used the tool outlined in the Cochrane Handbook for Systematic Reviews of Interventions (Higgins 2008). This tool incorporates assessment of randomisation (sequence generation and allocation concealment), blinding (of participants, treatment providers and outcome assessors), completeness of outcome data, selection of outcomes reported and other sources of bias. We considered 'hard' outcomes (death, admission to institutional care, readmission to hospital) and other outcomes (e.g. functional status) separately in our assessment of blinding and completeness of outcome data. We assessed three additional sources of bias: selection bias resulting from imbalances in key baseline characteristics (e.g. cognitive function, prior care); performance bias such as resulting from lack of comparability in the experience of care providers; and ascertainment bias such as differences in timing of follow-up assessment.

\section{Measures of treatment effect}

Quantitative data reported in individual trial reports for outcomes listed in the inclusion criteria are presented in the text and in the analyses, using risk ratios with $95 \%$ confidence intervals for dichotomous outcomes, and mean differences with $95 \%$ confidence intervals for continuous outcomes. The primary analyses is based on the rehabilitation setting: inpatient or ambulant. We specified a priori that unless predominantly delivered in an ambulant setting, care spanning over both settings or combinations of inpatient and ambulant settings would be initially included in the inpatient category.

\section{Unit of analysis issues}

Although we would have included cluster randomised trials, the unit of randomisation in the included trials was the individual patient.

\section{Dealing with missing data}

Where appropriate, we have performed intention-to-treat analyses to include all people randomised to the intervention groups. As planned, we have investigated the effect of drop outs and exclusions by conducting worse and best scenario analyses. We were alert to the potential mislabelling or non identification of standard errors and standard deviations. Unless missing standard deviations could be derived from confidence intervals or standard errors, we did not assume values in order to present these in the analyses.

\section{Assessment of heterogeneity}

Heterogeneity was assessed by visual inspection of the forest plot (analysis) along with consideration of the $\mathrm{chi}^{2}$ test for heterogeneity and the $\mathrm{I}^{2}$ statistic (Higgins 2003).

\section{Assessment of reporting biases}

We considered there were insufficient data available to assess publication bias by preparing a funnel plot. Our search of 'grey literature' and pursuit of trials listed in clinical trial registers should have helped to avoid publication bias.

\section{Data synthesis}

Results of comparable groups of trials were pooled, initially using the fixed-effect model and 95\% confidence intervals. We also used the random-effects model, especially where there was unexplained heterogeneity. In the absence of cluster randomised trials, we found it unnecessary to use the generic inverse variance to pool data ( Deeks 2005).

\section{Subgroup analysis and investigation of heterogeneity}

Our primary analysis is by setting: inpatient and ambulant. As an exploratory analysis, we pooled the data from both settings. We stated a priori that unless predominantly ambulant care, care spanning over both settings or combinations of inpatient and outpatient settings would be initially included in the inpatient category. In our protocol we stated that our planned subgroup analyses, which could have been based on the primary setting or the combined setting data, would be by the stage of rehabilitation; patient cognitive function (one measure of this would be the ability versus inability to give individual consent); and pre-injury residence or dependency status (own home/independent; dependent/ nursing home or institutional care). We also stated that presentation in separate subgroups would be considered where there is a fundamental difference in intervention, including types of service provision. In the event, our subgroup analysis was limited to categories of intervention. We used the test of interaction to establish whether the subgroups were statistically significantly different from one another (Altman 2003). 


\section{Sensitivity analysis}

Where possible, we planned to do sensitivity analyses examining various aspects of trial and review methodology. In the current review, these include the effects of missing data, and whether there was selection bias from imbalances in patient characteristics of the comparison groups. We used the test of interaction to establish whether the subgroups were statistically significantly different from one another (Altman 2003).

\section{RE S U L T S}

\section{Description of studies}

See: Characteristics of included studies; Characteristics of excluded studies; Characteristics of studies awaiting classification; Characteristics of ongoing studies.

\section{Results of the search}

Systematic searches, carried out for this review and for previous reviews (Cameron 2000; Cameron 2001; Halbert 2007), yielded a total of 37 eligible studies, of which 13 are included, 19 are excluded, two are ongoing, and three are Studies awaiting classification. All 13 included trials are reported in full and in English; exceptionally, Fordham 1986 is available only as a report. Multiple publications, often conference abstracts but also reports reporting longer term follow-up results, are available and included for several trials. Personal communications resulting in additional information and data have been recorded in the Included studies section of the references: some pertain to correspondence belonging to a previous review (Cameron 2001). Four other reports of Stenvall 2007a that focused on different aspects of the intervention were also available for this trial.

\section{Included studies}

Individual trial details of the methods, participants, interventions and outcome measurement for the 13 included trials are presented in the Characteristics of included studies.

\section{Design}

All 13 trials randomised individual patients into one of two intervention groups.

\section{Sample sizes}

The 13 included trials involved a total of 2498 randomised patients who had undergone surgery for hip fracture. Sample size at randomisation ranged from 66 patients recruited into Crotty 2003 to 378 into Galvard 1995.

\section{Setting}

The 13 trials took place in one of six countries: Australia (3 trials); Canada (1); Spain (1); Sweden (2); Taiwan (1); and UK (4). Recruitment start dates ranged from 1984 (Galvard 1995) to 2001 ( Shyu 2008); no information was available for Kennie 1988. Care was provided in an inpatient setting, thus before hospital discharge, for both intervention groups of 11 trials (Cameron 1993; Fordham 1986; Galvard 1995; Gilchrist 1988; Huusko 2002, Kennie 1988; Naglie 2002; Shyu 2008; Stenvall 2007a; Swanson 1998; Vidan 2005) but for the control intervention group only of Crotty 2003. Intervention group participants were discharged from acute care within 48 hours of randomisation in Crotty 2003. Only Ryan 2006 was set in the community, after hospital discharge.

\section{Participants}

The mean age of trial participants ranged from 78 to 84 years. Most trials set a lower age limit for trial entry: this ranged from 50 in Cameron 1993 and 70 in Stenvall 2007a. Three trials (Fordham 1986; Gilchrist 1988; Kennie 1988) included only women. The proportion of men in the remaining trials varied from $17 \%$ in Cameron 1993 and 33\% in Crotty 2003. Six trials (Crotty 2003; Fordham 1986; Galvard 1995; Ryan 2006; Shyu 2008; Swanson 1998) specifically excluded patients with dementia; however, a third of the participants of Shyu 2008 had mild cognitive impairment. Nearly half of the study population of Cameron 1993 had cognitive impairment; and just over half of the study population of Gilchrist 1988 had reduced cognitive scores. The proportion of the study population with dementia or severe cognitive impairment was a fifth in Huusko 2002, a third in Kennie 1988 and Stenvall 2007a, and a quarter in Vidan 2005. Only the proportion (26\%) of the study population with mild impairment was reported by Naglie 2002. There was no selection based on pre-fracture residence in nine trials. Two of these (Kennie 1988; Stenvall 2007a) excluded patients whose fracture had occurred in hospital. The four other trials (Crotty 2003; Galvard 1995; Ryan 2006; Swanson 1998) only included people living in the community and, except for Swanson 1998, exclusively in their own home.

\section{Interventions}

The nature of the intervention (multidisciplinary rehabilitation) varied considerably in the included trials. Similarly, there was variation in 'usual care', where described. In 11 trials, multidisciplinary rehabilitation was provided primarily in an inpatient setting. In 
Crotty 2003, the intervention was primarily home-based compared with usual inpatient care. Ryan 2006 involved ambulatory care.

\section{Inpatient rehabilitation}

In six trials, the intervention was based on the provision of rehabilitation, after patient transfer, in a GORU either in the same hospital (Gilchrist 1988; Naglie 2002; Stenvall 2007a) or in a hospital at a distance from the orthopaedic department (Fordham 1986; Galvard 1995; Kennie 1988). The control groups received the care that was usually provided by the orthopaedic teams. Patients were seen in consultation by geriatricians if required; some patients in Stenvall 2007a were transferred to a geriatric rehabilitation unit. Access to similar allied health staff was confirmed in Gilchrist 1988 and Kennie 1988; and probable but not confirmed in Fordham 1986 and Galvard 1995. Access to some staff (e.g. occupational therapist) was either greater or exclusive to the intervention group in Naglie 2002 and Stenvall 2007a. In four trials ( Fordham 1986; Gilchrist 1988; Kennie 1988; Naglie 2002), the major component of the intervention was combined ward rounds with the geriatrician and orthopaedic surgeons, and multidisciplinary case conferences. Similarly, the close co-operation of geriatrician and orthopaedic surgeons in the medical care of patients and multidisciplinary teamwork were central to Stenvall 2007a. Galvard 1995 provided little detail of the intervention.

In Cameron 1993, Shyu 2008, Swanson 1998 and Vidan 2005, the intervention consisted of a more intensive rehabilitation programme while the control group received the level and type of rehabilitation usually provided in those hospitals. Usual care in Shyu 2008 was more minimal than in other trials, with most participants receiving just one session of physical therapy and no care provision after hospital discharge. The intervention in Swanson 1998 also involved early surgery and the use of regional anaesthesia and local analgesia where possible. Though the interventions were focused on hip fracture patients in essence Cameron 1993, and possibly some of the other trials including Huusko 2002, provided care in a MARU (mixed assessment and rehabilitation unit) setting. Care in Vidan 2005 was provided in shared orthopaedic wards. Huusko 2002 compared multidisciplinary rehabilitation in a geriatric ward in the same hospital where the surgery was undertaken, with care in local community hospitals supervised by general practitioners.

The intervention in Cameron 1993, Shyu 2008, Swanson 1998 and Vidan 2005 was early assessment by the rehabilitation physician or geriatrician (or geriatric nurse), emphasis on re-establishing physical independence and detailed discharge planning. Early mobilisation, early participation in self-care and individualised discharge planning were also part of the care provided in a GORU in Naglie 2002 and Stenvall 2007a. Assessment, intensive rehabilitation in a specialist geriatric ward, detailed discharge planning with follow-up home visits including physiotherapy were provided by a multidisciplinary geriatric team for the intervention group in Huusko 2002.

\section{Ambulatory rehabilitation}

Crotty 2003 compared accelerated discharge, within 48 hours of randomisation, and home-based interdisciplinary rehabilitation with usual care involving routine interdisciplinary hospital care and rehabilitation in hospital. The rehabilitation programme at the patient's home focused on early resumption of self care and domestic activities.

Ryan 2006 compared intensive (six visits per week) with less intensive (three or less visits per week) multidisciplinary rehabilitation in the patient's own home.

\section{Outcomes}

Only 'poor outcome', the primary outcome, is considered here. This was defined a priori as death or deterioration of functional status leading to increased dependency in the community or admission to institutional care. Where data were available, 'poor outcome' was presented for long-term follow-up (between 4 and 12 months) and at hospital discharge. The definitions of deterioration in residential status varied. For some trials it was based on the requirement for institutional care, and in others the non-return to home or independent living. Using this definition, deterioration was not measured in those trials that included people from nursing homes who returned back to nursing homes.

\section{Excluded studies}

The reasons for exclusion of 19 studies are listed in the Characteristics of excluded studies. The primary reasons for exclusion were: treatment allocation not randomised ( 4 trials); not multidisciplinary rehabilitation (10 trials); mixed population without separate data for hip fracture patients ( 4 trials); and no comparative data available despite requests (Jette 1987). Reconsideration of the intervention in Sanchez Ferrin 1999, included in Cameron 2001, resulted in its exclusion.

\section{Ongoing studies}

The details of two ongoing trials are presented in the Characteristics of ongoing studies. Notably, Sletvold 2009 aims to establish the use of an orthogeriatric unit (GORU), both pre- and postoperatively.

\section{Studies awaiting classification}

Details of the three trials in this category are presented in the Characteristics of studies awaiting classification. All trials were identified after the main study selection process. Jalovaara 2009 
appears to have been registered retrospectively and only trial registration details have identified thus far. Uy 2008, which was ended prematurely and included 11 participants only, is unique in its focus on rehabilitation of nursing home residents. Although a full report of this trial is available, a consensus was not reached on whether it should be included in the current review.

\section{Risk of bias in included studies}

A summary of the review authors' assessments of the risk of bias associated with various aspects of study design/conduct is presented in Figure 1. 
Figure I. Summary of review author's assessments (+ = low; ? = unclear; - = high risk of bias) for aspects of study conduct for individual trials.

\begin{tabular}{|c|c|c|c|c|c|c|c|c|c|c|}
\hline & 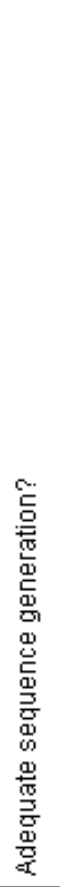 & 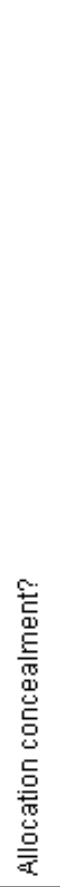 & 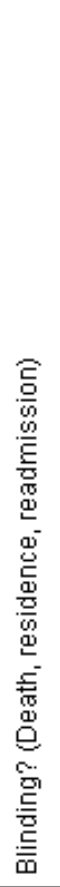 & 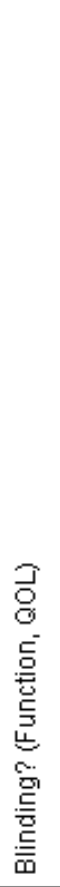 & 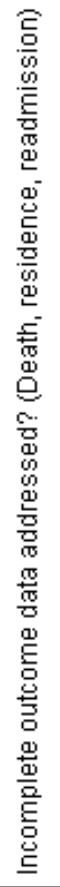 & 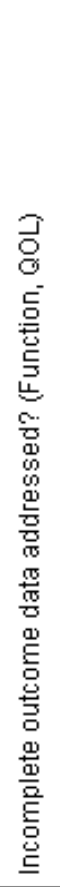 & 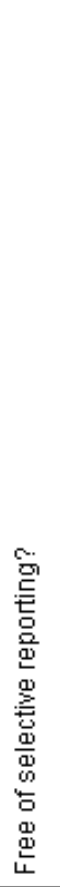 & 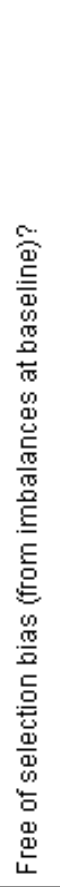 & 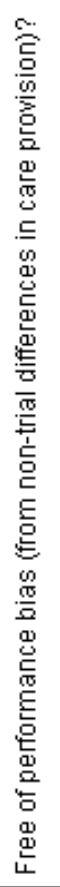 & 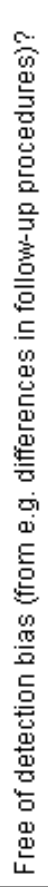 \\
\hline Cameron 1993 & + & + & $?$ & $?$ & + & $?$ & $?$ & $?$ & $?$ & + \\
\hline Crotty 2003 & + & + & $\odot$ & $?$ & $\odot$ & $?$ & $?$ & $\odot$ & $?$ & $\oplus$ \\
\hline Fordham 1986 & $?$ & + & $?$ & - & $?$ & - & $\oplus$ & $?$ & - & + \\
\hline Galvard 1995 & + & $?$ & + & $?$ & + & $\odot$ & $?$ & - & $\odot$ & $?$ \\
\hline Gilchrist 1988 & $?$ & $?$ & $?$ & $?$ & + & $?$ & $?$ & $\odot$ & $?$ & + \\
\hline Huusko 2002 & + & + & + & $?$ & - & & $\odot$ & - & $?$ & + \\
\hline Kennie 1988 & + & + & $?$ & $\odot$ & $\odot$ & $?$ & $?$ & & $?$ & + \\
\hline Naglie 2002 & 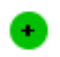 & + & + & $?$ & + & $\odot$ & $?$ & $\odot$ & $?$ & 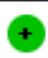 \\
\hline Ryan 2006 & + & + & + & $\oplus$ & + & $?$ & $?$ & & & + \\
\hline Shyu 2008 & + & + & $\odot$ & $?$ & $?$ & $?$ & $?$ & $\odot$ & + & + \\
\hline Stenvall 2007a & + & + & + & $?$ & + & 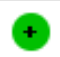 & $?$ & & $?$ & + \\
\hline Swanson 1998 & 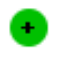 & $?$ & + & $?$ & + & + & $?$ & $?$ & $?$ & + \\
\hline Vidan 2005 & $?$ & $\odot$ & + & + & 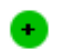 & $\odot$ & $?$ & + & $?$ & + \\
\hline
\end{tabular}




\section{Allocation}

Eight trials were considered at low risk of bias for randomisation sequence generation and allocation concealment. Insufficient information on sequence generation prevented judgement of the aspect for three trials (Fordham 1986; Gilchrist 1988; Vidan 2005); and on allocation concealment for three trials (Galvard 1995; Gilchrist 1988; Swanson 1998). Overall, there were no serious concerns regarding risk of selection bias from inappropriate methods of treatment allocation.

\section{Blinding}

Blinded assessment was reported for four trials (Crotty 2003; Naglie 2002; Ryan 2006; Vidan 2005). Despite lack of blinding, most other trials clearly applied systematic methods for data collection and often also had independent assessors. The outcomes of death, residence and readmission were considered to be less influenced by lack of blinding than other outcomes such as function and quality of life measures. Lack of blinding may have influenced assessment of these latter outcomes in Fordham 1986 and Kennie 1988.

\section{Incomplete outcome data}

Although sometimes this was achieved after contacting trial investigators, participant flow information was available for all trials. There were some concerns for possible bias for mortality, residence and readmission data for three trials (Fordham 1986; Huusko 2002; Shyu 2008), but this was only considered high risk in Huusko 2002 where there were post-randomisation exclusions and data excluded from participants without initial mental scores. The results for functional outcomes were judged at high risk of bias in Fordham 1986 (missing data and imbalances in missing data between the two groups), Galvard 1995 (data collected for a subgroup, imbalance in numbers assessed) and Huusko 2002 (as above; data only for those participants with baseline measurements).

\section{Selective reporting}

The study protocol was not available for any trial and so a cautious stance was taken in judging this item. The comprehensiveness of the reporting for Fordham 1986 made it very unlikely that selective reporting occurred in this trial. Huusko 2002 was the only trial judged to be at some risk of selective reporting bias.

\section{Other potential sources of bias}

Other biases considered pertained to selection bias from major imbalances in baseline characteristics, performance bias in terms of important differences in care provision outside of that of the trial interventions, and detection bias resulting from difference in follow-up procedures. Contamination bias resulting from the inadvertent application of the intervention being evaluated to peo- ple in the control group potentially leading to reduced differences between the intervention and control groups was also considered. Five trials (Galvard 1995; Huusko 2002; Kennie 1988; Ryan 2006; Stenvall 2007a) had major imbalances at baseline that could have influenced trial findings. In Kennie 1988 and Stenvall 2007a, this imbalance is likely to have favoured the intervention group, whereas the converse was likely in the other three trials.

Insufficient information on care programmes, especially in the control group and on clinician's experience, prevented judgement on the risks from performance bias. There was, however, a high risk of bias in three trials. In Fordham 1986, this was mainly in consequence of the location of the two study sites and arrangements for geriatrician cover. In Galvard 1995, the geriatric hospital had no prior experience with hip fracture patients; and in Ryan 2006, there was risk of compensatory care provision in the less intensive group. Contamination bias, resulting from shared care facilities and/or staff also seemed likely in Fordham 1986, Gilchrist 1988, Ryan 2006 and Vidan 2005.

Active and systematic methods of follow-up seemed to preclude detection bias in all trials except Galvard 1995, where imbalance in the follow-up of functional outcomes may have reflected different research environments at the two study sites.

\section{Effects of interventions}

\section{Inpatient rehabilitation}

\section{Poor outcome}

The outcomes of death or deterioration in residential status, generally the requirement for institutional care, were combined to give the overall outcome measure of 'poor outcome', which was assessed at the conclusion of follow-up and at hospital discharge. Data pooled from eight trials showed a non-statistically significant tendency in favour of the intervention (Analysis 1.1. Risk ratio $0.89,95 \%$ confidence interval 0.78 to 1.01 ) at long-term follow-up. The removal of Kennie 1988, which was the only trial with a statistically significant result and the source of the statistical heterogeneity in Analysis $1.1\left(\mathrm{I}^{2}=22 \%\right)$, from the analysis reduced the size of the effect (Analysis 1.2. RR 0.93, 95\% CI 0.82 to 1.07). A test for interaction $(\mathrm{P}=0.076)$ showed no difference between the results for trials subgrouped by type of intervention (specialist unit versus intensive rehabilitation): see Analysis 1.3. The removal of Kennie 1988, the source of the substantial heterogeneity $\left(\mathrm{I}^{2}=55 \%\right)$, from the specialist unit group again made the result non-statistically significant (RR $0.86,95 \%$ CI 0.66 to 1.12 : analysis not shown). A sensitivity analysis (Analysis 1.4) based on perceived risk of selection bias showed no statistically significant difference between the results for trials subgrouped by risk of selection bias (none versus unclear or high risk) from imbalances in patient characteristics (test for interaction: $\mathrm{P}=0.316$ ). As reported above, the risk of selection bias in Kennie 1988 and Stenvall 2007a meant that the results were likely to favour the intervention group, 
whereas the results were more likely to favour the control group in Huusko 2002.

Poor outcome at hospital discharge was based on mortality in hospital and discharge location. This outcome is more vulnerable to bias, such as differences in discharge policies and supply of alternative accommodation (as in Galvard 1995). Pooled results from seven trials, three of which (Fordham 1986; Galvard 1995; Gilchrist 1988) did not provide data for long-term 'poor outcome', showed a marginally statistically significant result in favour of the intervention (Analysis 1.5. RR 0.87, 95\% CI 0.75 to 1.00 ). The removal of the results for Kennie 1988 rendered the result nonsignificant (RR $0.90,95 \%$ CI 0.78 to 1.04 ; analysis not shown).

\section{Mortality}

Mortality data were reported for all 11 trials. Analysis 1.6 shows no statistically significant difference in mortality at the scheduled end of follow-up (RR $0.90,95 \%$ CI 0.76 to 1.07 ). There was no statistical heterogeneity in these results. The results for Cameron 1993 were for the four month follow-up period, the main trial follow-up period. The inclusion of 12 month mortality figures for Cameron 1993 did not alter the above finding (Analysis 1.7. RR $0.88,95 \%$ CI 0.74 to 1.04 ). The results for Swanson 1998 are 12 month mortality data provided by the lead trialist, rather than the six months post-discharge figures extrapolated from the main trial report. There was also no statistically significant difference in hospital mortality (Analysis 1.8. MD 0.77, 95\% CI 0.;56 to 1.06); only Vidan 2005 found a significant difference in hospital mortality.

\section{Functional status}

Measures of physical functioning varied between studies, and data pooling was either inappropriate or not possible. The numbers of participants for whom measurements were taken were unclear in several trials, and data were often incomplete. One trial (Gilchrist 1988) provided no data on function. The available data are shown in Analysis 1.9 and Analysis 1.10. Where possible the outcome for poor functional result in survivors combined with mortality data has been presented. This did not present an anomalous situation where the direction of effect differed between the result for the function in the survivors and the combined outcome. Cameron 1993 found no significant difference between the two groups at four months for regain of participant's former level of independence (29\% versus 26\%). Fordham 1986 also reported no difference in independent patient function based on several activities of daily living. Galvard 1995 reported no difference in long-term mobility but this was measured in a subgroup of participants, with a greater proportion from the control group (38 versus 60 ). Huusko 2002 found the intervention group recovered instrumental activities of daily living faster and Swanson 1998 reported a statistically significant improvement at three months and discharge but there was no longer a significant difference at six months or final one year follow-up for this trial. Both Kennie 1988 and Stenvall 2007a found significantly fewer people in the intervention were more dependent, or either more dependent or dead at one-year followup. Naglie 2002 found no difference in function either in terms of walking or transfers. Conversely, Shyu 2008 found significantly fewer participants of the intervention group failed to recover their former mobility. The difference between the two groups in the Chinese Barthel Index scores did not reach statistical significance (Analysis 1.9). Stenvall 2007a also found that activities of daily living were better maintained in the intervention group. Swanson 1998 reported a statistically significant difference at three months which was lost at final follow-up (Analysis 1.9). The difference between the two groups in the incomplete recovery of activities of daily living and mobility was not significant in Vidan 2005.

\section{Morbidity}

The available data for morbidity in terms of in hospital complications (Swanson 1998; Vidan 2005) or complications during 12 months follow-up (Huusko 2002), are presented in Analysis 1.11. Significantly fewer intervention group patients (6 versus 13) had chest infection, cardiac problems and/or bedsores in Swanson 1998, but more had stroke or emboli (4 versus 1). Vidan 2005 attributed the reduced overall incidence of medical complications in the intervention group (70 versus 100) to the early identification and daily patient care. The active prevention, identification and treatment of medical disorders was part of the intervention in Stenvall 2007a, where significantly fewer participants of the intervention were reported with post-operative delirium (reported $\mathrm{P}=0.003)$, urinary tract infection $(\mathrm{P}=0.005)$ or pressure ulcers $(\mathrm{P}=0.01)$. Identification of new medical disorders was part of the intervention of Gilchrist 1988, who from an inspection of postdischarge case records with full set of investigation results reported significantly fewer cases of untreated medical conditions in the intervention group (5/88 versus 33/69). Kennie 1988 reported there was no difference between the two groups in the "number of overall illnesses post-discharge". There was no difference between the two groups in the numbers of people with "some type of" complication during follow-up in Huusko 2002. Cameron 1993 reported that there were no medical complications that could be directly attributed to the intervention.

\section{Length of stay in hospital and hospital readmission}

The reported lengths of stay (all studies considered total length of stay) which included initial treatment in the orthopaedic unit and subsequent stay in the rehabilitation setting varied considerably. For example, the range of mean values in the control groups was from 10 days (Shyu 2008) to 56 days (Kennie 1988). Lengths of stay in Huusko 2002 were calculated from the day of surgery to the day of discharge lasting at least two weeks. The lengths of stay were shorter in the intervention groups of seven trials (Cameron 1993; Gilchrist 1988; Huusko 2002; Kennie 1988; Swanson 1998; Stenvall 2007a; Vidan 2005), longer in three (Fordham 1986; Galvard 1995; Naglie 2002) and similar in one (Shyu 2008). Stan- 
dard deviations were not available for Fordham 1986 (mean length of stay GORU: 56 days; control: 44 days; no difference reported); and data were presented as medians in Huusko 2002 (median 34 versus 42 days, reported $P=0.05$ ), and Vidan 2005 (median 16 versus 18 days, reported $\mathrm{P}=0.06$ ). The distribution of length of stay in Fordham 1986 showed more participants of the intervention group (10 versus 4) stayed over 91 days. Vidan 2005 reported two outliers whose stay was over 100 days. Where data were presented showing the distribution of lengths of stay, it was clear that they were not normally distributed but, for completeness, the graph of the available data from eight trials is presented in Analysis 1.12. These data were not pooled given the clearly considerable heterogeneity. The total number of days in hospital per patient was 80 in each group of Huusko 2002. There was also no difference in mean stay over six months in institutional care (either acute or rehabilitation hospital or nursing home) in Naglie 2002, which was reported to be 110 days for both groups. Mean hospital stay in Stenvall 2007a over one year was less in the intervention group (37.0 versus 51.4 days; reported $\mathrm{P}=0.051$ ).

Hospital readmissions, reported in six trials, did not significantly differ between intervention and control (Analysis 1.13. RR 0.99, 95\% CI 0.82 to 1.19$)$. However, there was some heterogeneity between the trial results $\left(\mathrm{I}^{2}=28 \%\right)$. In Galvard 1995 there was a marked and significant decrease in those readmitted in the intervention group whereas there were slightly more readmissions in the intervention group in four other trials (Cameron 1993; Shyu 2008; Stenvall 2007a; Swanson 1998). There was no difference in Vidan 2005. Swanson 1998 reported that no readmission was related to the original admission. The disparity of direction effect between Galvard 1995 and three trials (Cameron 1993, Stenvall 2007a; Swanson 1998) persisted when mortality data (these were deaths in hospital except for Cameron 1993, where results were for mortality at four months) were added to readmission data. (One intervention group patient who remained in hospital was included in the numerator for Swanson 1998.) The combined outcome favoured the intervention in Vidan 2005 given the large difference in-hospital mortality (1 versus 9 ) for this trial. Overall, there was no statistically significant difference between the two groups for the pooled data (Analysis 1.14. RR 0.93, 95\% CI 0.79 to 1.09). For readmission data, it is notable that three trials with shorter lengths of stay in the intervention groups (Cameron 1993; Stenvall 2007a; Swanson 1998) tended to have more readmissions in this group. In contrast, there were fewer readmissions in the intervention group of Galvard 1995, where average length of stay was 25 days more than in the control group.

\section{Carer burden}

Two studies (Cameron 1993; Kennie 1988) reported data relating to carer burden. A separate report of Cameron 1993 found that carer burden prior to fracture was the strongest predictor of subsequent burden and that carers of patients in nursing homes and patients with greater cognitive and physical disability were more burdened. In the 12 month follow-up of Kennie 1988, no difference in carer burden was reported between the intervention and control groups. Cameron 1993 found that the intervention did not significantly impact on carer burden. Without supporting data or indication of how outcome was assessed, Huusko 2002 reported no differences between the two groups in home nursing, food service or help from others.

\section{Costs}

Four trials reported the results from a cost analysis (Cameron 1993; Fordham 1986; Galvard 1995; Huusko 2002). Cameron 1993, who reported cost outcomes in a separate paper, found that costs (defined as cost per recovered patient) was significantly reduced in the intervention group (10,600 versus 12,800 Australian dollars). Costs assessed were direct costs due to treatment and aftercare up to four months after the fracture. Fordham 1986 concluded that the cost of care per patient ( $£ 2714$ versus $£ 2618$ at 1985 prices) was slightly greater in the intervention group due to costs generated by travel to the unit. Galvard 1995 reported increased costs for the intervention group (84,537 versus 94,026 Swedish krona at 1989 prices). Though the total direct cost per patient during the first year in the intervention group was estimated at 2000 euros (1999 prices: 17,900 versus 15,900 euros) more, Huusko 2002 considered that the costs did not differ remarkably and furthermore suggested that the costs in the control group were underestimated. Gilchrist 1988 noted that no additional funding had been allocated for the intervention in their trial. An estimate of the cost benefit of the Orthopaedic-Geriatrician liaison unit responsible for delivering the intervention in Swanson 1998 was given in the abstract of conference proceedings (Day 1997) but did not appear in the final report.

\section{Subgroup analysis by patient characteristics}

Aside from Huusko 2002, there were no data available from other trials that enabled meaningful subgroup analysis by patient characteristics. The initial report of Huusko 2002 presented the results split by the Mini Mental State Examination scores of patients into four categories (normal, suspected mild dementia, suspected moderate dementia, suspected severe dementia) (see Huusko 2000). However, we have not presented these data here. Given the significant imbalance in the numbers with suspected dementia between the two groups in this trial, the relatively small numbers of patients in the various subgroups, some potential discrepancies in the baseline characteristics data and failure to carry out intentionto-treat analyses, presenting the subgroup analyses based on the available data in the trial report could be misleading.

\section{Ambulatory rehabilitation}

The two trials in this category are considered in turn.

Crotty 2003 compared accelerated discharge, within 48 hours of randomisation, and home-based interdisciplinary rehabilitation with usual care consisting of routine interdisciplinary hospital care and rehabilitation in hospital in 66 people recovering from hip 
fracture surgery. There were no statistically significant differences between the two groups in the incidence of 'poor outcome' (mortality or higher level of care at 12 months), mortality, higher level of care (move to hostel or nursing home) or inability to walk (see Analysis 2.1). Similarly, as shown in Analysis 2.2, there were no statistically significant differences at 12 months in the SF-36 scores for the physical (MD 4.70, 95\% CI - 0.43 to 9.83) or mental (MD $1.50,95 \%$ CI -2.88 to 5.88 ) components. At four months followup, Crotty 2003 found statistically significant differences favouring the intervention group for the modified Barthel index (median 97.0 versus 94.0; clinical importance not established); and the Falls Efficacy Scale results, although there was no difference in the rate of falls. Participants in the home-based rehabilitation group had a shorter stay in hospital (see Analysis 2.3: MD -6.50 days, $95 \%$ CI -11.30 to -1.70 days), but a longer period of rehabilitation (MD 14.00 days, $95 \%$ CI 7.84 to 20.16 days). Therapists visited participants of the home-based group an average of 13.6 times. There was no difference in the numbers of participants who were readmitted to hospital within four months (see Analysis 2.4). At four months, there were no statistically significant differences in carer time, GP visits or use of community services. However, the burden of care, as rated by the Caregiver Strain Index (CSI), was reported to be statistically and clinically significantly less for carers of participants of the home-based group at 12 months (median CSI 1.0 versus 4.0; reported $\mathrm{P}=0.02$ ).

Ryan 2006 compared intensive with less intensive home-based multidisciplinary rehabilitation lasting a maximum of 12 weeks in 71 people who had been recently discharged from hospital after hip fracture surgery. There were no statistically significant differences between the two groups in any of the measured outcomes. The data for 'poor outcome' (mortality or institutional care at 12 months), mortality and institutional care are presented in Analysis 3.1. Intensification of intervention was based on at least doubling the number of contacts made by the multidisciplinary team per week. This was not achieved although statistically significantly more visits were made to the intervention group (see Analysis 3.2: mean difference 6.50 visits; $95 \%$ CI 3.01 to 9.99).

\section{Care in both settings}

In our protocol we stated that we would consider an exploratory analysis where data were pooled from both settings. Inclusion of data from Crotty 2003, where the care in the intervention group was predominantly at home, made very little difference (see Analysis 1.3) to the results for 'poor outcome' (Analysis 4.1: RR $0.88,95 \%$ CI 0.78 to 1.00$)$.

\section{DISCUSSION}

\section{Summary of main results}

The characteristics of multidisciplinary rehabilitation and 'usual care' varied considerably in the 13 included trials, and all findings need to be viewed in the context of the clinical heterogeneity of the trial interventions, trial populations and outcome measurement. Multidisciplinary rehabilitation was provided totally or primarily in an inpatient setting in 11 trials. Pooled results showed no statistically significant difference between intervention and control groups for poor outcome (risk ratio 0.89 ; $95 \%$ confidence interval 0.78 to 1.01 ). Although this tends to favour multidisciplinary rehabilitation, this result is not robust and the potential effect is reduced by the removal of Kennie 1988; a trial that may be biased because of imbalances in balance characteristics. Removal of Kennie 1988 halves the absolute risk reduction (from 4\% to 2\%). Subgroup analysis by type of intervention (specialised unit versus more intensive rehabilitation) did not show a significant difference. There was also no statistically significant difference for mortality (risk ratio $0.90,95 \%$ confidence interval 0.76 to 1.07 ) or readmission to hospital, whether for fracture-related or unrelated conditions. Individual trials reported more favourable results in the intervention group for activities of daily living and mobility, although this was sometimes short term. No quality of life measures were reported. There was considerable heterogeneity in length of stay and cost data; the intervention was less costly in two of the four trials providing quantitative data for costs. The three trials reporting carer burden showed no evidence of a detrimental effect from the intervention.

The only trial (Crotty 2003) comparing primarily home-based multidisciplinary rehabilitation with usual inpatient care found a marginal improvement in participant functioning and a clinically significantly lower long-term burden for carers in the intervention group. Although the participants in the home-based rehabilitation group had shorter hospital stays, they had a longer period of rehabilitation. Ryan 2006 found no significant effect from intensification aimed at doubling the number of weekly contacts at the patient's home from a multidisciplinary rehabilitation team.

\section{Overall completeness and applicability of evidence}

Some trial reports did not provide complete data for the primary outcome at long-term follow-up. Although this was often remedied by contact with trial investigators, data from only eight of the 11 inpatient-setting trials were available for pooling. This meant that data from only $69 \%(1633 / 2361)$ of the participants recruited into the 11 trials contributed to this outcome; although data were available for poor outcome at discharge for the other three trials. This deficiency also hindered subgroup analyses, as did the general absence of data for different categories of patients (Huusko 2002 being the exception for dementia status). Additionally, data for the various validated measures of function used in the trials were generally incomplete.

As emphasised above, the trials identified are a disparate group. 
This, together with inadequate details of 'usual care', hampers considerations of the applicability of the findings of the review. Nonetheless, the majority of the 11 trials conducted in an inpatient setting investigated collaborative care between orthopaedic surgeons and geriatricians with involvement of a multidisciplinary team. Some basic grouping by intervention (specialist unit versus intensive rehabilitation) was also possible; but subgroup analysis was inconclusive. The interventions of trials evaluating more intensive rehabilitation were more complex and multicomponent than for trials comparing care in a GORU compared with conventional orthopaedic care. Although Stenvall et al (Stenvall 2007a) included interventions which were aimed at different outcomes (delirium, nutritional status, falls), separate publications (respectively: Lundstrom 2007; Olofsson 2007; Berggren 2008 and Stenvall 2007b) reporting these outcomes rightly set them in the context of the whole rehabilitation programme. This recognises that interaction with the selected components and other components of the intervention cannot be ruled out or quantified. Essentially, any application of the findings of this review needs to be levelled at the general concept of multidisciplinary rehabilitation. However, the evidence to date means that our review cannot conclusively answer the question of effectiveness of this approach, although observed trends favour the principle of co-ordinated multidisciplinary approaches to rehabilitation after hip fracture.

Another question is to whom these results apply aside from the target population. We cannot answer this question too specifically but note that there were marked differences in study populations and contexts. For example, usual care in Shyu 2008, which included one session of physiotherapy only and discharge home without aftercare after a relatively short stay in hospital, contrasts greatly with usual care in the other trials. Additionally, patients with dementia or from nursing homes are under-represented in the included trials and, as pointed out, our primary outcome does not measure a deterioration in those who are already in institutional care.

Potentially very pertinent to but not appraised in Shyu 2008 was carer burden. The three inpatient rehabilitation trials reporting carer burden did not show a negative effect on carers from the intervention. The only trial (Crotty 2003) evaluating primarily home-based multidisciplinary rehabilitation found a clinically significantly lower long-term burden for carers in the intervention group.

Costs were incompletely assessed in the included trials and the findings from four trials were mixed. A proxy for direct costs for inpatient rehabilitation is length of hospital stay; the direction of effect also varied between individual trials. Some trials aimed for early supported discharge from hospital. A finding from Crotty 2003 was that the actual length of rehabilitation can still take longer in home-based rehabilitation.

While the GORU is still relevant, in practice and as a research topic, the general relevance of this review needs to be monitored in the light of evolving and changing clinical practice. This is likely to be complex, with much variation and so the heterogeneity of the already included trials and those in the future is likely to be an inevitable feature of this review.

Finally, the implementation of the intervention in Ryan 2006 was poor and, as acknowledged by the trial investigators, the lack of information on the actual care provided hampers interpretation of trial findings.

\section{Quality of the evidence}

Although most trials appeared well designed, an impression usually enhanced upon gaining additional information from trial investigators, some were at risk of bias. In the above, we have drawn particular attention to imbalances in key patient characteristics (e.g. gender, mental health) that could have influenced trial results of five trials. It is notable that this selection bias occurred despite seemingly adequate randomisation methods and points to the need for larger study sizes. Lack of blinding and incomplete outcome data are more likely to have affected the reliability of functional assessment rather than mortality and other 'hard' outcomes. Nonetheless, some trial reports gave a confusing or an incomplete account of mortality and residence, which required clarification from trial authors. Sometimes this resulted in some small unaccountable discrepancies between published and unpublished findings. Some questions remained unanswered on conduct of some trials, including those relating to performance and contamination biases.

\section{Potential biases in the review process}

Given the sustained effort over the years in searching for trials in this area, and the continued involvement of one author (IC) and his colleagues in primary research, we think it is unlikely that we have overlooked fully published trials in this slow-moving research area. It is hard to ascertain whether we have missed many unpublished trials but the identification due to post-registration of one trial that now awaits classification shows that it is possible. While we consider that we have included and excluded trials appropriately, it was sometimes hard to decide whether trials evaluated multidisciplinary rehabilitation or not. This is illustrated by the exclusion of Sanchez Ferrin 1999, formerly included in Cameron 2001 but actually a trial testing geriatric assessment. Despite the clear heterogeneity of trial comparisons, populations, outcome assessment and some aspects of trial quality, we pooled data for several 'hard' outcomes provided by the trials comparing multidisciplinary rehabilitation with usual care in the inpatient setting. This activity in itself is not a potential bias in the review process but we acknowledge that it does hamper interpretation and considerations of external validity. It is notable that statistical heterogeneity in poor outcome in the long-term or at discharge was not substantial and could be alleviated by the removal of just one trial. Lack of data prevented the potential to examine the 
effects of clinical heterogeneity through subgroup analysis.

The emphasis on the primary outcome and other 'hard' outcomes, for which most trials provided data, could have meant that important findings from the various measures of function and independence may have been given less attention than merited. However, data for the various validated measures of function in use were generally incomplete and, where complete, pooling was either not possible or appropriate.

A strength of the review is the often successful acquisition of extra data and details from trial investigators. This can add to the complexity of the data extraction and checking processes, and lead to disparities between the published and subsequently provided data. In this review, the process has reinforced the perception of the inherent dangers of reporting percentages without the data from which they are derived.

\section{Agreements and disagreements with other studies or reviews}

This review stems from Cameron 2001, of which the fourth update appeared in Issue 2, 2003 of The Cochrane Library. Despite the addition of four trials resulting in a total of nine trials in the final update, successive updates resulted no substantive change to the conclusions. Those in Cameron 2001 were: "While this review concludes that there is no conclusive evidence of the effectiveness of co-ordinated post-surgical care typified by the GORU model following proximal femoral fracture, there is a trend towards effectiveness in all main outcomes." Our current review has been expanded in scope, with some re-evaluation of the inclusion criteria and updating of review methods. Despite the inclusion of three new trials in the inpatient category, and exclusion of a formerly included trial (Sanchez Ferrin 1999), our conclusions for this setting remain consistent with those in Cameron 2001.

Three review authors also contributed to Halbert 2007, which shared the increased scope of our review. Halbert 2007 concluded that patients who received multidisciplinary rehabilitation were at lower risk of a poor outcome defined as death or admission to a nursing home at discharge from rehabilitation. Our review focused on long-term outcome, which ranged between four months and one year, but crucially was less susceptible to differences in discharge policies or practicalities between intervention groups in individual trials. Halbert 2007 also pooled data from Crotty 2003 with those from the inpatient rehabilitation trials. Feedback at the protocol stage for our review persuaded us that we should only pool from different settings in an exploratory way. Halbert 2007 concluded that the result supported "the routine provision of organized care following hip fracture, as is current practice for patients after stroke." The findings from our review make such a conclusion more tentative.

\section{A U THORS' CONCLUSIONS}

\section{Implications for practice}

While there is no conclusive evidence of the effectiveness of multidisciplinary inpatient rehabilitation following hip fracture surgery in older people, there is a trend towards effectiveness in all main outcomes. Importantly, no serious detriment (in terms of patient outcomes or crude cost comparisons) has been demonstrated as a result of this care. Therefore, although further evidence of the potential costs and benefits of multidisciplinary inpatient rehabilitation are required, there is some rationale to justify its adoption in the meantime. The optimal structure, setting and intensity of this care are not known. There is insufficient evidence to conclude for multidisciplinary rehabilitation in the ambulatory setting.

\section{Implications for research}

The available studies are a heterogeneous group, and there is insufficient information to draw robust conclusions about effectiveness and cost-effectiveness of multidisciplinary rehabilitation in either the inpatient or ambulant setting. This is unsatisfactory, especially set in the context of the increasingly elderly population, with the numbers of hip fracture patients increasing at the same time as the pressures on health care funds are increasing. Societal changes, including the loss of traditional carers, also contribute to the urgency in finding the most optimal forms of affordable good quality provision of care for hip fracture patients.

Future research evaluating the effectiveness of specialised inpatient rehabilitation needs to pay attention to several factors. A modest effect size, such as a $10 \%$ reduction in poor outcome, would be an important result for this population. To obtain definitive evidence for such a reduction larger trials are needed. Measures of outcome should be standardised (particularly with regard to functional status) and assessed by a blinded observer. Trials should include careful monitoring of direct and indirect costs as well as carer burden and cost effectiveness. Components of the interventions used in trials should be carefully specified. Some account should be taken of other strategies including those of early discharge and a more community-based emphasis. Patient characteristics, including cognitive status, should be clearly presented and if subgroup analyses are considered, these should be a priori, sufficiently powered, and an analysis of the outcome of patients with or without evident dementia considered. With current knowledge, studies should aim to establish the effectiveness of multidisciplinary rehabilitation overall. An evaluation of its components should be delayed until more general evidence is available.

As well as trial registration and making the trial protocol publicly available, it is important that trial reports conform to the requirements of the nonpharmacologic CONSORT statement (Boutron 2008). Complying with this version of CONSORT should mean that adequate descriptions of the interventions under test will be available. 


\section{ACKNOWLEDGEMENTS}

We thank Peter Langhorne for his contribution to the protocol for this review (2008). We thank Joanne Elliott for her help with the search strategy. We thank the following for helpful comments at the editorial and external review of the protocol: Bill Gillespie, Peter Herbison, David Stott and Janet Wale. We thank Joanne Elliott and Lindsey Elstub for their help during editorial processing of the protocol. We thank the following for helpful comments at the editorial and external review of the review: Bill Gillespie, Lesley Gillespie, Peter Herbison, David Stott and Janet Wale. We thank Lindsey Elstub, Lesley Gillespie and Amy Kavanagh for their help during editorial processing of the review.

We are also very grateful to the trial investigators who have, sometimes on several occasions and over the years, provided additional data and clarification of their trials on this topic. For this review, thanks are due to Michelle Miller, Tony Ryan, Yeaing Shyu and Maria Vidan.

\section{RE FER E N C E S}

\section{References to studies included in this review}

\section{Cameron 1993 \{published and unpublished data\}}

* Cameron ID, Lyle DM, Quine S. Accelerated rehabilitation after proximal femoral fracture: a randomized controlled trial. Disability and Rehabilitation 1993;15(1):29-34. [PUBMED: 8431589] Cameron ID, Lyle DM, Quine S. Cost effectiveness of accelerated rehabilitation after proximal femoral fracture. Journal of Clinical Epidemiology 1994;47(11):1307-13. [PUBMED: 7722567] Quine S, Helby L, Cameron I, Lyle D. Carer burden after proximal femoral fracture. Disability and Rehabilitation 1994;16(4):191-7. [PUBMED: 7812019]

\section{Crotty 2003 \{published and unpublished data\}}

Crotty M, Finucane P, Hayball N, Gray S, Krishnan J, Wells V, et al.A trial of rehabilitation in the home (RITHOM) for patients with fractured neck of femur: an early report [abstract]. Australian \& New Zealand Journal of Medicine 2000;30(2):295.

Crotty M, Gray S, Whitehead CH, Gray S. Early discharge and home rehabilitation after hip fracture achieves functional improvements: A randomized controlled trial. Clinical Rehabilitation 2002;16(4):406-13.

Crotty M, Kittel A, Hayball N. Home rehabilitation for older adults with fractured hips: how many will take part?. Journal of Quality in Clinical Practice 2000;20(2-3):65-8.

Crotty M, Whitehead C, Gray S, Finucane P, Hayball N. Rehabilitation in the home (RITHOM) for patients with fractured neck of femur: preliminary results [abstract]. Internal Medicine Journal 2002;32 (Suppl):A38

* Crotty M, Whitehead C, Miller M, Cray S. Patient and caregiver outcomes 12 months after home-based therapy for hip fracture: A randomized, controlled trial. Archives of Physical Medicine and Rehabilitation 2003;84:1237-9. [MEDLINE: 12917867] Miller M. personal correspondence December 172008.
Fordham 1986 \{published data only\}

Fordham R, Thompson R, Holmes J, Hodkinson C. A cost-benefit study of geriatric-orthopaedic management of patients with fractured neck of femur. Discussion paper 14. University of York: York: Centre for Health Economics, 1986. Available from www.york.ac.uk/inst/che/pdf/dp14.pdf.

Galvard 1995 \{published data only\}

Galvard H, Samuelsson SM. Orthopedic or geriatric rehabilitation of hip fracture patients: a prospective, randomized, clinically controlled study in Malmo, Sweden. Aging - Clinical o Experimental Research 1995;7(1):11-6. [MEDLINE: 7599241]

Gilchrist 1988 \{published data only\}

* Gilchrist WJ, Newman RJ, Hamblen DL, Williams BO. Prospective randomised study of an orthopaedic geriatric inpatient service. BMJ 1988;297(6656):1116-8. [MEDLINE: 3143450] Newman RJ, Gilchrist WJ, Hamblen DL, et al.A prospective, randomised study of an orthopaedic-geriatric inpatient service [abstract]. Journal of Bone Joint Surgery - British Volume 1989;71: 871

Huusko 2002 \{published and unpublished data\}

Huusko T. personal communication November 92004 Huusko TM, Karppi P, Avikainene V, Kautiainen H, Sulkava R. Randomised, clinically controlled trial of intensive geriatric rehabilitation in patients with hip fracture: subgroup analysis of patients with dementia. BMJ 2000;321(7269):1107-11. [PUBMED: 11061730]

* Huusko TM, Karppi P, Avikainen V, Kautiainen H, Sulkava R. Intensive geriatric rehabilitation of hip fracture patients. Acta Orthopaedica Scandinavica 2002;73(4):425-31. [MEDLINE: 12358116]

Kennie 1988 \{published and unpublished data\} Burns A, Park K. Proximal femoral fractures in the female patient, a 
controlled trial: the role of the occupational therapist and the physiotherapist. British Journal of Occupational Therapy 1992;55 (10):397-400

* Kennie DC, Reid J, Richardson IR, Kiamari AA, Kelt C. Effectiveness of geriatric rehabilitative care after fractures of the proximal femur in elderly women: a randomised clinical trial. $B M J$ 1988;297(6656):1083-6. [MEDLINE: 3143436]

Reid J, Kennie DC. Geriatric rehabilitative care after fractures of the proximal femur: one year follow up of a randomised clinical trial. BMJ 1989;299:25-6.

Smith N. Effectiveness of geriatric rehabilitative care [letter]. BMJ 1988;297:1609.

\section{Naglie 2002 \{published and unpublished data\}}

Naglie G. personal communication November 122002.

Naglie G, Goldlist B, Etchells E, Kirkland J, Detsky A, Tansey C, et al.A randomized trial of interdisciplinary care on an orthopedicgeriatric unit for elderly hip fracture patients [abstract]. Gerontologist 1999;39 Special Issue 1:420.

* Naglie G, Tansey C, Kirkland JL, Ogilvie-Harris DJ, Detsky AS, Etchells $\mathrm{E}$, et al.Interdisciplinary inpatient care for elderly people with hip fracture: A randomized controlled trial. Canadian Medical Association Journal 2002;167(1):25-32. [MEDLINE: 12137074]

Ryan 2006 \{published data only\}

Ryan T, Enderby P, Rigby AS. A randomized controlled trial to evaluate intensity of community-based rehabilitation provision following stroke or hip fracture in old age. Clinical Rehabilitation 2006;20(2):123-31. [PUBMED: 16541932]

* Ryan T, Enderby P, Rigby AS. A randomized controlled trial to evaluate intensity of community-based rehabilitation provision following stroke or hip fracture in old age: Results at 12-month followup. International Journal on Disability and Human Development 2006;5(1):83-9. [EMBASE: 2007133670]

\section{Shyu 2008 \{published and unpublished data\}}

Shyu Y. personal communication December 92008.

Shyu YI, Liang J, Wu CC, Su JY, Cheng HS, Chou SW, et al.A pilot investigation of the short-term effects of an interdisciplinary intervention program on elderly patients with hip fracture in Taiwan. Journal of the American Geriatrics Society 2005;53(5): 811-8. [PUBMED: 15877556]

* Shyu YI, Liang J, Wu CC, Su JY, Cheng HS, Chou SW, et al.Interdisciplinary intervention for hip fracture in older Taiwanese: benefits last for 1 year. Journals of Gerontology Series A - Biological Sciences and Medical Sciences 2008;63(1):92-7. [PUBMED: 18245766]

Stenvall 2007a \{published data only\}

Berggren M, Stenvall M, Olofsson B, Gustafson Y. Evaluation of a fall-prevention program in older people after femoral neck fracture: a one-year follow-up. Osteoporosis International 2008;19(6):801-9. Lundstrom M, Olofsson B, Stenvall M, Karlsson S, Nyberg L, Englund U, et al.Postoperative delirium in old patients with femoral neck fracture: a randomized intervention study. AgingClinical \& Experimental Research 2007;19(3):178-86. Olofsson B, Stenvall M, Lundstrom M, Svensson O, Gustafson Y. Malnutrition in hip fracture patients: an intervention study. Journal of Clinical Nursing 2007;16(11):2027-38. Stenvall M, Olofsson B, Lundstrom M, Englund U, Borssen B, Svensson, et al.A multidisciplinary, multifactorial intervention program reduces postoperative falls and injuries after femoral neck fracture. Osteoporosis International 2007;18(2):167-75.

[MEDLINE: 17061151]

* Stenvall M, Olofsson B, Nyberg L, Lundstrom M, Gustafson Y. Improved performance in activities of daily living and mobility after a multidisciplinary postoperative rehabilitation in older people with femoral neck fracture: a randomized controlled trial with 1-year follow-up. Journal of Rehabilitation Medicine 2007;39(3):232-8. [PUBMED: 17468792]

Swanson 1998 \{published and unpublished data\}

Day GA, Swanson C, Yelland C, Broome J, Dimitri K, Massey L, et al.Surgical outcomes of a randomized prospective trial involving patients with a proximal femoral fracture. Australian \& New Zealand Journal of Surgery 2001;71(1):11-4.

Day GA, Yelland C, Swanson CE, Dimitri K, Broome J, Massey L, et al.Early rehabilitation in patients with hip fractures [abstract]. Journal of Bone and Joint Surgery - British Volume 1997;79 Suppl 4: 410 .

Swanson CE. personal communication December 52001. * Swanson CE, Day GA, Yelland CE, Broome JR, Massey L, Richardson HR, et al.The management of elderly patients with femoral fractures. A randomised controlled trial of early intervention versus standard care. Medical Journal of Australia 1998;169(10):515-8. [PUBMED: 9861907]

Vidan 2005 \{published and unpublished data\}

Vidan M. personal communication December 102008.

* Vidan M, Serra JA, Moreno C, Riquelme G, Ortiz J. Efficacy of a comprehensive geriatric intervention in older patients hospitalized for hip fracture: a randomized, controlled trial. Journal of the American Geriatrics Society 2005;53(9):1476-82.

\section{References to studies excluded from this review}

\section{Abe 2001 \{published data only\}}

Abe T, Tsuchida N, Ishibashi H, Yamamoto S. Comparison between the short program and long program of post-operative rehabilitation of hip fracture for making the critical path [Japanese]. Nippon Ronen Igajkkai Zasshi - Japanese Journal of Geriatrics 2001; 38(4):514-8. [PUBMED: 11523164]

Allegrante 2001 \{published and unpublished data\} Allegrante JP. Improving functional recovery after hip fracture. clinicaltrials.gov/ct2/show/NCT00000436 (accessed 12 June 2009).

* Ruchlin HS, Elkin EB, Allegrante JP. The economic impact of a multifactorial intervention to improve postoperative rehabilitation of hip fracture patients. Arthritis \& Rheumatism 2001;45(5): 446-52. [PUBMED: 11642644]

Bai 2003 \{published data only\} Bai B, Wang KZ, Liu WK, Song JH, Chen JC. Comprehensive treatment for old patients with hip fractures. Chinese Journal of Traumatology 2003;6(5):297-301.

Choong 2000 \{published data only\}

Choong PF, Langford AK, Dowsey MM, Santamaria NM. Clinical pathway for fractured neck of femur: a prospective, controlled study [see comments]. Medical Journal of Australia 2000;172(9):423-6. 


\section{Cuncliffe 2004 \{published data only\}}

Cuncliffe A, Dewey M, Gladman J, Harwood R, Husbands S, Miller P. Evaluation of an early discharge scheme for elderly people: outcomes at 3 months [abstract]. www.nottingham.ac.uk/rehab/ whatwentright/eds' gladman.pdf (accessed 04 September 2003). Cuncliffe A, Dewey M, Gladman J, Harwood R, Husbands S, Miller P. Evaluation of an early discharge scheme for elderly people: use of hospital beds at 3 months [abstract]. Age \& Ageing 2001;30 (Suppl 2):33.

Cuncliffe A, Dewey M, Gladman J, Harwood R, Husbands S, Miller P. Evaluation of an early discharge scheme for elderly people: use of hospital beds at 3 months [abstract]. www.nottingham.ac.uk/rehab/whatwentright/eds' gladman.pdf (accessed 04 September 2003).

Cuncliffe A, Dewey M, Gladman J, Harwood R, Husbands S, Miller P. Evaluation of an early discharge scheme for older people: outcomes at 12 months [abstract]. www.nottingham.ac.uk/rehab/ whatwentright/eds' gladman.pdf (accessed 04 September 2003).

* Cunliffe AL, Gladman JR, Husbands SL, Miller P, Dewey ME,

Harwood RH. Sooner and healthier: a randomised controlled trial and interview study of an early discharge rehabilitation service for older people. Age \& Ageing 2004;33(3):246-52. [PUBMED: 15082429]

Gladman J, Dewey ME, Miller P, Whynes D. Randomised comparison of an early discharge scheme for patients with stroke, hip (and other) fracture, and geriatric medical patients [abstract]. www.nottingham.ac.uk/tihsr/research/research.html (accessed 04 September 2003).

Kamath S, Galdman J, Cunliffe AL, Husbands SL, Miller P, Dewey ME, et al.Early discharge and rehabilitation service (EDRS): outcomes in patients with stroke, hip fracture, and other conditions [abstract]. Age \& Ageing 2004;33(Suppl 1):i22.

Miller P, Gladman JR, Cunliffe AL, Husbands SL, Dewey ME, Harwood RH. Economic analysis of an early discharge rehabilitation service for older people. Age \& Ageing 2005;34(3): $274-80$.

\section{Fordham 1995 \{published data only\}}

Fordham RJ. Hip fracture rehabilitation: Economic evaluation \& outcome assessment of geriatric orthopaedic care [thesis]. Perth: University of Western Australia, 1995.

\section{Hempsall 1990 \{published data only\}}

Hempsall VJ, Robertson DRC, Campbell MJ, Briggs RS. Orthopaedic geriatric care - Is it effective?A prospective populationbased comparison of outcome in fractured neck of femur. Journal of the Royal College of Physicians of London 1990;24(1):47-50.

Houldin 1995 \{published data only\}

Houldin AD, Hogan-Quigley B. Psychological intervention for older hip fracture patients. Journal of Gerontological Nursing 1995; 21(12):20-6

\section{Huang 2005 \{published data only\}}

Huang TT, Liang SH. A randomized clinical trial of the effectiveness of a discharge planning intervention in hospitalized elders with hip fracture due to falling. Journal of Clinical Nursing 2005;14(10):1193-201. [PUBMED: 16238765]

\section{Jette 1987 \{published data only\}}

Jette AM, Harris BA, Cleary PD, Campion EW. Functional recovery after hip fracture. Archives of Physical Medicine and Rehabilitation 1987;68(10):735-40. [MEDLINE: 3662784]

\section{Krichbaum 2007 \{published data only\}}

Krichbaum K. GAPN postacute care coordination improves hip fracture outcomes. Western Journal of Nursing 2007;29(5):523-44.

\section{Kuisma 1994 \{published data only\}}

Kuisma R. A randomized, controlled comparison of home versus institutional rehabilitation of patients with hip fracture. Clinical Rehabilitation 1994;76:553-61.

\section{Marcantonio 2001 \{published data only\}}

Marcantonio ER, Flacker JM, Wright RJ, Resnick NR. Reducing delirium after hip fracture: a randomized trial. Journal of the American Geriatrics Society 2001;49(5):516-22. [PUBMED: 11380742]

Marcantonio ER, Flacker JN, Wright JR, Resnick NM. Reducing delirium after hip fracture: a randomized trial [abstract]. Journal of the American Geriatrics Society 1999;47(9):S3.

\section{Pearson 1988 \{published data only\}}

Pearson A, Durand I, Punton S. Effects of admission to a nursing unit. Australian Journal of Advanced Nursing 1988;6:38-42.

\section{Richards 1998 \{published data only\}}

Coast J, Richards SH, Peters TJ, Gunnell DJ, Darlow M, Pounsford J. Hospital at home or acute hospital care? A cost minimisation analysis. BMJ 1998;316:1802-6.

* Richards SH, Coast J, Gunnell DJ, Peters TJ, Pounsford J, Darlow M. Randomised controlled trial comparing effectiveness and acceptability of an early discharge, hospital at home scheme with acute hospital care. BMJ 1998;316:1796-801.

Sims J, Rink E, Cleary M, Pearson C, Lloyd K, Lilford R, et al.Hospital at home. Schemes evolve gradually [letters]. BMJ 1998; 317(7173):1651-2. [MEDLINE: 9848913]

Roder 2003 \{published data only\}

Oberst M, Schwab M, Roder F, Klotz U, Thon KP. Near the hip thigh fracture in older people: Is a residential rehabilitation always wise? [Huftgelenksnahe oberschenkelfraktur beim alten menschen: Ist eine stationare rehabilitation immer sinnvoll?]. Hefte zur der Unfallchirurg 1999;272:353-4.

* Roder F, Schwab M, Aleker T, Morike K, Thon KP, Klotz U. Proximal femur fracture in older patients--rehabilitation and clinical outcome. Age \& Ageing 2003;32(1):74-80.

Rubenstein 1984 \{published data only\}

Rubenstein LZ, Josephson KR, Wieland GD, English PA, Sayre JA, Kane RL. Effectiveness of a geriatric evaluation unit. A randomized clinical trial. New England Journal Medicine 1984;311(26): 1664-70. [PUBMED: 6390207]

\section{Sanchez Ferrin 1999 \{published data only\}}

Sanchez Ferrin P, Manas Magana M, Asuncion Marquez J, Dojoz Preciado MT, Quintana Riera S, Gonzalez Ortega F. Geriatric assessment of elderly patients with proximal fractures of the femur [Valoracion geriatrica en ancianos con fractura proximal de femur]. Revista Espanola de Geriatria y Gerontologia 1999;34(2):65-71. 
Siu 1996 \{published data only\}

Siu AL, Kravitz RL, Keeler E, Hemmerling K, Kington R, Davis JW, et al.Postdischarge geriatric assessment of hospitalized frail elderly patients. Archives of Internal Medicine 1996;156(1):76-81.

\section{References to studies awaiting assessment}

\section{Jalovaara 2009 \{unpublished data only\}}

Jalovaara P. Geriatric- and physiatric-oriented rehabilitation after hip fracture to improve the ability to live independently: a randomised controlled trial. WHO International Clinical Trials Registry Platform: http://www.controlled-trials.com/ ISRCTN94467061 (accessed 23/04/09).

Uy 2008 \{published data only\}

Uy C, Kurrle SE, Cameron ID. Inpatient multidisciplinary rehabilitation after hip fracture for residents of nursing homes: a randomised trial. Australasian Journal on Ageing 2008;27(1):43-4. [MEDLINE: 18713215]

\section{Ziden 2008 \{published data only\}}

Ziden L, Frandin K, Kreuter M. Home rehabilitation after hip fracture. A randomized controlled study on balance confidence, physical function and everyday activities. Clinical Rehabilitation 2008;22(12):1019-33. [PUBMED: 19052241]

\section{References to ongoing studies}

Gustafson 2009 \{published data only\}

Gustafson Y. Home rehabilitation for older people with hip fracture - a randomised controlled trial. www.controlled-trials.com/ ISRCTN15738119 (accessed 23 April 2009).

Sletvold 2009 \{published data only\}

Sletvold O. New clinical pathway for patients with fractured neck of femur. clinicaltrials.gov/show/NCT00667914 (assessed 29 April 2009).

\section{Additional references}

\section{Altman 2003}

Altman DG, Bland JM. Interaction revisited: the difference between two estimates. BMJ 2003;326(7382):219.

\section{Berggren 2008}

Berggren M, Stenvall M, Olofsson B, Gustafson Y. Evaluation of a fall-prevention program in older people after femoral neck fracture: a one-year follow-up. Osteoporosis International 2008;19(6):801-9.

\section{Boutron 2008}

Boutron I, Moher D, Altman DG, Schulz KF, Ravaud P, CONSORT Group. Extending the CONSORT statement to randomized trials of nonpharmacologic treatment: explanation and elaboration. Annals of Internal Medicine 2008;148(4):295-309.

\section{Cameron 2000}

Cameron I, Crotty M, Currie C, Finnegan T, Gillespie L, Gillespie W, et al.Geriatric rehabilitation following fractures in older people: a systematic review. Health Technology Assessment 2000;4(2):i-iii, 1102.

\section{Cameron 2001}

Cameron ID, Handoll HHG, Finnegan TP, Madhok R, Langhorne P. Co-ordinated multidisciplinary approaches for inpatient rehabilitation of older patients with proximal femoral fractures. Cochrane Database of Systematic Reviews 2001, Issue 3. [DOI: 10.1002/14651858.CD000106]

\section{Cummings 2002}

Cummings SR, Melton III LJ. Epidemiology and outcomes of osteoporotic fractures. Lancet 2002;359(9319):1361-7.

Day 1997

Day GA, Yelland C, Swanson CE, Dimitri K, Broome J, Massey L, et al.Early rehabilitation in patients with hip fractures [abstract]. Journal of Bone and Joint Surgery - British Volume 1997;79 Suppl 4: 410 .

\section{Deeks 2005}

Deeks JJ, Higgins, JPT, Altman DG, editors. Analysing and presenting results. In: Higgins JPT, Green S, editors. Cochrane Handbook for Systematic Reviews of Interventions 4.2.5 [updated May 2005]; Section 8. http://www.cochrane.org/resources/ handbook/hbook.htm (accessed 2 February 2008).

\section{Gullberg 1997} Gullberg B, Johnell O, Kanis JA. World-wide projections for hip fracture. Osteoporosis International 1997;7(5):407-13.

\section{Halbert 2007}

Halbert J, Crotty M, Whitehead C, Cameron I, Kurrle S, Graham $S$, et al.Multi-disciplinary rehabilitation after hip fracture is associated with improved outcome: a systematic review. Journal of Rehabilitation Medicine 2007;39(7):507-12.

\section{Handoll 2007}

Handoll HHG, Sherrington C. Mobilisation strategies after hip fracture surgery in adults. Cochrane Database of Systematic Reviews 2007, Issue 1. [DOI: 10.1002/14651858.CD001704.pub3]

\section{Handoll 2008}

Handoll HHG, Parker MJ. Conservative versus operative treatment for hip fractures in adults. Cochrane Database of Systematic Reviews 2008, Issue 3. [DOI: 10.1002/14651858.CD000337.pub2]

\section{Higgins 2003}

Higgins JPT, Thompson SG, Deeks JJ, Altman DG. Measuring inconsistency in meta-analyses. BMJ 2003;327(7414):557-60.

\section{Higgins 2006}

Higgins JPT, Green S, editors. Highly sensitive search strategies for identifying reports of randomized controlled trials in MEDLINE. Cochrane Handbook for Systematic Reviews of Interventions 4.2.6 [updated September 2006]; Appendix 5b. www.cochrane.org/ resources/handbook/hbook.htm (accessed 15 November 2007).

\section{Higgins 2008}

Higgins JPT, Altman DG (editors). Chapter 8: Assessing risk of bias in included studies Table 8.5a. Chapter 8: Assessing risk of bias in included studies. In: Higgins JPT, Green $S$ (editors). Cochrane Handbook for Systematic Reviews of Interventions Version 5.0.1 (updated September 2008). The Cochrane Collaboration, 2008. Available from www.cochrane-handbook.org.

\section{Huusko 2000}

Huusko TM, Karppi P, Avikainene V, Kautiainen H, Sulkava R. Randomised, clinically controlled trial of intensive geriatric rehabilitation in patients with hip fracture: subgroup analysis of patients with dementia. BMJ 2000;321:1107-11. 


\section{Lundstrom 2007}

Lundstrom M, Olofsson B, Stenvall M, Karlsson S, Nyberg L, Englund $U$, et al.Postoperative delirium in old patients with femoral neck fracture: a randomized intervention study. AgingClinical \& Experimental Research 2007;19(3):178-86.

Lyons 1997

Lyons AR. Clinical outcomes and treatment of hip fractures. American Journal of Medicine 1997;103(2A):51S-64S.

\section{Magaziner 2000}

Magaziner J, Hawkes W, Hebel JR, Zimmerman SI, Fox KM Dolan $M$, et al.Recovery from hip fracture in eight areas of function. Journals of Gerontology Series A-Biological Sciences \& Medical Sciences 2000;55(9):498-507.

\section{Marottoli 1992}

Marottoli RA, Berkman LF, Cooney LM Jr. Decline in physical function following hip fracture. Journal of the American Geriatrics Society 1992;40(9):861-6.

\section{Norton 1997}

Norton R, Campbell AJ, Lee-Joe T, Robinson E, Butler M. Circumstances of falls resulting in hip fractures among older people. Journal of the American Geriatrics Society 1997;45(9):1108-12.

\section{Olofsson 2007}

Olofsson B, Stenvall M, Lundstrom M, Svensson O, Gustafson Y. Malnutrition in hip fracture patients: an intervention study. Journal of Clinical Nursing 2007;16(11):2027-38.

\section{Parker 1991}

Parker MJ, Anand JK. What is the true mortality of hip fractures? Public Health 1991;105(6):443-6.

\section{Piscitelli 2007}

Piscitelli P, Iolascon G, Gimigliano F, Muratore M, Camboa P, Borgia $\mathrm{O}$, et al.Incidence and costs of hip fractures compared to acute myocardial infarction in the Italian population: A 4-year survey. Osteoporosis International 2007;18(2):211-9.

\section{Rosell 2003}

Rosell PA, Parker MJ. Functional outcome after hip fracture. A 1year prospective outcome study of 275 patients. Injury 2003;34(7): $529-32$.

\section{Schneider 1990}

Schneider EL, Guralnik JM. The aging of America: impact on health care costs. JAMA 1990;263(17):2335-40.

\section{SIGN 2002}

Scottish Intercollegiate Guidelines Network. Guideline 56: Prevention and management of hip fracture in older people. A national clinical guideline 2002. Scottish Intercollegiate Guidelines Network: www.sign.ac.uk/guidelines/published/support/ guideline56/index.html (accessed 05 November 2007).

\section{Stenvall 2007b}

Stenvall M, Olofsson B, Lundstrom M, Englund U, Borssen B, Svensson, et al.A multidisciplinary, multifactorial intervention program reduces postoperative falls and injuries after femoral neck fracture. Osteoporosis International 2007;18(2):167-75. [MEDLINE: 17061151]

\section{Stroke Collaboration 1997}

Anonymous. How do stroke units improve patient outcomes? A collaborative systematic review of the randomized trials. Stroke Unit Trialists Collaboration. Stroke 1997;28(11):2139-44. [MEDLINE: 9368554]

\section{Stroke Collaboration 2007} Stroke Unit Trialists' Collaboration. Organised inpatient (stroke unit) care for stroke. Cochrane Database of Systematic Reviews 2007, Issue 4. [DOI: 10.1002/14651858.CD000197.pub2]

\section{WHO 2003}

United Nations. World programme of action concerning disabled persons. Division for Social and Policy Development, United Nations 2003. www.un.org/esa/socdev/enable/diswpa01.htm (accessed 5 November 2007).

* Indicates the major publication for the study 
CHARACTERISTICS OF STUDIES

\author{
Characteristics of included studies [ordered by study ID]
}

Cameron 1993

\begin{tabular}{ll}
\hline Methods & $\begin{array}{l}\text { Randomised trial: stratification (using sealed envelopes) } \\
\text { Assessor blinding: no } \\
\text { Length of follow-up: } 4 \text { months (12 months for some outcomes) }\end{array}$ \\
\hline Participants & $\begin{array}{l}\text { General hospital in Sydney, Australia. } \\
\text { Conducted: January } 1989 \text { to October } 1990 .\end{array}$ \\
\hline $\begin{array}{l}252 \text { people with hip fracture; } 17 \% \text { male. Mean age } 84 \text { years. Cognitive status: } 122 \text { were } \\
\text { cognitively impaired. } \\
\text { Inclusion criteria: Aged }>50 \text { years, had undergone surgery within } 7 \text { days of injury for } \\
\text { an uncomplicated hip fracture, resident in district, informed consent. }\end{array}$ \\
$\begin{array}{l}\text { Exclusion criteria: pathological fracture, other fractures, fracture sustained while a hos- } \\
\text { pital inpatient, transferred to another hospital for surgery. } \\
\text { Assigned: } 127 / 125 \text { [Accelerated care / Usual care] } \\
\text { Assessed (4 and12 months): } 127 / 125 \\
\text { Loss to follow-up: none lost to follow-up. }\end{array}$ \\
\hline
\end{tabular}

Interventions

Randomisation took place at time of surgery.

(1) Accelerated rehabilitation and early discharge. Early assessment by physician experienced in rehabilitation and geriatric medicine, to identify and treat concurrent illness, and establish rehabilitation goals. Early commencement of rehabilitation (mobilisation and self-care), greater emphasis on retraining physical independence, closer family care giver support and more detailed discharge planning. Nursing home patients: contact by rehabilitation physician and arrangements made for mobilisation; supervised by nursing staff, visiting physiotherapist. Review of progress by rehabilitation physician; and orthopaedic review according to need. Other patients, mobilisation in hospital, supervised by physiotherapist, continued by nursing staff. Joint 3 or 4 times weekly review by orthopaedic surgeon and rehabilitation physician. Patients with limited disability direct discharge to home: seen by occupational therapist, input too from social worker and nutritionist. Additional / more intensive treatment for those with moderate to severe disability prior to fracture: transfer to rehabilitation ward with interdisciplinary rehabilitation programme and regular contact with nursing, medical, physiotherapy, occupational therapy and social workers. Additional support upon discharge, e.g. delivered meals, nursing help, physiotherapy, day hospital attendance.

(2) Conventional care and rehabilitation (of these $56 \%$ had multidisciplinary rehabilitation)as per standard treatment provided at study hospital at time of trial. Patients living in nursing homes and those with limited disability were discharged when deemed orthopaedically appropriate. Patients likely to need additional assistance to return home were referred to Rehabilitation and Geriatric service several days post surgery. Many were transferred to a rehabilitation ward.

The following summary is given: "In summary, accelerated rehabilitation differs from conventional care in its early assessment of rehabilitation goals, early commencement (usually within 24 hours of surgery), greater emphasis on retraining for physical independence, closer family care-giver contact and more detailed discharge planning." 


\section{Cameron 1993 (Continued)}

\begin{tabular}{l|l} 
Outcomes & $\begin{array}{l}\text { 'Poor outcome': mortality at discharge or discharge to institutional care; mortality at } 12 \\
\text { months or institutional care. } \\
\text { Other outcomes: mortality ( } 4 \text { and } 12 \text { months), ADL/functional status (Barthel Index), } \\
\text { length of stay, place of residence, readmissions, carer burden, cost effectiveness. }\end{array}$ \\
\hline Notes & $\begin{array}{l}\text { Data and clarifications received from Ian Cameron (including emails: 26/02/1997, 19/ } \\
06 / 2000) \text { on mortality at } 4 \text { and } 12 \text { months, institutional care, dependency, SDs for } \\
\text { hospital stay. }\end{array}$ \\
\hline
\end{tabular}

\section{Risk of bias}

\begin{tabular}{|c|c|c|}
\hline Item & Authors' judgement & Description \\
\hline Adequate sequence generation? & Yes & $\begin{array}{l}\text { "A stratified randomization procedure was } \\
\text { used." Stratification by prior living arrange- } \\
\text { ments and disability. }\end{array}$ \\
\hline Allocation concealment? & Yes & $\begin{array}{l}\text { "The surgeon was blind to the outcome } \\
\text { of randomization, which was performed } \\
\text { at the time of surgery." Use of sealed en- } \\
\text { velopes. }\end{array}$ \\
\hline $\begin{array}{l}\text { Blinding? } \\
\text { Death, residence, readmission }\end{array}$ & Unclear & $\begin{array}{l}\text { Not blinded but data collection unlikely to } \\
\text { be affected for these outcomes. }\end{array}$ \\
\hline $\begin{array}{l}\text { Blinding? } \\
\text { Function, QOL }\end{array}$ & Unclear & $\begin{array}{l}\text { Clinical assessor was not blinded to group } \\
\text { assignment. However, there was high cor- } \\
\text { relation between the findings and that of an } \\
\text { independent blind assessor who evaluated } \\
\text { Barthel scores for } 10 \text { participants. }\end{array}$ \\
\hline $\begin{array}{l}\text { Incomplete outcome data addressed? } \\
\text { Death, residence, readmission }\end{array}$ & Yes & $\begin{array}{l}\text { "All } 252 \text { patients were successfully followed } \\
\text { up until death or } 4 \text { months after injury." } \\
\text { However, there were discrepancies in the } \\
\text { mortality data between the reports and } \\
\text { those provided by the author from his the- } \\
\text { sis. }\end{array}$ \\
\hline $\begin{array}{l}\text { Incomplete outcome data addressed? } \\
\text { Function, QOL }\end{array}$ & Unclear & $\begin{array}{l}\text { Despite reporting that all patients were fol- } \\
\text { lowed up, discrepancies in mortality data } \\
\text { (see above) meant that this was unclear. }\end{array}$ \\
\hline Free of selective reporting? & Unclear & $\begin{array}{l}\text { Incompletely reported but data provided } \\
\text { subsequently. The study protocol is not } \\
\text { available but it seems very likely that the } \\
\text { published reports included all expected } \\
\text { outcomes, including those that were pre- } \\
\text { specified. }\end{array}$ \\
\hline
\end{tabular}




\section{Cameron 1993 (Continued)}

Free of selection bias (from imbalances at Unclear baseline)?
Intervention group was slightly younger (82.4 versus 85.4 ); this was reportedly due to "differences in the subgroup from nursing homes".

Free of performance bias (from non-trial Unclear differences in care provision)?

Insufficient details for the control group to judge this.

Follow-up procedures were the same in both groups and all participants were accounted for.

\section{Crotty 2003}

Methods

Randomised trial: using computer-generated randomisation and sealed, opaque envelopes; independent pharmacist with no other involvement with study.

Assessor blinding: yes

Length of follow-up: 12 months
Interventions
3 hospitals in Adelaide, Australia.

Conducted: July 1998 to March 1999.

66 people with hip fracture, 33\% male. Mean age 82.5 years. Cognitive status: 14 had confusion; otherwise needed to be able to participate in rehabilitation programme.

Inclusion criteria: Aged 65+ years, had undergone surgery for fall related hip fracture; medically stable; adequate medical and mental capacity to participate in a rehabilitation programme; expected to return home after hospital discharge; home environment suitable for rehabilitation; agreed to hospital admission should complications occur; written consent.

Exclusion criteria: inadequate support in community; no telephone at home; or not resident in Adelaide's Southern Metropolitan Region.

Assigned: 34/32 [Accelerated care / Usual care]

Assessed (12 months): 28/28

Loss to follow-up: 3 lost to follow-up; 7 died

Randomisation took place in acute care, after surgery

(1) Accelerated discharge and home-based interdisciplinary rehabilitation. Initial assessment by study co-ordinator who visited patient's home and organised modifications, equipment and assistive aids before patient's discharge. GPs were contacted. Participants were discharged from acute care within 48 hours of randomisation and were visited by physiotherapists, occupational therapists, speech pathologists, social workers and therapy aides, who negotiated a set of realistic, short-term, and measurable treatment goals with both participants and their carers. Standard therapy services (e.g. podiatry, nursing care, assistance with light domestic tasks) provided as required. Weekly multidisciplinary case conference also attended by specialist in rehabilitation medicine or geriatrician. Decision to discharge from rehabilitation programme made in consultation with rehabilitation consultant. When necessary participants were referred to community agencies for ongoing care.

(2) Usual or 'conventional' care, involving routine interdisciplinary hospital care and 
Crotty 2003 (Continued)

rehabilitation in hospital. Inpatient services, care pathways and discharge planning.

\begin{tabular}{ll}
\hline Outcomes & $\begin{array}{l}\text { 'Poor outcome': mortality at } 12 \text { months or living in more dependent residence (hostel } \\
\text { or nursing home). } \\
\text { Other outcomes: mortality (4 and } 12 \text { months), quality of life (SF-36: physical component } \\
\text { summary and mental component summary); ADL (Modified Barthel Index), Balance } \\
\text { Confidence Scale, mobility (timed up and go test and inability to walk), length of stay } \\
\text { in hospital/of rehabilitation (including at home), change in residence (indicating higher } \\
\text { level of care), readmissions, home visits by therapists (as part of intervention), use of } \\
\text { community services, GP visits, Caregiver Strain Index. }\end{array}$ \\
\hline Notes & $\begin{array}{l}\text { Data and clarifications received from Michelle Miller (17/12/2008): separate data by } \\
\text { group for deaths, admission to higher level of care; inability to walk, readmission to } \\
\text { hospital; SDs for SF36 data, and hospital stay. }\end{array}$ \\
\hline
\end{tabular}

\section{Risk of bias}

\begin{tabular}{|c|c|c|}
\hline Item & Authors' judgement & Description \\
\hline Adequate sequence generation? & Yes & "computer-generated allocation sequence" \\
\hline Allocation concealment? & Yes & $\begin{array}{l}\text { "Randomization was undertaken by the } \\
\text { hospital pharmacy department, which } \\
\text { maintained a computer-generated alloca- } \\
\text { tion sequence in sealed opaque envelopes." } \\
\text { "Randomization ... was performed by a } \\
\text { hospital pharmacist who was unaware of } \\
\text { the medical status of the patient and who } \\
\text { had no other involvement in the study." }\end{array}$ \\
\hline $\begin{array}{l}\text { Blinding? } \\
\text { Death, residence, readmission }\end{array}$ & Yes & $\begin{array}{l}\text { "Follow-up data were collected at } 4 \text { and } 12 \\
\text { months ... by an assessor who was blinded } \\
\text { to treatment allocation." }\end{array}$ \\
\hline $\begin{array}{l}\text { Blinding? } \\
\text { Function, QOL }\end{array}$ & Unclear & $\begin{array}{l}\text { "Follow-up data were collected at } 4 \text { and } 12 \\
\text { months ... by an assessor who was blinded } \\
\text { to treatment allocation." However, trial } \\
\text { participants were not blinded. }\end{array}$ \\
\hline $\begin{array}{l}\text { Incomplete outcome data addressed? } \\
\text { Death, residence, readmission }\end{array}$ & Yes & $\begin{array}{l}\text { Loss to follow-up and death fully reported } \\
\text { and data split by treatment group provided. }\end{array}$ \\
\hline $\begin{array}{l}\text { Incomplete outcome data addressed? } \\
\text { Function, QOL }\end{array}$ & Unclear & $\begin{array}{l}\text { Although denominators stated the } 3 \text { lost to } \\
\text { follow-up were all in the accelerated care } \\
\text { group. }\end{array}$ \\
\hline Free of selective reporting? & Unclear & $\begin{array}{l}\text { Incompletely reported but data provided } \\
\text { subsequently. The study protocol is not }\end{array}$ \\
\hline
\end{tabular}


available but it seems very likely that the published reports included all expected outcomes, including those that were prespecified.

Free of selection bias (from imbalances at Yes

Baseline characteristics, as well as prior care baseline)?

and timing seemed comparable.

Free of performance bias (from non-trial Unclear

Not enough detail to confirm this.

differences in care provision)?

Free of detection bias (from e.g. differences Yes

in follow-up procedures)?

\section{Fordham 1986}

Methods

Randomised trial: method unclear although independent of clinicians providing care Assessor blinding: no mention

Length of follow-up: to discharge

Participants

Interventions

Outcomes
General hospital in Huddersfield, UK; (intervention patients transferred to community hospital).

Conducted: March 1985 to March 1985.

108 women with hip fracture (surgically treated). Mean age not stated. Cognitive status: none retained in trial with long standing dementia.

Inclusion criteria: Women aged over 65 years with hip fracture.

Exclusion criteria: (Post-randomisation)Patients transferred from other hospitals or health authorities. Non consent. Confusion and terminal illness.

Assigned: 50/58 [Joint geriatric and orthopaedic care / Orthopaedic care]

Assessed (mortality): 50/58

Loss to follow-up: none, but no data on 25 omitted (14 versus 11) post-randomisation.
Randomisation took place immediately after the operation.

(1) Joint geriatric and orthopaedic management involving early post-admission assessment by geriatrician on the orthopaedic ward, joint decision for transfer to geriatricorthopaedic ward ( 6 beds in orthopaedic rehabilitation ward converted to geriatric-orthopaedic beds), joint clinical rounds once a week and liaison away from bed side, joint responsibility for rehabilitation programme, joint decisions about and facilitation of discharge or transfer, joint junior medical staff.

(2) Orthopaedic management (geriatrician available for advice) including decision to transfer to orthopaedic rehabilitation unit.

hospital at 2 months)
Other outcomes: mortality (discharge), patient function / activities of daily living (
standing, getting in/out of bed, getting in/out of a chair; walking; dressing) assessed
using 9 categories $(1=$ independent), length of stay, place of residence (at discharge or 2
months), transfer to community hospital, costs (staff and hospital stay)


Fordham 1986 (Continued)

\section{Notes}

\section{Risk of bias}

\begin{tabular}{|c|c|c|}
\hline Item & Authors' judgement & Description \\
\hline Adequate sequence generation? & Unclear & $\begin{array}{l}\text { "Randomly assigned" by research team } \\
\text { within first few of hospital admission. }\end{array}$ \\
\hline Allocation concealment? & Yes & $\begin{array}{l}\text { Randomisation by research team - then ap- } \\
\text { propriate clinicians were informed. }\end{array}$ \\
\hline $\begin{array}{l}\text { Blinding? } \\
\text { Death, residence, readmission }\end{array}$ & Unclear & $\begin{array}{l}\text { Unlikely that mortality data affected by } \\
\text { lack of blinding. However, discharge loca- } \\
\text { tion might have been. }\end{array}$ \\
\hline $\begin{array}{l}\text { Blinding? } \\
\text { Function, QOL }\end{array}$ & No & $\begin{array}{l}\text { The lack of blinding may have influenced } \\
\text { these outcomes. }\end{array}$ \\
\hline $\begin{array}{l}\text { Incomplete outcome data addressed? } \\
\text { Death, residence, readmission }\end{array}$ & Unclear & $\begin{array}{l}\text { Post randomisation exclusions means that } \\
\text { there is some risk of bias. Full data for death } \\
\text { and residence at discharge provided for all } \\
\text { those retained in trial. }\end{array}$ \\
\hline $\begin{array}{l}\text { Incomplete outcome data addressed? } \\
\text { Function, QOL }\end{array}$ & No & $\begin{array}{l}\text { Functional outcome data (standing, getting } \\
\text { in/out of bed, getting in/out of a chair; } \\
\text { walking; dressing) were incomplete with } \\
\text { data missing for some participants; with } \\
\text { some imbalances between groups in those } \\
\text { not assessed. }\end{array}$ \\
\hline Free of selective reporting? & Yes & Very comprehensive and planned analyses. \\
\hline $\begin{array}{l}\text { Free of selection bias (from imbalances at } \\
\text { baseline)? }\end{array}$ & Unclear & $\begin{array}{l}\text { No significant differences reported in pop- } \\
\text { ulation after post-randomisation exclu- } \\
\text { sions (mainly not in catchment area) but } \\
\text { larger numbers of subtrochanteric ( } 12 / 50 \\
\text { versus } 5 / 58 \text { ) fractures and less hip replace- } \\
\text { ment in the intervention group. }\end{array}$ \\
\hline $\begin{array}{l}\text { Free of performance bias (from non-trial } \\
\text { differences in care provision)? }\end{array}$ & No & $\begin{array}{l}\text { The three mile distance between the hos- } \\
\text { pitals, with no clinics held in the acute } \\
\text { hospital by the geriatricians, may have af- } \\
\text { fected performance. Potential contamina- } \\
\text { tion as some clinicians were involved in pa- } \\
\text { tient management in both groups. }\end{array}$ \\
\hline
\end{tabular}




\section{Fordham 1986 (Continued)}

Free of detection bias (from e.g. differences Yes

Follow-up appeared thorough. in follow-up procedures)?

\section{Galvard 1995}

\begin{tabular}{ll} 
Methods & $\begin{array}{l}\text { Randomised trial: use of a random number generator } \\
\text { Assessor blinding: no mention } \\
\text { Length of follow-up: } 12 \text { months }\end{array}$ \\
\hline Participants & $\begin{array}{l}\text { General hospital in Malmo, Sweden. } \\
\text { Conducted: November } 1988 \text { to December } 1989 .\end{array}$ \\
& 378 people with hip fracture. Of $371: 26 \%$ male. Mean age 79 years, range 52 to 102 \\
years. Cognitive status: no information but all independent. \\
Inclusion criteria: People living in own home, perhaps receiving meals on meals or home \\
help service, with hip fractures. Patient consent. \\
Exclusion criteria: People resident in nursing home or waiting for a nursing home bed, \\
or already in hospital. Second hip fracture. \\
Assigned: $182 / 196$ [Geriatric hospital / Orthopaedic hospital] \\
Assessed (mortality): $179 / 192$ \\
Loss to follow-up varied according to outcome assessed: it was markedly incomplete for \\
hip pain (38/60), walking ability and gait speed.
\end{tabular}

Interventions

Randomisation took place immediately after the operation.

(1) Geriatric rehabilitation: transfer to geriatric hospital (usually on second post-operative day) and weekly visit by orthopaedic surgeon.

(2) Usual orthopaedic care

Outcomes

'Poor outcome': mortality at discharge + discharge to nursing home (or other)

Other outcomes: mortality (discharge and 1 year), patient function (subset at 1 year: hip pain and mobility), length of stay, place of residence (at discharge), readmissions (during 1 year), costs

Although 378 patients were entered into the study, 7 were excluded (protocol violations) : 4 with a second hip fracture wrongly included; 2 did not give consent, 1 did not live locally.

\section{Risk of bias}

\begin{tabular}{lll}
\hline Item & Authors' judgement & Description \\
\hline Adequate sequence generation? & Yes & $\begin{array}{l}\text { "Randomisation took place at the or- } \\
\text { thopaedic department immediately after } \\
\text { the operation, using andom number gen- } \\
\text { erator." }\end{array}$ \\
\hline Allocation concealment? & Unclear & No details.
\end{tabular}


Galvard 1995 (Continued)

\begin{tabular}{|c|c|c|}
\hline $\begin{array}{l}\text { Blinding? } \\
\text { Death, residence, readmission }\end{array}$ & Yes & $\begin{array}{l}\text { All patient records, from a central data reg- } \\
\text { istration facility, reviewed by the trial in- } \\
\text { vestigators. }\end{array}$ \\
\hline
\end{tabular}

\begin{tabular}{|c|c|c|}
\hline $\begin{array}{l}\text { Blinding? } \\
\text { Function, QOL }\end{array}$ & Unclear & $\begin{array}{l}\text { No reference made to blinding but it was } \\
\text { considered unlikely that the trial alloca- } \\
\text { tion influenced the physiotherapist assess- } \\
\text { ing mobility at one year follow-up. }\end{array}$ \\
\hline
\end{tabular}

Incomplete outcome data addressed? Yes

Death, residence, readmission

Incomplete outcome data addressed? No

Function, QOL
No

\begin{tabular}{|c|c|}
\hline runction, QuL & $\begin{array}{l}\text { participants ( } 38 \text { versus } 60 \text { ) attending fol- } \\
\text { low-up session at } 1 \text { year. Report noted that } \\
\text { a potential contributing factor to the dif- } \\
\text { ference in numbers of attendees was "that } \\
\text { patients treated at the orthopaedic depart- } \\
\text { ment traditionally participate in trials and } \\
\text { studies, while patients treated at the geri- } \\
\text { atric hospital had no such tradition at the } \\
\text { time." }\end{array}$ \\
\hline
\end{tabular}

Free of selective reporting?

Unclear pain) only provided for a subgroup of trial participants (38 versus 60 ) attending follow-up session at 1 year. Report noted that a potential contributing factor to the difpatients treated at the orthopaedic department traditionally participate in trials and atric hospital had no such tradition at the time."

The study protocol is not available but
Full data for death, residence at discharge and readmission provided.

Functional outcome data (mobility and it is very likely that the published report includes all expected outcomes, including those that were pre-specified.

Free of selection bias (from imbalances at No baseline)?

Free of performance bias (from non-trial No differences in care provision)?
As reported by the trial authors, there is significant bias due a) the men in the geriatric hospital group being older (79.1 versus 73.6 years), and b) the higher proportion of patients with subtrochanteric fractures, which often require longer rehabilitation, in the same group $(21 / 179(12 \%)$ versus $8 / 192(4 \%))$

In contrast to the orthopaedic hospital, the geriatric hospital had no prior experience with hip fracture patients.

It was noted that "the orthopaedic department had first priority to home help services, alterations in patient's flats, and convalescent homes." This and the fact that there was a lack of nursing home beds in Malmo was mooted as a factor contributing to the longer hospital stay in geriatric 
Galvard 1995 (Continued)

hospital.

Free of detection bias (from e.g. differences Unclear in follow-up procedures)?
While detection bias was unlikely for outcomes such as death, the imbalance in the follow-up of functional outcomes could have been related to the different research environments at the two trial sites (see above).

\section{Gilchrist 1988}

Methods

\begin{tabular}{ll} 
& $\begin{array}{l}\text { Assessor blinding: no mention } \\
\text { Length of follow-up: } 6 \text { months after discharge (for mortality). }\end{array}$ \\
\hline Participants & General hospital in Glasgow, UK. \\
& Conducted: October 1984 to July 1986 \\
& 222 women with hip fracture. Mean age 81 years. Cognitive status: initial mental function \\
assessed using mini object test (101 had scores $>19 / 30$, would have had better mental \\
function). \\
Inclusion criteria: Women aged over 65 years with hip fractures, transferred to the \\
hospital for rehabilitation. \\
Exclusion criteria: None (6 patients had pathological fractures). \\
Assigned: $97 / 125$ [Orthopaedic-geriatric ward / Orthopaedic ward] \\
Assessed (mortality): $97 / 125$ \\
Loss to follow-up: none.
\end{tabular}

Method of randomisation: unclear, stratified by fracture type

Assessor blinding: no mention

Loss to follow-up: none.

\begin{tabular}{ll} 
Interventions & $\begin{array}{l}\text { Randomisation took place at transfer, which occurred at a mean of } 10 \text { days after admission } \\
\text { for hip fracture, from another hospital. } \\
\text { (1) Combined geriatric-orthopaedic care in special designated unit. Weekly ward round } \\
\text { with a geriatrician, an orthopaedic senior registrar and a senior ward nurse; followed by } \\
\text { a case conference with in addition a physiotherapist, occupational therapist and a social } \\
\text { worker. } \\
\text { (2) Usual orthopaedic care in orthopaedic ward. Referral to geriatrician (different person } \\
\text { from the one attending the geriatric-orthopaedic ward) by letter. } \\
\text { All patients had similar nursing cover, access to similar paramedical services and remained } \\
\text { under the care of the orthopaedic surgical staff. }\end{array}$ \\
\hline Outcomes & $\begin{array}{l}\text { 'Poor outcome': mortality at discharge and discharge to nursing home (or institution) } \\
\text { Other outcomes: mortality (discharge, } 3 \text { and } 6 \text { months post discharge), length of stay, } \\
\text { place of residence (at discharge), medical conditions (recognised; untreated), length of } \\
\text { time patient seen by geriatrician }\end{array}$ \\
\hline Notes & $\begin{array}{l}\text { Although both groups were reported to have had home visits at } 3 \text { and } 6 \text { months after } \\
\text { discharge, there were no data pertaining follow-up at these times aside from mortality. }\end{array}$ \\
\hline
\end{tabular}

Risk of bias 
Gilchrist 1988 (Continued)

\begin{tabular}{|c|c|c|}
\hline Item & Authors' judgement & Description \\
\hline Adequate sequence generation? & Unclear & $\begin{array}{l}\text { "Randomised". Method not stated. How- } \\
\text { ever, "stratified on the basis of the site of the } \\
\text { fracture (intracapsular;extracapsular)" and } \\
\text { a } 5 \text { to } 4 \text { bias introduced in favour of the } \\
\text { orthopaedic wards due to a larger number } \\
\text { of beds. }\end{array}$ \\
\hline Allocation concealment? & Unclear & No details. \\
\hline $\begin{array}{l}\text { Blinding? } \\
\text { Death, residence, readmission }\end{array}$ & Unclear & $\begin{array}{l}\text { Not blinded, nor was blinding possible, but } \\
\text { prospective and active follow-up for death. } \\
\text { Unclear if discharge placement was influ- } \\
\text { enced by knowledge of group allocation. }\end{array}$ \\
\hline $\begin{array}{l}\text { Blinding? } \\
\text { Function, QOL }\end{array}$ & Unclear & $\begin{array}{l}\text { No blinding. No function or QOL data } \\
\text { but, while some standardisation was evi- } \\
\text { dent, assessment of morbidity (untreated } \\
\text { conditions)may have been influenced by } \\
\text { knowledge of group allocation. }\end{array}$ \\
\hline
\end{tabular}

Death, residence, readmission
Incomplete outcome data addressed? Yes

No lost to follow-up or post-randomisation exclusions; no transfer between wards. However, there was an incomplete account of placement of participants who had not been living in the community before their fracture.

Not clear if function assessed.

Incomplete outcome data addressed? Unclear Function, QOL

Free of selective reporting? Unclear

The study protocol is not available but it is very likely that the choice of main outcomes was pre-specified.

Free of selection bias (from imbalances at Yes baseline)?

No important differences in age, gender (all female), type of fracture, dementia (mini object score) and time to transfer

Free of performance bias (from non-trial Unclear differences in care provision)?
None detected, however, possible contamination with geriatric intervention 'spilling over' to the control group. A greater interest was taken by the orthopaedic surgeons in the medical and social aspects of care in the control group such that patient management (e.g. more comprehensive discharge notes and fewer drugs) had "considerably 
Gilchrist 1988 (Continued)

changed". This may have been influenced by the rotation of junior staff during training.

Free of detection bias (from e.g. differences Yes

Follow-up appeared active and systematic. in follow-up procedures)?

\section{Huusko 2002}

\begin{tabular}{ll} 
Methods & $\begin{array}{l}\text { Randomised using opaque sealed envelopes; independently computer generated alloca- } \\
\text { tion sequence. } \\
\text { Assessor blinding: no } \\
\text { Length of follow-up: } 12 \text { months. }\end{array}$ \\
\hline Participants & $\begin{array}{l}\text { Specialist district hospital in Jyvaskyla, Finland. } \\
\text { Conducted: October } 1994 \text { to December } 1998 . \\
260 \text { people with hip fracture. Of } 243: 28 \% \text { male. Mean age } 80 \text { years, range } 66 \text { to } 97 \\
\text { years. Cognitive status: } 52 \text { had dementia. } \\
\text { Inclusion criteria: community dwelling, }>64 \text { years with surgically treated hip fracture, } \\
\text { informed consent, independent ambulation. } \\
\text { Exclusion criteria: pathological fracture, multiple fractures, terminally ill, serious early } \\
\text { complication, receiving calcitonin, unable to communicate. } \\
\text { Assigned: } 130 / 130 \text { [Intensive care/ Usual care]; } 120 / 123 \text { (after post-randomisation ex- } \\
\text { clusions) } \\
\text { Assessed (12 months): } 120 / 123 \text { (mortality); } 119 / 119 \text { (residence); } 95 / 98 \text { (ADL) }\end{array}$ \\
\hline
\end{tabular}

Interventions

Patient consent obtained on first post-operative day; assume randomisation followed this. All patients mobilised on first post-operative day.

(1) Intensive geriatric rehabilitation within hospital: Multidisciplinary geriatric team ( geriatrician, specially trained GP and nurses, occupational therapist, physiotherapists, social worker, neuropsychologist)working with other specialists (in physical medicine, neurology, psychiatry)providing intensive rehabilitation programme (assessment; twice daily physiotherapy; ADL practice; daily schedule; counselling; information; discharge plan; home visits, treatment at home after discharge)based in geriatric ward in same hospital as surgery. During first two months after discharge, patients discharged to independent living were visited 10 times by physiotherapist.

(2) Discharge to local community hospitals, treatment by general practitioners; physiotherapist usually available. Transfer 2 to 5 days after surgery. Around half of the patients on the long term wards are long-term patients. (No details given of actual non-specialist care.)

Outcomes

'Poor outcome': mortality at discharge or non-return to independent living; transfer to more dependent residence mortality or institutional care or hospital at 12 months. Other outcomes: mortality (in hospital and 12 months), functional status (ADL and instrumental ADL), morbidity (any complication during 12 months), length of stay, discharge location (incomplete data); place of residence (12 months), any complication during follow-up, costs, physiotherapy sessions, home services. 
Huusko 2002 (Continued)

Patients were also randomised to nasal calcitonin or placebo for 3 months (full report
in 2002). The distribution of patients taking calcitonin was claimed to be similar in the
two groups considered here.
A pre-planned sub-group analysis by cognitive impairment (based on the mini mental
state examination)was performed and reported before (2000) the report of the full pop-
ulation (2002).
Data from Huusko on return to independent living at discharge; on independence in
ADL; and overall length of hospital stay over 1 year follow-up.

Risk of bias

\begin{tabular}{|c|c|c|}
\hline Item & Authors' judgement & Description \\
\hline Adequate sequence generation? & Yes & $\begin{array}{l}\text { "Allocation sequence was computer-gener- } \\
\text { ated" }\end{array}$ \\
\hline Allocation concealment? & Yes & $\begin{array}{l}\text { "Allocation sequence was computer-gener- } \\
\text { ated and sealed in numbered, opaque en- } \\
\text { velopes in Helsinki, Finland, by the in- } \\
\text { formation technology department of No- } \\
\text { vartis before the study was started. The } \\
\text { envelopes were stored on the orthopaedic } \\
\text { ward by the head nurse until patients were } \\
\text { randomised." }\end{array}$ \\
\hline $\begin{array}{l}\text { Blinding? } \\
\text { Death, residence, readmission }\end{array}$ & Yes & Not blinded, but unlikely to affect results \\
\hline $\begin{array}{l}\text { Blinding? } \\
\text { Function, QOL }\end{array}$ & Unclear & $\begin{array}{l}\text { "We could not blind the staff doing the in- } \\
\text { terventions or assessments". Geriatrician in } \\
\text { charge of study didn't take part in geriatric } \\
\text { rounds or team meetings. }\end{array}$ \\
\hline
\end{tabular}

Death, residence, readmission
Incomplete outcome data addressed? No
Incomplete outcome data addressed?

Function, QOL
Baseline data were not presented for 17 participants (10 versus 7): 11 'violation of randomization criteria'; 3 'withdrawal of consent'; 3 'protocol violation'. Residence data also not available for 5 participants without initial mental state scores.

As well as post-randomisation exclusions, additional losses for functional outcomes (ADL and instrumental ADL) because results provided only for those with data measured at baseline.
No protocol available and incomplete reporting. 
Huusko 2002 (Continued)

\begin{tabular}{l|l|l}
$\begin{array}{l}\text { Free of selection bias (from imbalances at } \\
\text { baseline)? }\end{array}$ & No & $\begin{array}{l}\text { Imbalance in patient characteristics. For ex- } \\
\text { ample, intervention group had a greater } \\
\text { number with dementia }(32 / 120 \text { versus }\end{array}$ \\
& 20/123); fewer were functionally indepen- \\
dent in ADL before hip fracture (41 versus &
\end{tabular}

Free of performance bias (from non-trial Unclear

No details of staff training or motivation. differences in care provision)? Hard to determine for complex packages.

Free of detection bias (from e.g. differences Yes in follow-up procedures)?

Appeared systematic and thorough.

\section{Kennie 1988}

Methods

Randomised using random numbers and sealed envelopes

Assessor blinding: not done

Length of follow-up: 12 months

\begin{tabular}{|c|c|}
\hline Participants & $\begin{array}{l}\text { District hospital in Stirling, UK. } \\
\text { Conducted: over an } 18 \text { month period } \\
108 \text { women with hip fracture. Median ages of the } 2 \text { groups: } 79 \text { and } 84 \text { years, range } 65 \text { to } \\
\text { 94. Cognitive status: initial mental function assessed using short portable mental status } \\
\text { questionnaire ( } 56 \text { with at least mild cognitive impairment; } 35 \text { had moderate or severe } \\
\text { impairment). } \\
\text { Inclusion criteria: Women aged over } 65 \text {, fractured proximal femur requiring operative } \\
\text { fixation } \\
\text { Exclusion criteria: not fit enough for enrolment into trial; pathological fracture; likely } \\
\text { to be discharged within } 7 \text { days of trial entry; remaining unfit for transfer, e.g. prolonged } \\
\text { traction. } \\
\text { Assigned: } 54 / 54 \text { [Multidisciplinary care / Orthopaedic care] } \\
\text { Assessed ( } 12 \text { months): } 53 / 54 \\
\text { Loss to follow-up: one patient, who was known to be alive. }\end{array}$ \\
\hline Interventions & $\begin{array}{l}\text { Randomisation when orthopaedic surgeon judged the patient was fit enough to go to a } \\
\text { rehabilitation ward. } \\
\text { (1) Multidisciplinary care (general practitioner (GP), geriatrician and advice when } \\
\text { needed from orthopaedic specialist)in orthopaedic beds at peripheral hospital. Transfer } \\
0 \text { to } 7 \text { days after trial entry. Day to day care by GP. Each week, geriatrician attended } \\
2 \text { ward rounds and one multidisciplinary team conference. Orthopaedic surgeon gave } \\
\text { advice on demand. } \\
\text { (2) Routine orthopaedic care in orthopaedic admission ward (a few moved to other short } \\
\text { stay wards). } \\
\text { Allied health care (physiotherapy, occupational therapy; orthotic and other services) } \\
\text { received by both groups. Attempt to standardise these overall. }\end{array}$ \\
\hline
\end{tabular}


Kennie 1988 (Continued)

$\begin{array}{ll}\text { Outcomes } & \text { 'Poor outcome': mortality or in nursing care at } 1 \text { year (or mortality or physically depen- } \\ \text { dent at } 1 \text { year) } & \text { Other outcomes: mortality (discharge, } 1 \text { year), functional status (mobility; physical in- } \\ \text { dependence), length of stay, place of residence, life satisfaction index, carer burden (at } \\ 12 \text { months); medical conditions (no difference post discharge). }\end{array}$

\begin{tabular}{l} 
Notes \\
$\begin{array}{l}\text { A few patients from the control group (not stated a number) was moved into other short } \\
\text { stay wards at the discretion of the consultant orthopaedic surgeon, and were 'encouraged } \\
\text { early discharge'. } \\
\text { Data for mortality and residence at one year are taken from the Reid } 1989 \text { paper. There } \\
\text { were still discrepancies with those provided in Burns 1992, which was also internally } \\
\text { inconsistent and thus not included here. The data trends were the same. }\end{array}$ \\
\hline
\end{tabular}

Risk of bias

\begin{tabular}{|c|c|c|}
\hline Item & Authors' judgement & Description \\
\hline Adequate sequence generation? & Yes & $\begin{array}{l}\text { Randomised: "random sequence deter- } \\
\text { mined before the start of the study after the } \\
\text { method of Tukey". }\end{array}$ \\
\hline Allocation concealment? & Yes & $\begin{array}{l}\text { "The allocation was in sealed envelopes } \\
\text { held by a departmental secretary." }\end{array}$ \\
\hline $\begin{array}{l}\text { Blinding? } \\
\text { Death, residence, readmission }\end{array}$ & Unclear & $\begin{array}{l}\text { "No attempt was made to blind either staff } \\
\text { or patients". } \\
\text { Assessments of independence in the activi- } \\
\text { ties of daily living were made jointly by an } \\
\text { occupational therapist and a physiothera- } \\
\text { pist, and all other assessments were made } \\
\text { by a doctor. Blinding at } 1 \text { year assessment } \\
\text { was not stated, but seems unlikely. }\end{array}$ \\
\hline $\begin{array}{l}\text { Blinding? } \\
\text { Function, QOL }\end{array}$ & No & $\begin{array}{l}\text { "No attempt was made to blind either staff } \\
\text { or patients". } \\
\text { Assessments of independence in the activi- } \\
\text { ties of daily living were made jointly by an } \\
\text { occupational therapist and a physiother- } \\
\text { apist. Meetings were held to ensure con- } \\
\text { sistent assessment throughout the study. } \\
\text { Blinding at } 1 \text { year assessment was not } \\
\text { stated, but seems unlikely. }\end{array}$ \\
\hline $\begin{array}{l}\text { Incomplete outcome data addressed? } \\
\text { Death, residence, readmission }\end{array}$ & Yes & $\begin{array}{l}\text { "No patient was excluded on grounds of } \\
\text { non-compliance." One patient lost to fol- } \\
\text { low-up was confirmed to be alive. }\end{array}$ \\
\hline
\end{tabular}


Kennie 1988 (Continued)

\begin{tabular}{l|l|l}
\hline $\begin{array}{l}\text { Incomplete outcome data addressed? } \\
\text { Function, QOL }\end{array}$ & Unclear & $\begin{array}{l}\text { As above, but some discrepancies between } \\
\text { the Reid and the Burns papers in the num- } \\
\text { bers followed up. }\end{array}$ \\
\hline Free of selective reporting? & Unclear & $\begin{array}{l}\text { The study protocol is not available but it } \\
\text { is very likely that the choice of main out- } \\
\text { comes was pre-specified. }\end{array}$ \\
\hline
\end{tabular}

Free of selection bias (from imbalances at No baseline)?

The treatment group were younger (median ages 79 versus 84 ) and had higher cognitive function $(P=0.06)$.

Free of performance bias (from non-trial Unclear differences in care provision)?

"the consultant geriatrician ... may have ..used community resources more fully, and been more willing than the orthopaedic surgeon to take calculated risks when discharging frail elderly patients back to the community." In the control group: "the demand for beds encouraged their early discharge".

Both treatment and control groups received physiotherapy, occupational therapy, and orthotic and other services. However, the intervention group may have received more physiotherapy and nursing care. it is unclear whether there "was a greater ability of the nurses to conduct functionally orientated care when working outside the acute orthopaedic ward with its emphasis on caring for highly dependent patients".

Free of detection bias (from e.g. differences Yes Follow-up appeared active and systematic. in follow-up procedures)?

\section{Naglie 2002}

Methods

Randomised trial: using computer-generated randomisation (block size of 4), stratified by age and place of residence, sequentially numbered, sealed, opaque envelopes.

Assessor blinding: yes

Length of follow-up: 6 months

Participants
Teaching hospital in Toronto, Canada.

Conducted: June 1993 to March 1997.

280 people with hip fracture. Of 279: 20\% male. Mean age 84 years. Cognitive status: 74 had mild to moderate mental impairment; unknown numbers with no impairment or severe impairment.

Inclusion criteria: Aged 70+ years, had undergone surgery for hip fracture; resident in community or nursing home. 
Naglie 2002 (Continued)

\begin{tabular}{l} 
Exclusion criteria: fracture occurred in acute care setting or hospital, pathological fracture, \\
multiple trauma, previous surgery of fractured hip, expected survival $<6$ months, nursing \\
home and dependent for ambulation before fracture, technical failure of surgery, no bed \\
available on interdisciplinary unit. \\
Assigned: $141 / 139$ [Multidisciplinary care / Usual care] \\
Assessed ( 6 months): $141 / 138$ \\
Loss to follow-up: one withdrawal from usual care group \\
\hline
\end{tabular}

Interventions

Randomisation took place in post-anaesthetic care unit when the patient was considered stable enough for transfer to a ward.

(1) Interdisciplinary care consisting of routine postoperative surgical care plus daily medical care by internist-geriatrician, and regular care by physiotherapist, occupational therapist, social worker and clinical nurse specialist. Twice weekly interdisciplinary rounds to set goals and monitor patient's progress. (Emphasis on preventing medical problems, such as pressure sores; early mobilisation; early participation in self-care; individualised discharge planning; priority assessment $\&$ specialised training.)

(2) Usual care on orthopaedic units (same hospital but different care teams) which included access to geriatric consultation and allied health care professionals if requested; access to occupational therapists and clinical nurse specialists was limited.

There was no specialist follow-up care.

Outcomes

'Poor outcome': mortality at discharge or transfer to more dependent residence (e.g. nursing home or rehabilitation hospital); mortality at 6 months or living in more dependent residence (nursing home etc); mortality or decline in ambulation; or mortality or decline in ambulation or chair or bed transfers and place of residence.

Other outcomes: mortality (at discharge, 3 and 6 months), ADL (Barthel Index), mobility (transfers and walking), length of stay, days in hospitals over 6 months, change in residence (indicating deterioration), health care utilisation.

Notes

The discrepancies between the full report of the trial, published in 2002, and an abstract (1999) in the numbers randomised resulted from the exclusion of 18 participants in the abstract report. These comprised one patient who withdrew and 17 who were deemed ineligible after randomisation. The latter 17 were included in an intention-to-treat analysis in the full report.

Risk of bias

\begin{tabular}{|c|c|c|}
\hline Item & Authors' judgement & Description \\
\hline Adequate sequence generation? & Yes & $\begin{array}{l}\text { "Stratified, computer-generated random- } \\
\text { ization scheme with a block size of } 4 \text {." Strat- } \\
\text { ification by age ( } 70 \text { to } 79 ; 80+\text { years) and } \\
\text { place of residence at admission (private res- } \\
\text { idence; retirement home; nursing home). }\end{array}$ \\
\hline Allocation concealment? & Yes & $\begin{array}{l}\text { "Orthopaedic residents, who were blinded } \\
\text { to block size, assigned the patients to treat- } \\
\text { ment group according to sequentially num- } \\
\text { bered, sealed opaque envelopes that were }\end{array}$ \\
\hline
\end{tabular}


Naglie 2002 (Continued)

colour coded by stratum.”

\begin{tabular}{l|l|l}
\hline $\begin{array}{l}\text { Blinding? } \\
\text { Death, residence, readmission }\end{array}$ & Yes & $\begin{array}{l}\text { "All follow-up assessments were conducted } \\
\text { by research assistants blinded to group as- } \\
\text { signments." }\end{array}$ \\
\hline $\begin{array}{l}\text { Blinding? } \\
\text { Function, QOL }\end{array}$ & Unclear & $\begin{array}{l}\text { "All follow-up assessments were conducted } \\
\text { by research assistants blinded to group } \\
\text { assignments." Providers and participants } \\
\text { were not blinded. }\end{array}$ \\
\hline $\begin{array}{l}\text { Incomplete outcome data addressed? } \\
\text { Death, residence, readmission }\end{array}$ & Yes & $\begin{array}{l}\text { Intention-to-treat analysis. Data missing } \\
\text { only for one participant who withdrew } \\
\text { from the trial. Flow diagram presented. (At } \\
\text { review, 17 patients were deemed ineligible } \\
(8 \text { versus 9) but there were included in the } \\
\text { full report.) }\end{array}$ \\
\hline $\begin{array}{l}\text { Incomplete outcome data addressed? } \\
\text { Function, QOL }\end{array}$ & Yes & As above. \\
\hline Free of selective reporting? & Unclear & $\begin{array}{l}\text { The study protocol is not available but it } \\
\text { is very likely that the choice of main out- } \\
\text { comes was pre-specified. }\end{array}$ \\
\hline
\end{tabular}

Free of selection bias (from imbalances at Yes

None of the differences between treatment baseline)? groups was statistically significant.

Free of performance bias (from non-trial Unclear differences in care provision)?

"To minimise the risk of contamination bias, interdisciplinary care and usual care were provided by different staff on different wards." Insufficient information - there was no specialist follow-up care.

Free of detection bias (from e.g. differences Yes Systematic and active follow-up. in follow-up procedures)?

\section{Ryan 2006}

Methods

Randomised trial: random numbers table, sealed opaque envelopes Assessor blinding: yes

Length of follow-up: 12 months.

Participants
In the community, Sheffield, UK

Conducted: July 2000 to June 2002

71 people with hip fracture. $24 \%$ male. Mean age 81 years. Cognitive status: None had dementia

Inclusion criteria: Aged 65 years or over recovering from (stroke or) hip fracture, recently 


\begin{tabular}{l} 
discharged from hospital to their own home. Contact within 5 days of notification of \\
patient eligibility. \\
Exclusion criteria: Concomitant disease (e.g. Parkinson's disease or dementia). \\
Assigned: $37 / 34$ [intensive / less intensive] \\
Assessed ( 12 months): $30 / 28$ \\
Loss to follow-up $=7$ versus 6 (withdrew, deceased, unavailable, in hospital) \\
\hline
\end{tabular}

Interventions
Randomisation within 5 working days of referral to community rehabilitation team. Maximum duration of treatment period was 12 weeks. All treatment (and assessment) undertaken in patient's own home.

(1) Intensive: 6 or more face-to-face contacts per week from members of a multidisciplinary rehabilitation team

(2) Less intensive: 3 or less face-to-face contacts per week from members of a multidisciplinary rehabilitation team

The service (both augmented and routine) was provided to both groups of patients by a local multidisciplinary team (physiotherapist, occupational therapist, speech and language therapist or therapy assistant). There were 4 teams, divided by geographical area, but belonging to the same city-wide service managed by the same Primary Care Trust.

'Poor outcome': mortality at 12 months and admission to institutional care Other outcomes: mortality ( 3 and 12 months), function (Barthel Index; Frenchay activities index), admission to institutional care, days spent in hospital (*stroke and hip fracture), use of home care services readmissions $\left({ }^{*}\right)$, number of contacts during treatment period $\left(^{*}\right)$, Euroqol (no data), therapy outcome measure (no data).

Notes

Some data for hip fracture patients received from Dr Ryan on 5 February 2009: gender and co-residing carer; death and institutional care at 3 and 12 months follow-up.

\section{Risk of bias}

\begin{tabular}{l|l|l}
\hline Item & Authors' judgement & Description \\
\hline Adequate sequence generation? & Yes & $\begin{array}{l}\text { "Randomization was carried out using a } \\
\text { random } \\
\text { number table (blocks of 10) and sealed } \\
\text { opaque } \\
\text { envelopes. Randomization was stratified on } \\
\text { the } \\
\text { basis of the diagnosis of hip fracture or } \\
\text { stroke and locality team." }\end{array}$ \\
\hline Allocation concealment? & Yes & $\begin{array}{l}\text { sealed opaque envelopes. .... An adminis- } \\
\text { trator based within each of the teams car- } \\
\text { ried out the allocation procedure. The re- } \\
\text { sult was recorded on each patient file ... and } \\
\text { was immediately communicated to the re- } \\
\text { search team." }\end{array}$ \\
\hline
\end{tabular}


Ryan 2006 (Continued)

\begin{tabular}{|c|c|c|}
\hline $\begin{array}{l}\text { Blinding? } \\
\text { Death, residence, readmission }\end{array}$ & Yes & $\begin{array}{l}\text { "Blinded follow-up assessments were car- } \\
\text { ried out" }\end{array}$ \\
\hline $\begin{array}{l}\text { Blinding? } \\
\text { Function, QOL }\end{array}$ & Yes & $\begin{array}{l}\text { "Blinded follow-up assessments were car- } \\
\text { ried out" "Blinding was achieved by follow- } \\
\text { up being undertaken by trained therapy as- } \\
\text { sistants who were not involved in the pro- } \\
\text { vision of service } \\
\text { to participating patients and who worked } \\
\text { in another part of the city to that of the } \\
\text { patient." }\end{array}$ \\
\hline $\begin{array}{l}\text { Incomplete outcome data addressed? } \\
\text { Death, residence, readmission }\end{array}$ & Yes & Participant flow diagram provided. \\
\hline $\begin{array}{l}\text { Incomplete outcome data addressed? } \\
\text { Function, QOL }\end{array}$ & Unclear & $\begin{array}{l}\text { "A method of imputation, using the me- } \\
\text { dian for each group, was used for missing } \\
\text { data." }\end{array}$ \\
\hline Free of selective reporting? & Unclear & $\begin{array}{l}\text { The study protocol is not available but } \\
\text { it is very likely that the published report } \\
\text { includes all expected outcomes, including } \\
\text { those that were pre-specified. }\end{array}$ \\
\hline $\begin{array}{l}\text { Free of selection bias (from imbalances at } \\
\text { baseline)? }\end{array}$ & No & $\begin{array}{l}\text { There was more males }(12 / 37 \text { versus } 5 / 34) \\
\text { and significantly more patients with a re- } \\
\text { siding carer in the intensive group. }\end{array}$ \\
\hline $\begin{array}{l}\text { Free of performance bias (from non-trial } \\
\text { differences in care provision)? }\end{array}$ & No & $\begin{array}{l}\text { The same multidisciplinary team provided } \\
\text { care to both groups. In this pragmatic trial, } \\
\text { therapists were requested to provide a more } \\
\text { intensive service to those allocated to the in- } \\
\text { tervention group. However, what occurred } \\
\text { within those additional face-to-face con- } \\
\text { tacts was not prescribed, neither was it } \\
\text { known. }\end{array}$ \\
\hline $\begin{array}{l}\text { Free of detection bias (from e.g. differences } \\
\text { in follow-up procedures)? }\end{array}$ & Yes & Active and systematic follow-up \\
\hline
\end{tabular}

\section{Shyu 2008}

Methods
Randomised trial: coin tossed by a third party

Assessor blinding: no, but independent data collectors

Length of follow-up: 12 months. 
Shyu 2008 (Continued)

\begin{tabular}{ll}
\hline Participants & Teaching hospital in Taiwan \\
& Conducted: September 2001 to November 2003 \\
& 162 people with hip fracture. $31.5 \%$ male. Mean age 78 years. Cognitive status: About \\
a third of participants had mild cognitive impairment; severe impairment not included. & Inclusion criteria: Aged 60 years or over, admitted for acute hip fracture surgery, unilateral \\
& hip fracture, resided in Northern Taiwan, prefracture score Chinese Barthel index $>70 ;$ \\
& able to perform full range of motion against gravity and resistance. Approval sought for \\
data collection. & Exclusion criteria: Severe cognitive impairment; completely unable to follow instructions \\
& (< 10 on Chinese mini-mental state examination); or terminally ill. \\
& Assigned: $72 / 87$ [Multidisciplinary care / Usual care] \\
Assessed (12 months): $60 / 62$ & Loss to follow-up (patient withdrew) $=16$ versus 14 \\
\hline
\end{tabular}

Interventions

(1nterventions
Randomisation took place soon after admission to emergency department.

(1) Interdisciplinary programme of geriatric consultation, continuous rehabilitation and discharge planning. Geriatrician and geriatric nurses provided geriatric assessment/consultation; physiotherapist, geriatric nurses, and rehabilitation physician were responsible for rehabilitation programme; geriatric nurse co-ordinated discharge planning service. Early mobilisation, home visit and follow-up services provided. In addition to routine care, 1 physical therapy session a day from geriatric nurse (total 4 times, -30 minutes each), 2 assessments by a physical therapist (each 20 minutes), one visit from rehabilitation physician (20 minutes). Post hospital discharge: 4 home visits during first month (once a week for -30 minutes) and 4 home visits during second and third month $(-30$ minutes each) from a geriatric nurse.

(2) Usual care on trauma or orthopaedic ward. Some consultations of other disciplines (e.g. internal medicine) occasionally made depending on patient's condition. Exercises taught by nurses in first 2 to 3 days. Number of physical therapy sessions varied because insurance policy: 18 received 3 sessions, the rest only 1 session. Discharge approximately 7 days from surgery with no care provision subsequently.

Outcomes

'Poor outcome': mortality at 12 months and admission to institutional care; mortality + functional deterioration at 12 months (non recovery of walking function).

Other outcomes: mortality (1, 3, 6 and 12 months), function (mobility), function (modified Barthel Index), depressive symptoms, Chinese Barthel Index, admission to institutional care, length of hospital stay, readmissions (emergency room visit), falls.

Notes

Confirmation that the study populations of the 2005 and 2008 reports were the same received from Dr Shyu. Additional data for 12 months follow-up also received on 9 December 2008.

\section{Risk of bias}

\begin{tabular}{lll}
\hline Item & Authors' judgement & Description \\
\hline Adequate sequence generation? & Yes & $\begin{array}{l}\text { "randomly assigned to an experimental or } \\
\text { control group by the flip of a coin" }\end{array}$
\end{tabular}




\section{Shyu 2008 (Continued)}

\begin{tabular}{l|l|l}
\hline Allocation concealment? & Yes & $\begin{array}{l}\text { "a neutral third party not involved in de- } \\
\text { livering the intervention or assessing out- } \\
\text { comes flipped the coin". Adherence as- } \\
\text { sumed. }\end{array}$ \\
\hline $\begin{array}{l}\text { Blinding? } \\
\text { Death, residence, readmission }\end{array}$ & Yes & $\begin{array}{l}\text { Insufficient information but data collection } \\
\text { was probably independent. }\end{array}$ \\
\hline $\begin{array}{l}\text { Blinding? } \\
\text { Function, QOL }\end{array}$ & Unclear & $\begin{array}{l}\text { "participants were blinded but evaluators } \\
\text { were not". However, different nurses (data } \\
\text { collectors)from those who delivered the in- } \\
\text { tervention conducted the follow-up assess- } \\
\text { ments at participant's home. }\end{array}$ \\
\hline
\end{tabular}

\begin{tabular}{|c|c|c|}
\hline $\begin{array}{l}\text { Incomplete outcome data addressed? } \\
\text { Death, residence, readmission }\end{array}$ & Unclear & $\begin{array}{l}\text { Participant flow obtained. Some discrep- } \\
\text { ancies in data (e.g. mortality) (between pa- } \\
\text { pers and data from author) although not an } \\
\text { imbalance in numbers of participants who } \\
\text { withdrew. }\end{array}$ \\
\hline $\begin{array}{l}\text { Incomplete outcome data addressed? } \\
\text { Function, QOL }\end{array}$ & Unclear & As above. \\
\hline Free of selective reporting? & Unclear & $\begin{array}{l}\text { The study protocol is not available but } \\
\text { it is very likely that the published report } \\
\text { includes all expected outcomes, including } \\
\text { those that were pre-specified. }\end{array}$ \\
\hline
\end{tabular}

Free of selection bias (from imbalances at Yes

No serious imbalance.

baseline)?

Free of performance bias (from non-trial Yes differences in care provision)?

Insurance policy determined number of physiotherapy sessions in control group. However, the difference was between one or three sessions. Notably, the active followup of the control group can be considered additional to usual care.

Free of detection bias (from e.g. differences Yes in follow-up procedures)?

Sufficiently similar and independent follow-up procedures 


\begin{tabular}{l} 
Teaching hospital in Sweden \\
Conducted: May 2000 to December 2002 \\
199 people with hip fracture. $26 \%$ male. Mean age 82 years. Cognitive status: 64 had \\
dementia. \\
Inclusion criteria: Aged 70 years or over, admitted for acute hip fracture surgery, oral \\
and written consent by patient or carer. \\
Exclusion criteria: Severe rheumatoid arthritis or hip osteoarthritis; pathological fracture; \\
severe renal failure; bedridden; fracture sustained in hospital. \\
Assigned: $102 / 97$ [Multidisciplinary care / Usual care] \\
Assessed (12 months): $84 / 76$ (survivors) \\
Loss to follow-up (patient withdrew) $=2$ versus 2 \\
\hline
\end{tabular}

Interventions

Randomisation envelope received in the emergency room but envelope not opened until immediately before surgery.

(1) Geriatric unit specialising in geriatric orthopaedic care. Multidisciplinary team providing comprehensive geriatric assessments and rehabilitation. Active prevention, detection and treatment of post-operative complications, such as falls, delirium, pain, pressure sores and malnutrition. Early mobilisation, with daily training, provided by physiotherapists ( 2 full time), occupational therapists ( 2 full time) and care staff, including dietician (0.2) during hospital stay. Staffing ratio 1.07 nurses or aides per bed. A geriatric team, including a physician, assessed patients at 4 months including for further rehabilitation needs.

(2) Usual care on specialist orthopaedic ward. Care included that by physiotherapists (2 full time), occupational therapist ( 0.5 full time) and care staff, not including dietician during hospital stay. Staffing ratio 1.01 nurses or aides per bed in orthopaedic ward; 1.07 in geriatric control ward used for longer stays. No 4 month assessment.

Outcomes

'Poor outcome': mortality at discharge and not discharged to previous residence; mortality + not in same residence at 12 months; or mortality and reduced activity of daily living.

Other outcomes: mortality (in hospital; 4 and 12 months), function (mobility), function (Katz ADL), independent living, complications including falls, length of hospital stay (initial episode; over 1 year), return to previous residence, readmissions, falls.

Notes

Separate publications produced by trial group reporting outcomes (delirium, nutritional status, and falls) in association with selected components of the intervention but set in the context of the whole programme, are not considered in this review.

\section{Risk of bias}

\begin{tabular}{|c|c|c|}
\hline Item & Authors' judgement & Description \\
\hline Adequate sequence generation? & Yes & $\begin{array}{l}\text { Mention of 'lots' in the envelopes; stratif- } \\
\text { cation by methods of surgery. }\end{array}$ \\
\hline
\end{tabular}




\section{Stenvall 2007a (Continued)}

\begin{tabular}{|c|c|c|}
\hline Allocation concealment? & Yes & $\begin{array}{l}\text { Randomised "using opaque sealed en- } \\
\text { velopes". "The lots in the envelopes were } \\
\text { numbered sequentially." "The selection } \\
\text { procedures were carried out by people not } \\
\text { involved in the study." }\end{array}$ \\
\hline $\begin{array}{l}\text { Blinding? } \\
\text { Death, residence, readmission }\end{array}$ & Yes & $\begin{array}{l}\text { Systematic data collection. "A geriatrician, } \\
\text { who was unaware of the study-group allo- } \\
\text { cation, analysed all assessments and docu- } \\
\text { mentations after the study was finished." }\end{array}$ \\
\hline $\begin{array}{l}\text { Blinding? } \\
\text { Function, QOL }\end{array}$ & Unclear & Not blinded but independent assessors. \\
\hline $\begin{array}{l}\text { Incomplete outcome data addressed? } \\
\text { Death, residence, readmission }\end{array}$ & Yes & Participant flow diagram provided. \\
\hline $\begin{array}{l}\text { Incomplete outcome data addressed? } \\
\text { Function, QOL }\end{array}$ & Yes & Data provided. \\
\hline Free of selective reporting? & Unclear & $\begin{array}{l}\text { The main report of the trial that covers } \\
\text { the whole intervention is probably protocol } \\
\text { driven. This doesn't apply to the subsidiary } \\
\text { publications, see Notes. }\end{array}$ \\
\hline
\end{tabular}

Free of selection bias (from imbalances at No baseline)?

Significant differences between the two groups in the numbers of patients with diagnosed depression (33 versus 45) and on antidepressants (29 versus 45).

Free of performance bias (from non-trial Unclear

Outpatient rehabilitation was not standifferences in care provision)? dardised.

Free of detection bias (from e.g. differences Yes in follow-up procedures)?

\section{Swanson 1998}

Methods

Randomised trial: use of a computer-generated randomisation list Assessor blinding: no

Length of follow-up: 12 months post hospital discharge.

Participants
Teaching hospital in Brisbane, Australia.

Conducted: October 1994 to July 1995

71 people with hip fracture. $22 \%$ male. Mean age 78 years. Cognitive status: none had dementia.

Inclusion criteria: Aged 55 years or over, admitted for acute hip fracture surgery, resided at home or in a hostel, independently mobile, accessible for follow-up, public-health 


patient, informed consent.
Exclusion criteria: Dementia, pathological fracture, inadequate English; residing in a
nursing home.
Assigned: $38 / 33$ [Multidisciplinary care / Usual care]
Assessed: $38 / 33$
No loss to follow-up.

'Poor outcome': mortality at discharge + discharge to nursing home or hostel; mortality + functional deterioration at 12 months [or institutional care].

Other outcomes: mortality (discharge, 6 and 12 months post discharge), functional decline (mobility), function (modified Barthel Index), ADL, mobility, complications, dynamic balance, length of stay, place of residence (institutional care at discharge and 12 months), social support (dependency), readmissions (all for "unrelated causes"), analgesia, costs.

Six months post-discharge results were presented in the main trial report (Swanson 1998). A further report (Day 2001) reported phone and postal follow-up at 12 months postdischarge.

Clarification of method of randomisation, mortality and length of data results and data for readmissions, functional decline and institutional care received from Cheryl Swanson on 5 December 2001.

\section{Risk of bias}

\begin{tabular}{l|l|l} 
Item & Authors' judgement & Description \\
\hline Adequate sequence generation? & Yes & "computer-generated randomisation list" \\
\hline Allocation concealment? & Unclear & $\begin{array}{l}\text { ".. trial co-ordinator, who, having sole pos- } \\
\text { session of the treatment codes, obtained } \\
\text { consent then randomised each patient to } \\
\text { one of the treatment arms." However, trial } \\
\text { co-ordinator also co-ordinated care in the } \\
\text { intervention group. }\end{array}$ \\
\hline
\end{tabular}




\begin{tabular}{|c|c|c|}
\hline $\begin{array}{l}\text { Blinding? } \\
\text { Death, residence, readmission }\end{array}$ & Yes & $\begin{array}{l}\text { Specific discharge criteria were established } \\
\text { to eliminate bias. Data obtained from med- } \\
\text { ical records. }\end{array}$ \\
\hline $\begin{array}{l}\text { Blinding? } \\
\text { Function, QOL }\end{array}$ & Unclear & $\begin{array}{l}\text { Intervention group patients followed-up at } \\
\text { six months while attending an outpatient } \\
\text { clinic. Usual care were followed up at out- } \\
\text { patient clinic or phoned up by trial co-or- } \\
\text { dinator. }\end{array}$ \\
\hline $\begin{array}{l}\text { Incomplete outcome data addressed? } \\
\text { Death, residence, readmission }\end{array}$ & Yes & $\begin{array}{l}\text { No loss to follow-up and intention-to-treat } \\
\text { analysis implied. }\end{array}$ \\
\hline $\begin{array}{l}\text { Incomplete outcome data addressed? } \\
\text { Function, QOL }\end{array}$ & Yes & $\begin{array}{l}\text { No loss to follow-up and intention-to-treat } \\
\text { analysis implied. }\end{array}$ \\
\hline Free of selective reporting? & Unclear & $\begin{array}{l}\text { The study protocol is not available but } \\
\text { it is very likely that the published report } \\
\text { includes all expected outcomes, including } \\
\text { those that were pre-specified. }\end{array}$ \\
\hline $\begin{array}{l}\text { Free of selection bias (from imbalances at } \\
\text { baseline)? }\end{array}$ & Unclear & $\begin{array}{l}\text { Slight imbalance in male/female composi- } \\
\text { tion of groups (Males: } 11 / 38 \text { versus } 5 / 33 \text { ). }\end{array}$ \\
\hline $\begin{array}{l}\text { Free of performance bias (from non-trial } \\
\text { differences in care provision)? }\end{array}$ & Unclear & $\begin{array}{l}\text { Given the comprehensive nature of the in- } \\
\text { tervention group hard to tell. No hint of } \\
\text { contamination of the control group. }\end{array}$ \\
\hline $\begin{array}{l}\text { Free of detection bias (from e.g. differences } \\
\text { in follow-up procedures)? }\end{array}$ & Yes & Sufficiently similar follow-up procedures. \\
\hline
\end{tabular}

Vidan 2005

Methods

Randomised trial: closed envelopes in a secure box, administered by one person; stratified by pre-fracture ADL level

Assessor blinding: yes, for patient interviews

Length of follow-up: 12 months

Participants

General hospital in Madrid, Spain.

Conducted: February 1997 to December 1997.

321 people with hip fracture. Of 319: 18.5\% male. Mean age 82 years, (SD 7.7). Cognitive status: $24.5 \%$ had dementia.

Inclusion criteria: Previously ambulant, aged 65 years or over, admitted for acute hip fracture surgery. Informed consent for patient or proxy.

Exclusion criteria: Unable to walk before fracture; dependency in all ADL; pathological hip fracture; known terminal illness; life expectancy < 12 months.

Assigned: 157/196 [Multidisciplinary care / Usual care]

Assessed (mortality): 148/164 
Vidan 2005 (Continued)

Loss to follow-up included 2 in Multidisciplinary care group that did not have surgery.

\begin{tabular}{ll}
\hline Interventions & Randomisation took place after baseline assessment, within 48 hours of admission. All \\
participants had an orthopaedic surgeon and a nurse assigned on hospital admission. \\
All shared same orthopaedic wards and used same hospital support services, including \\
physical therapy and social work. Orthopaedic surgeon determined discharge in both \\
groups. \\
(1) Multidisciplinary care: Geriatric team (geriatrician, rehabilitation specialist, specific \\
social worker); geriatric assessment; daily visits from geriatrician who was responsible \\
for medical care; rehabilitation specialist planned schedule, duration and intensity of \\
physical therapy; social worker assessed social environment and advised where necessary. \\
Within 72 hours of admission, an interdisciplinary meeting, including orthopaedic and \\
geriatric teams, to formulate a comprehensive treatment plan. Meeting repeated weekly \\
to monitor compliance with plan. \\
(2) Usual orthopaedic care: Management by orthopaedic surgeon and nurses. Coun- \\
selling from different specialists as required.
\end{tabular}

Outcomes

'Poor outcome': mortality at 12 months + admission to long-term care institution; mortality in hospital + discharge to rehabilitation facility (incomplete data)

Other outcomes: mortality (in hospital and 1 year), patient function (mobility; recovery in ADL at 3, 6 and 12 months), length of stay, discharge to rehabilitation facility; admission to long-term care institution, readmissions (during 1 year); morbidity, medical and surgical complications; receipt and duration of physical therapy.

Notes

Details of method of randomisation and data received from trial investigator: Maria Vidan.

\section{Risk of bias}

\begin{tabular}{|c|c|c|}
\hline Item & Authors' judgement & Description \\
\hline Adequate sequence generation? & Unclear & $\begin{array}{l}\text { No details: stratified by pre-fracture ADI } \\
\text { level (independent in } 4 \text { or more ADLs or } \\
4 \text { ADLs) }\end{array}$ \\
\hline
\end{tabular}

\begin{tabular}{|l|l|l|l|l}
\hline Allocation concealment? & Yes & $\begin{array}{l}\text { "We used a system of closed envelopes } \\
\text { in a secure place (box), administrated by } \\
\text { only one person." (personal communica- } \\
\text { tion from trialist) }\end{array}$ \\
\hline
\end{tabular}

\begin{tabular}{l|l|l} 
Blinding? & Yes & Data obtained from medical records.
\end{tabular}

Death, residence, readmission

\begin{tabular}{|c|c|c|}
\hline $\begin{array}{l}\text { Blinding? } \\
\text { Function, QOL }\end{array}$ & Yes & $\begin{array}{l}\text { "A research assistant who was not involved } \\
\text { in patient care and was blinded to the allo- } \\
\text { cation group conducted all interviews." }\end{array}$ \\
\hline
\end{tabular}

Incomplete outcome data addressed? Yes Death, residence, readmission
Full data for death, residence at discharge and readmission provided. 
Vidan 2005 (Continued)

\begin{tabular}{|c|c|c|}
\hline $\begin{array}{l}\text { Incomplete outcome data addressed? } \\
\text { Function, QOL }\end{array}$ & Yes & Data on ADL and mobility provided. \\
\hline Free of selective reporting? & Unclear & $\begin{array}{l}\text { The study protocol is not available but } \\
\text { it is very likely that the published report } \\
\text { includes all expected outcomes, including } \\
\text { those that were pre-specified. }\end{array}$ \\
\hline $\begin{array}{l}\text { Free of selection bias (from imbalances at } \\
\text { baseline)? }\end{array}$ & Yes & $\begin{array}{l}\text { No major differences in baseline character- } \\
\text { istics. }\end{array}$ \\
\hline $\begin{array}{l}\text { Free of performance bias (from non-trial } \\
\text { differences in care provision)? }\end{array}$ & Unclear & $\begin{array}{l}\text { Trial authors noted that there was a shorter } \\
\text { length of stay in the control group than in } \\
\text { previous years that they thought may be ex- } \\
\text { plained by the Hawthorne effect (that the } \\
\text { improvement resulted because the physi- } \\
\text { cians were being observed). There were, } \\
\text { however, some delays in the discharge of } \\
\text { patients with dementia and ADL depen- } \\
\text { dency "because home care services or reha- } \\
\text { bilitation centre facilities could not be ar- } \\
\text { ranged in a timely manner." } \\
\text { Potential for contamination bias given both } \\
\text { groups had same location and staff. }\end{array}$ \\
\hline $\begin{array}{l}\text { Free of detection bias (from e.g. differences } \\
\text { in follow-up procedures)? }\end{array}$ & Yes & Identical follow-up procedures. \\
\hline
\end{tabular}

Allocation concealment: $\mathrm{A}=$ yes, $\mathrm{B}=$ unclear, $\mathrm{C}=$ no

ADL: activities of daily living

GP: General Practitioner

PFF: proximal femoral fracture

vs: versus

Characteristics of excluded studies [ordered by study ID]

\begin{tabular}{ll} 
Abe 2001 & $\begin{array}{l}\text { Trial of a four (short) versus eight (long) weeks rehabilitation training programme in surgically treated hip } \\
\text { fracture patients. A translation from Japanese revealed that the two intervention groups were not concurrent } \\
\text { (historical control). }\end{array}$ \\
\hline Allegrante 2001 & Multicomponent as opposed to multidisciplinary rehabilitation. \\
\hline Bai 2003 & Complete care package rather than multidisciplinary care. \\
\hline Choong 2000 & Randomised evaluation of a clinical care pathway. Not in scope of review.
\end{tabular}


(Continued)

\begin{tabular}{|c|c|}
\hline Cuncliffe 2004 & Only $28 \%$ of participants had fractures: additionally, the percentage with hip fracture is not reported. \\
\hline Fordham 1995 & $\begin{array}{l}\text { Not randomised: observational study of a geriatric orthopaedic programme at one hospital and conventional } \\
\text { orthopaedic care at another. Study produced equivalent groups at both hospitals. }\end{array}$ \\
\hline Hempsall 1990 & Not randomised: allocation to GORU by area of residence. \\
\hline Houldin 1995 & Pilot study evaluating a psychological intervention in eight hip fracture patients. Not in scope of review. \\
\hline Huang 2005 & Not multidisciplinary rehabilitation: discharge planning led by nurse only (and then extra care as requested). \\
\hline Jette 1987 & $\begin{array}{l}\text { Quasi-randomised (based on on-call roster) study involving } 75 \text { participants with proximal femoral fracture } \\
\text { patients. Intensive rehabilitation (standard care plus education sessions, a geriatric team evaluation, weekly } \\
\text { team meetings, home visit post discharge, monthly follow-up by phone) compared with standard orthopaedic } \\
\text { care. Main outcome measures: mortality, functional status, length of stay, place of residence. } \\
\text { No comparative data available: requests for information and comparative data sent with no response. }\end{array}$ \\
\hline Krichbaum 2007 & $\begin{array}{l}\text { While nurse co-ordinator, who could not provide direct care, arranged multidisciplinary care, this is not } \\
\text { multidisciplinary rehabilitation. }\end{array}$ \\
\hline Kuisma 1994 & Unidisciplinary intervention (physiotherapy)only. \\
\hline Marcantonio 2001 & $\begin{array}{l}\text { Intervention comprised a geriatric consultation aimed at reducing delirium. Excluded as not multidisciplinary } \\
\text { rehabilitation and thus not in scope of review. }\end{array}$ \\
\hline Pearson 1988 & $\begin{array}{l}\text { Specialised nursing unit rather than GORU. Mixed population of CVA, amputation and hip fracture patients } \\
(40 \%) \text {. Only limited outcome data for hip fracture patients. }\end{array}$ \\
\hline Richards 1998 & $\begin{array}{l}\text { Location (evaluating early supported discharge and hospital at home) rather than multidisciplinary care. } \\
\text { Mixed population: } 31 \% \text { hip fracture. }\end{array}$ \\
\hline Roder 2003 & Not a randomised trial, although treatment was left to chance. \\
\hline Rubenstein 1984 & No extractable data for fracture patients ( $23 \%$ of trial population): unclear how many had hip fracture. \\
\hline Sanchez Ferrin 1999 & $\begin{array}{l}\text { Functional geriatric unit staff involved in initial geriatric assessment and monitoring of uptake of recommen- } \\
\text { dations versus usual orthopaedic care. Assessment not multidisciplinary rehabilitation. }\end{array}$ \\
\hline Siu 1996 & Mixed population: $<5 \%$ (17) had hip fracture. \\
\hline
\end{tabular}

GORU: geriatric-orthopaedic rehabilitation unit CVA : cerebral vascular accident (stroke) 


\section{Characteristics of studies awaiting assessment [ordered by study ID]}

\section{Jalovaara 2009}

\begin{tabular}{ll}
\hline Methods & Randomised trial \\
\hline Participants & $\begin{array}{l}\text { Included: both males and females, aged } 50 \text { years or over. Patients who were living in their own home or in sheltered } \\
\text { housing (comparable to a home of their own but controlled by a warden and with some assistance available)at the } \\
\text { time of sustaining the fracture. } \\
\text { Excluded: patients who were institutionalised; or who had a pathological fracture. }\end{array}$ \\
\hline Interventions & $\begin{array}{l}\text { 1. Physiatric-oriented rehabilitation } \\
\text { 2. Geriatric-oriented rehabilitation } \\
\text { 3. Control group: Routine rehabilitation in health centre hospitals }\end{array}$ \\
\hline Outcomes & $\begin{array}{l}\text { The following were assessed at } 4 \text { and } 12 \text { months: } \\
\text { 1. Residential status } \\
\text { 2. Walking ability } \\
\text { 3. Use of walking aids } \\
\text { 4. Activities of daily living (ADL) functions } \\
\text { 5. Mortality }\end{array}$ \\
\hline Notes & \begin{tabular}{l} 
Trial is completed (2000); retrospective application for trial registration (March 2009) \\
\hline
\end{tabular}
\end{tabular}

Uy 2008

Methods Randomised trial: use of "numbered opaque envelopes, with the randomised sequence generated from a random number table". Blind assessment of outcomes at 4 months.

\begin{tabular}{ll} 
Participants & $\begin{array}{l}11 \text { participants (10 followed up). } \\
\text { Included: Female, living in a nursing home in the hospital catchment area, ambulant prior to hip fracture, able to } \\
\text { follow commands at time of seeking informed consent. } \\
\text { Excluded: Non consent or not fulfilling the inclusion criteria. }\end{array}$ \\
\hline Interventions & $\begin{array}{l}\text { 1. Inpatient multidisciplinary rehabilitation programme involving accelerated rehabilitation (as in Cameron 1993). } \\
\text { 2. Usual care: discharge back to the nursing home soon after hip fracture surgery. }\end{array}$ \\
\hline Outcomes & $\begin{array}{l}\text { The following were assessed at } 1 \text { and } 4 \text { months: } \\
\text { 1. Barthel index } \\
\text { 2. Gait velocity } \\
\text { 3. Mortality }\end{array}$ \\
\hline Notes & $\begin{array}{l}\text { The trial, a full report for which is available, was ended prematurely after recruiting only } 11 \text { participants because of } \\
\text { a change in Australian Government regulations. Of the } 10 \text { participants followed up, only } 3 \text { were in the intervention } \\
\text { group. A consensus for inclusion of this trial was not achieved due to questions over applicability and its small sample } \\
\text { size. Its inclusion will be considered for the next update. Its inclusion will be more likely should another trial on this } \\
\text { previously overlooked patient group appear. }\end{array}$ \\
\hline
\end{tabular}


Ziden 2008

\begin{tabular}{ll} 
Methods & Randomised trial (see Notes) \\
\hline Participants & 212 community-dwelling patients, aged 65 years or more, with surgery for hip fracture. \\
\hline Interventions & $\begin{array}{l}\text { 1. A geriatric, multiprofessional home rehabilitation programme focused on supported discharge, independence in } \\
\text { daily activities, and enhancing physical activity and confidence in performing daily activities. } \\
\text { 2. Conventional care in which no structured rehabilitation after discharge was included. }\end{array}$ \\
\hline Outcomes & $\begin{array}{l}\text { The following were assessed at } 1 \text { month: } \\
\text { 1. Falls } \\
\text { 2. Degree of dependency and frequency in daily activities } \\
\text { 3. Habitual physical activity } \\
\text { 4. Basic functional performance }\end{array}$ \\
\hline Notes & $\begin{array}{l}\text { Randomisation and allocation occurred at emergency unit without patient consent. Subsequent exclusion of } 99 \\
\text { patients, before patients invited to participate. Eleven declined consent, resulting in } 102 \text { study participants. }\end{array}$ \\
\hline
\end{tabular}


Characteristics of ongoing studies [ordered by study ID]

\section{Gustafson 2009}

\begin{tabular}{|c|c|}
\hline Trial name or title & Home rehabilitation for older people with hip fracture - a randomised controlled trial \\
\hline Methods & Randomised controlled trial \\
\hline Participants & $\begin{array}{l}200 \text { patients aged } 70 \text { years and above who have had hip fracture surgery. Live in the municipality of Umeå } \\
\text { (both independent living and from institutions). }\end{array}$ \\
\hline Interventions & $\begin{array}{l}\text { 1. Multidisciplinary home rehabilitation; these patients will have home rehabilitation as long as necessary but } \\
\text { not longer than } 10 \text { weeks. } \\
\text { 2. Conventional multidisciplinary rehabilitation at hospital; these patients will be at hospital as long as } \\
\text { necessary. } \\
\text { Both groups will have comprehensive geriatric assessments, management and rehabilitation with active pre- } \\
\text { vention, detection and treatment of postoperative complications such as falls, delirium, pain and infections, } \\
\text { for example. Those randomised to home rehabilitation will receive some of these assessments and rehabilita- } \\
\text { tion at home. }\end{array}$ \\
\hline Outcomes & $\begin{array}{l}\text { Follow-up at } 12 \text { weeks after randomisation and } 12 \text { months after surgery. } \\
\text { Primary outcomes: } \\
\text { 1. In-patient days and re-admissions } \\
\text { 2. Complications, for example falls and injuries } \\
\text { 3. Depression, assessed by the Geriatric Depression Scale (GDS) } \\
\text { 4. Delirium, assessed by the Organic Brain Syndrome Scale } \\
\text { 5. Functional performance regarding activities of daily living (ADL), assessed by the Katz ADL index and } \\
\text { Barthel ADL index } \\
\text { 6. Walking ability and use of walking aids, assessed by the Swedish version of the Clinical Outcome Variable } \\
\text { Scale (S-COVS). } \\
\text { Secondary outcomes } \\
\text { 1. Balance, assessed by the Bergs Balance Scale and Fear of Falling } \\
\text { 2. Quality of life, assessed by EQ-5D } \\
\text { 3. Nutritional status, assessed by the mini nutritional assessment (MNA) } \\
\text { 4. Costs } \\
\text { 5. Self-perceived health, assessed by the 36-item Short Form (SF-36) health survey } \\
\text { 6. Pain, assessed by a visual analogue scale (VAS) } \\
\text { 7. Subjective well-being, assessed by the Philadelphia Geriatric Morale Scale (PGCM) }\end{array}$ \\
\hline Starting date & $01 / 08 / 2008$ to $01 / 08 / 2010$ \\
\hline Contact information & $\begin{array}{l}\text { Professor Yngve Gustafson } \\
\text { Umeå University } \\
\text { Geriatric Medicine } \\
\text { Umeå } \\
\text { SE-901 } 87 \\
\text { Sweden }\end{array}$ \\
\hline Notes & \\
\hline
\end{tabular}


Sletvold 2009

Trial name or title A new clinical pathway for patients with fractured neck of femur - the Orthopaedics operate, the Geriatricians manage the medical work-up

\begin{tabular}{ll}
\hline Methods & Randomised, single-blind (outcomes assessor) controlled trial \\
\hline Participants & $\begin{array}{l}400 \text { patients, aged } 70 \text { years or above, with hip fracture. Live in nearby municipalities, able to walk } 10 \mathrm{~m} \\
\text { before fracture. } \\
\text { Excluded: nursing home residents, expected to die within 3 months, pathological fractures. }\end{array}$ \\
\hline Interventions & $\begin{array}{l}\text { 1. Pre- and postoperative treatment in an orthogeriatric unit (geriatric evaluation and management) } \\
\text { 2. Treatment on ordinary orthopaedic unit } \\
\text { No specific follow-up after discharge from hospital }\end{array}$ \\
\hline Outcomes & $\begin{array}{l}\text { Follow-up: } 1,4 \text { and } 12 \text { months post-surgery } \\
\text { 1. Primary outcome: mobility }\end{array}$ \\
2. Secondary outcome: site of residence \\
\hline Starting date & April 2008 to April 2013 \\
\hline Contact information & $\begin{array}{l}\text { Olav Sletvold or Pernille Thingstad } \\
\text { St Olav University Hospital } \\
\text { Trondheim } \\
\text { Norway, } 7040\end{array}$ \\
\hline Notes & \\
\hline
\end{tabular}


DATA AND ANALYSES

Comparison 1. Multidisciplinary inpatient rehabilitation versus usual care

\begin{tabular}{|c|c|c|c|c|}
\hline Outcome or subgroup title & $\begin{array}{l}\text { No. of } \\
\text { studies }\end{array}$ & $\begin{array}{c}\text { No. of } \\
\text { participants }\end{array}$ & Statistical method & Effect size \\
\hline $\begin{array}{l}1 \text { 'Poor outcome' (long-term } \\
\text { follow-up) }\end{array}$ & 8 & 1633 & Risk Ratio (M-H, Fixed, 95\% CI) & $0.89[0.78,1.01]$ \\
\hline $\begin{array}{l}2 \text { 'Poor outcome' (long-term } \\
\text { follow-up) - Kennie } 1988\end{array}$ & 7 & 1525 & Risk Ratio (M-H, Fixed, 95\% CI) & $0.93[0.82,1.07]$ \\
\hline $\begin{array}{l}3 \text { 'Poor outcome' (long-term } \\
\text { follow-up) by intervention type }\end{array}$ & 8 & 1633 & Risk Ratio (M-H, Fixed, 95\% CI) & $0.89[0.78,1.01]$ \\
\hline 3.1 Specialist unit & 3 & 586 & Risk Ratio (M-H, Fixed, 95\% CI) & $0.75[0.60,0.94]$ \\
\hline $\begin{array}{l}3.2 \text { Intensive inpatient } \\
\text { rehabilitation programme }\end{array}$ & 5 & 1047 & Risk Ratio (M-H, Fixed, 95\% CI) & $0.97[0.83,1.13]$ \\
\hline $\begin{array}{l}4 \text { 'Poor outcome' (long-term } \\
\text { follow-up) by selection bias }\end{array}$ & 8 & 1633 & Risk Ratio (M-H, Fixed, 95\% CI) & $0.89[0.78,1.01]$ \\
\hline 4.1 No selection bias & 3 & 760 & Risk Ratio (M-H, Fixed, 95\% CI) & $0.97[0.78,1.21]$ \\
\hline $\begin{array}{l}4.2 \text { Unclear or high risk of } \\
\text { selection bias }\end{array}$ & 5 & 873 & Risk Ratio (M-H, Fixed, 95\% CI) & $0.84[0.71,0.98]$ \\
\hline 5 'Poor outcome' (at discharge) & 7 & 1331 & Risk Ratio (M-H, Fixed, 95\% CI) & $0.87[0.75,1.00]$ \\
\hline $\begin{array}{l}6 \text { Mortality (end of scheduled } \\
\text { follow-up) }\end{array}$ & 11 & 2334 & Risk Ratio (M-H, Fixed, 95\% CI) & $0.90[0.76,1.07]$ \\
\hline $\begin{array}{l}7 \text { Mortality (end of scheduled } \\
\text { follow-up) - with } 12 \text { month } \\
\text { data for Cameron } 1993\end{array}$ & 11 & 2334 & Risk Ratio (M-H, Fixed, 95\% CI) & $0.88[0.74,1.04]$ \\
\hline 8 Mortality (at discharge) & 9 & 1920 & Risk Ratio (M-H, Fixed, 95\% CI) & $0.77[0.56,1.06]$ \\
\hline 9 Functional outcomes & 5 & & Risk Ratio (M-H, Fixed, 95\% CI) & Totals not selected \\
\hline $\begin{array}{l}\text { 9.1 More dependent (based } \\
\text { on Katz index) at } 1 \text { year }\end{array}$ & 2 & & Risk Ratio (M-H, Fixed, 95\% CI) & Not estimable \\
\hline $\begin{array}{l}9.2 \text { More dependent or dead } \\
\text { at } 1 \text { year }\end{array}$ & 2 & & Risk Ratio (M-H, Fixed, 95\% CI) & Not estimable \\
\hline $\begin{array}{l}9.3 \text { Non-recovery/decline in } \\
\text { walking at long-term follow-up }\end{array}$ & 2 & & Risk Ratio (M-H, Fixed, 95\% CI) & Not estimable \\
\hline $\begin{array}{l}\text { 9.4 Non-recovery in walking } \\
\text { or dead at long-term follow-up }\end{array}$ & 2 & & Risk Ratio (M-H, Fixed, 95\% CI) & Not estimable \\
\hline $\begin{array}{l}9.5 \text { Decline in transfers (bed } \\
\text { to chair etc) at long-term } \\
\text { follow-up }\end{array}$ & 1 & & Risk Ratio (M-H, Fixed, 95\% CI) & Not estimable \\
\hline $\begin{array}{l}\text { 9.6 Decline in transfers or } \\
\text { dead at long-term follow-up }\end{array}$ & 1 & & Risk Ratio (M-H, Fixed, 95\% CI) & Not estimable \\
\hline $\begin{array}{l}9.7 \text { Non-recovery in activities } \\
\text { of daily living (ADL) at } 1 \text { year }\end{array}$ & 1 & & Risk Ratio (M-H, Fixed, 95\% CI) & Not estimable \\
\hline $\begin{array}{l}\text { 9.8 Non-recovery in ADL or } \\
\text { dead at } 1 \text { year }\end{array}$ & 1 & & Risk Ratio (M-H, Fixed, 95\% CI) & Not estimable \\
\hline $\begin{array}{l}9.9 \text { Incomplete recovery of } \\
\text { ADL and mobility at } 1 \text { year }\end{array}$ & 1 & & Risk Ratio (M-H, Fixed, 95\% CI) & Not estimable \\
\hline
\end{tabular}

Multidisciplinary rehabilitation for older people with hip fractures (Review)

Copyright $(2009$ The Cochrane Collaboration. Published by John Wiley \& Sons, Ltd. 
9.10 Incomplete recovery of

ADL and mobility, or dead at 1

year

10 Functional outcomes: Barthel scores at long-term follow-up

10.1 Chinese Barthel Index at 6 months

10.2 Modified Barthel Index at 6 months

11 Complications

11.1 pressure sores

11.2 heart failure

11.3 pneumonia

11.4 confusion

11.5 chest infection, cardiac problem, bedsore

11.6 stroke, emboli

11.7 any complication

12 Length of hospital stay

13 Readmitted to hospital during follow-up

14 Dead or readmitted to hospital during follow-up
Risk Ratio (M-H, Fixed, 95\% CI)

Not estimable

Mean Difference (IV, Fixed, 95\% CI)

Totals not selected

Mean Difference (IV, Fixed, 95\% CI)

Not estimable

Mean Difference (IV, Fixed, 95\% CI)

Not estimable

Risk Ratio (M-H, Fixed, 95\% CI)

Risk Ratio (M-H, Fixed, 95\% CI)

Risk Ratio (M-H, Fixed, 95\% CI)

Risk Ratio (M-H, Fixed, 95\% CI)

Risk Ratio (M-H, Fixed, 95\% CI)

Risk Ratio (M-H, Fixed, 95\% CI)

Risk Ratio (M-H, Fixed, 95\% CI)

Risk Ratio (M-H, Fixed, 95\% CI)

Mean Difference (IV, Random, 95\% CI)

1269

Risk Ratio (M-H, Fixed, 95\% CI)

1221

Risk Ratio (M-H, Fixed, 95\% CI)
Totals not selected

Not estimable

Not estimable

Not estimable

Not estimable

Not estimable

Not estimable

Not estimable

Totals not selected

0.99 [0.82, 1.19]

$0.93[0.79,1.09]$

Comparison 2. Accelerated discharge and multidisciplinary home-based rehabilitation versus usual inpatient rehabilitation

$\begin{array}{llcll}\text { Outcome or subgroup title } & \begin{array}{c}\text { No. of } \\ \text { studies }\end{array} & \begin{array}{c}\text { No. of } \\ \text { participants }\end{array} & \text { Statistical method } & \text { Effect size }\end{array}$

\begin{tabular}{|c|c|c|c|}
\hline $\begin{array}{l}1 \text { 'Poor outcome', mortality, } \\
\text { institutional care and unable to } \\
\text { walk (12 months) }\end{array}$ & 1 & Risk Ratio (M-H, Fixed, 95\% CI) & Totals not selected \\
\hline $\begin{array}{l}\text { 1.1 Poor outcome (dead or } \\
\text { moved to higher level of care) }\end{array}$ & 1 & Risk Ratio (M-H, Fixed, 95\% CI) & Not estimable \\
\hline 1.2 Mortality & 1 & Risk Ratio (M-H, Fixed, 95\% CI) & Not estimable \\
\hline $\begin{array}{l}1.3 \text { Moved to higher level of } \\
\text { care }\end{array}$ & 1 & Risk Ratio (M-H, Fixed, 95\% CI) & Not estimable \\
\hline 1.4 Unable to walk & 1 & Risk Ratio (M-H, Fixed, 95\% CI) & Not estimable \\
\hline $\begin{array}{l}2 \text { SF-36 scores at } 12 \text { months ( } 0 \text { : } \\
\text { worst to } 100 \text { : best) }\end{array}$ & 1 & Mean Difference (IV, Fixed, 95\% CI) & Totals not selected \\
\hline $\begin{array}{l}2.1 \text { Physical component } \\
\text { summary scores }\end{array}$ & 1 & Mean Difference (IV, Fixed, 95\% CI) & Not estimable \\
\hline $\begin{array}{l}2.2 \text { Mental component } \\
\text { summary scores }\end{array}$ & 1 & Mean Difference (IV, Fixed, 95\% CI) & Not estimable \\
\hline $\begin{array}{l}3 \text { Lengths of hospital or } \\
\text { rehabilitation stays (days) }\end{array}$ & 1 & Mean Difference (IV, Fixed, 95\% CI) & Totals not selected \\
\hline 3.1 Length of hospital stay & 1 & Mean Difference (IV, Fixed, 95\% CI) & Not estimable \\
\hline
\end{tabular}

Copyright (๑ 2009 The Cochrane Collaboration. Published by John Wiley \& Sons, Ltd. 


\begin{tabular}{llll}
$\begin{array}{l}\text { 3.2 Length of rehabilitation } \\
\text { (hospital + home) }\end{array}$ & 1 & Mean Difference (IV, Fixed, 95\% CI) & Not estimable \\
$\begin{array}{l}\text { Readmission to hospital during } \\
\text { 4 months follow-up }\end{array}$ & 1 & Risk Ratio (M-H, Fixed, 95\% CI) & Totals not selected \\
\hline
\end{tabular}

Comparison 3. Intensive versus less intensive community rehabilitation

\begin{tabular}{|c|c|c|c|c|}
\hline Outcome or subgroup title & $\begin{array}{l}\text { No. of } \\
\text { studies }\end{array}$ & $\begin{array}{c}\text { No. of } \\
\text { participants }\end{array}$ & Statistical method & Effect size \\
\hline $\begin{array}{l}1 \text { 'Poor outcome', mortality and } \\
\text { institutional care (12 months) }\end{array}$ & 1 & & Risk Ratio (M-H, Fixed, 95\% CI) & Totals not selected \\
\hline $\begin{array}{l}\text { 1.1 Poor outcome (dead or in } \\
\text { institutional care) }\end{array}$ & 1 & & Risk Ratio (M-H, Fixed, 95\% CI) & Not estimable \\
\hline 1.2 Mortality & 1 & & Risk Ratio (M-H, Fixed, 95\% CI) & Not estimable \\
\hline 1.3 Institutional care & 1 & & Risk Ratio (M-H, Fixed, 95\% CI) & Not estimable \\
\hline $\begin{array}{l}2 \text { Number of contacts over } 12 \\
\text { weeks (for participants with hip } \\
\text { fracture or stroke) }\end{array}$ & 1 & & Mean Difference (IV, Fixed, 95\% CI) & Totals not selected \\
\hline
\end{tabular}

Comparison 4. Exploratory analysis: all settings

\begin{tabular}{lcccc} 
Outcome or subgroup title & $\begin{array}{c}\text { No. of } \\
\text { studies }\end{array}$ & $\begin{array}{c}\text { No. of } \\
\text { participants }\end{array}$ & Statistical method & Effect size \\
\hline $\begin{array}{l}\text { 1 'Poor outcome' (long-term } \\
\text { follow-up) by intervention type }\end{array}$ & 9 & 1699 & Risk Ratio (M-H, Fixed, 95\% CI) & $0.88[0.78,1.00]$ \\
$\quad+$ Crotty 2003 & 3 & 586 & Risk Ratio (M-H, Fixed, 95\% CI) & $0.75[0.60,0.94]$ \\
$\quad \begin{array}{l}1.1 \text { Specialist unit } \\
\text { 1.2 Intensive rehabilitation }\end{array}$ & 6 & 1113 & Risk Ratio (M-H, Fixed, 95\% CI) & $0.96[0.82,1.12]$ \\
$\quad$\begin{tabular}{l} 
programme \\
\hline
\end{tabular} & & & & \\
\hline
\end{tabular}


Analysis I.I. Comparison I Multidisciplinary inpatient rehabilitation versus usual care, Outcome I 'Poor outcome' (long-term follow-up).

Review: Multidisciplinary rehabilitation for older people with hip fractures

Comparison: I Multidisciplinary inpatient rehabilitation versus usual care

Outcome: I 'Poor outcome' (long-term follow-up)

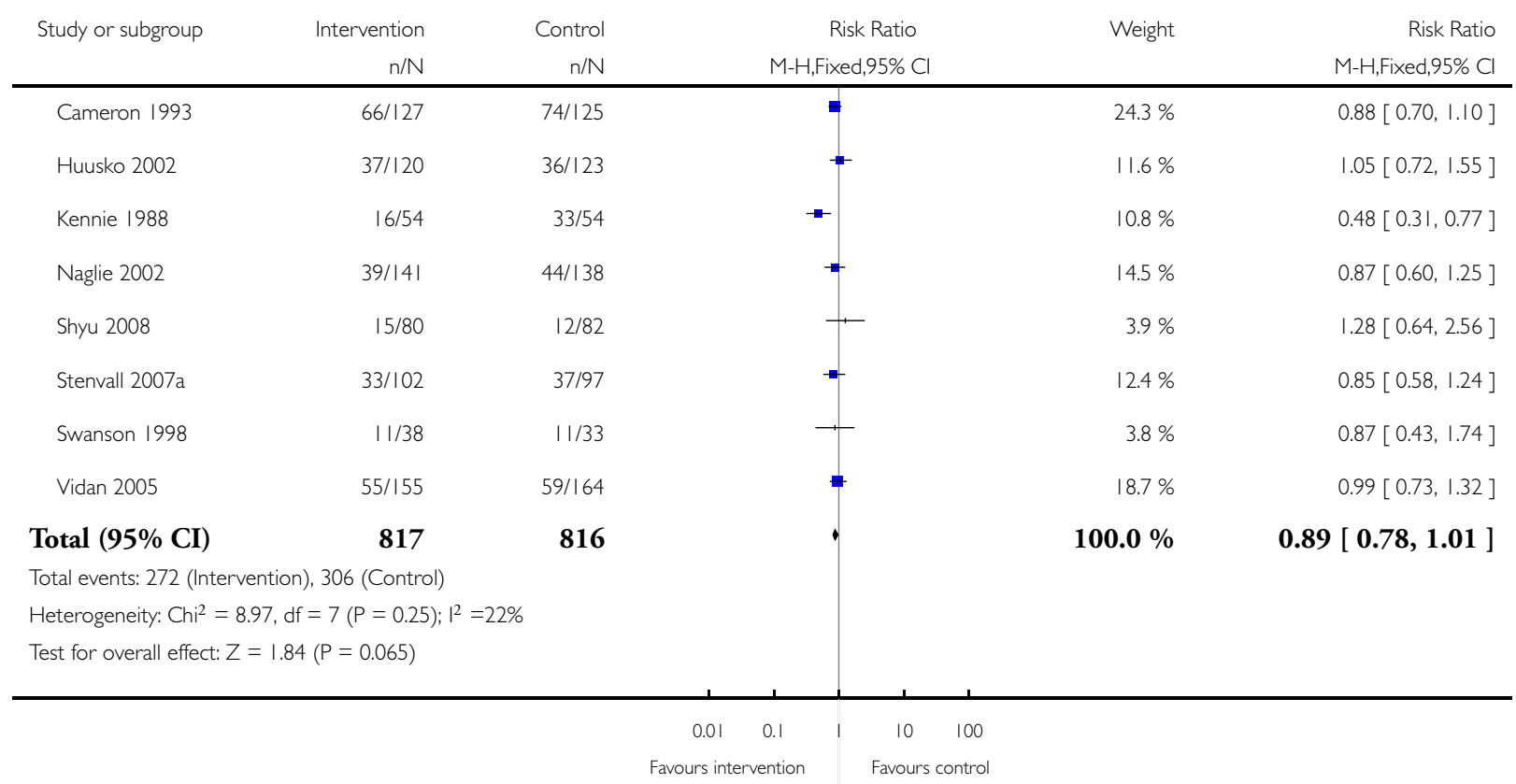


Analysis I.2. Comparison I Multidisciplinary inpatient rehabilitation versus usual care, Outcome 2 'Poor outcome' (long-term follow-up) - Kennie 1988.

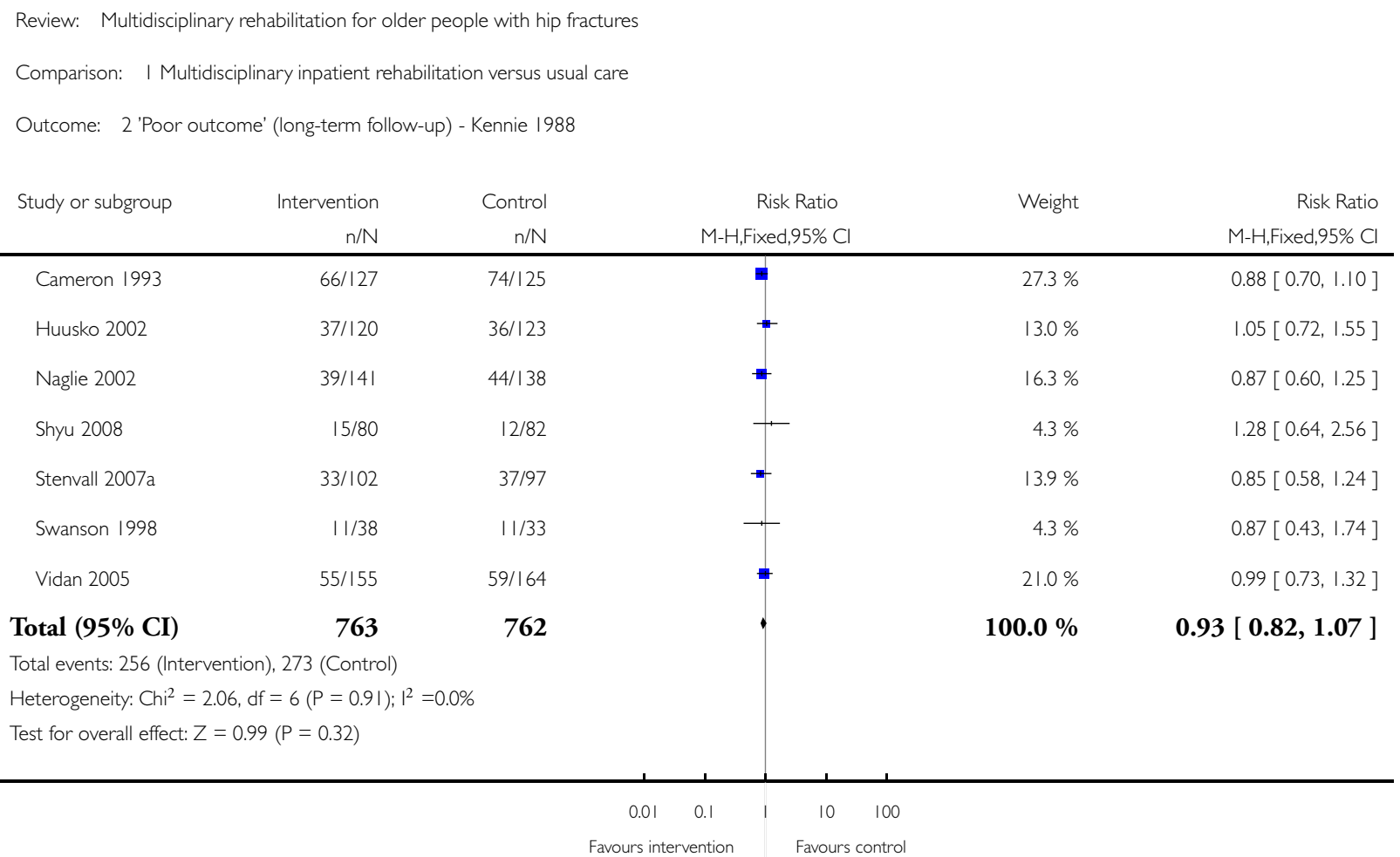


Analysis I.3. Comparison I Multidisciplinary inpatient rehabilitation versus usual care, Outcome 3 'Poor outcome' (long-term follow-up) by intervention type.

Review: Multidisciplinary rehabilitation for older people with hip fractures
Comparison: I Multidisciplinary inpatient rehabilitation versus usual care
Outcome: 3 'Poor outcome' (long-term follow-up) by intervention type

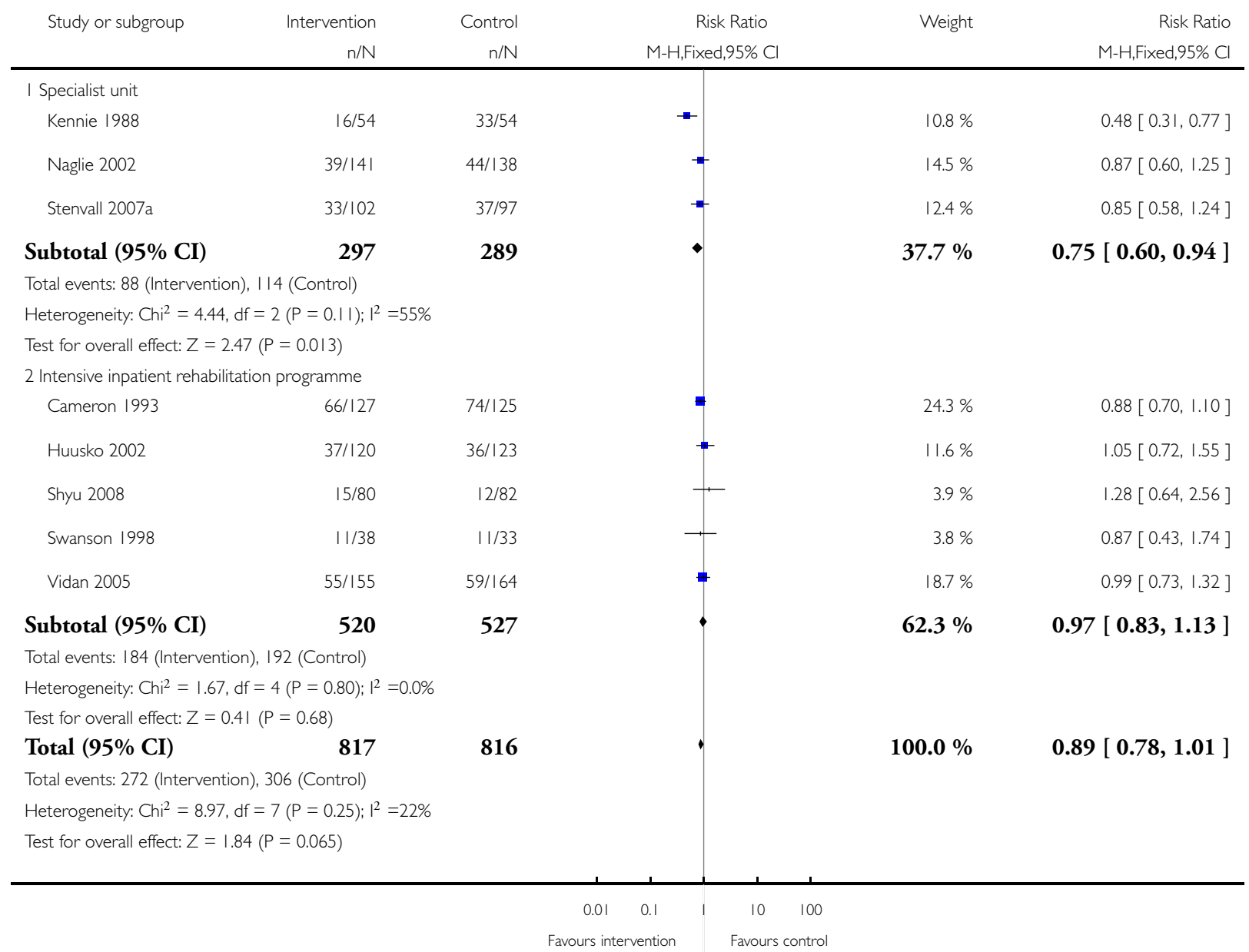


Analysis I.4. Comparison I Multidisciplinary inpatient rehabilitation versus usual care, Outcome 4 'Poor outcome' (long-term follow-up) by selection bias.

Review: Multidisciplinary rehabilitation for older people with hip fractures
Comparison: I Multidisciplinary inpatient rehabilitation versus usual care
Outcome: 4 'Poor outcome' (long-term follow-up) by selection bias

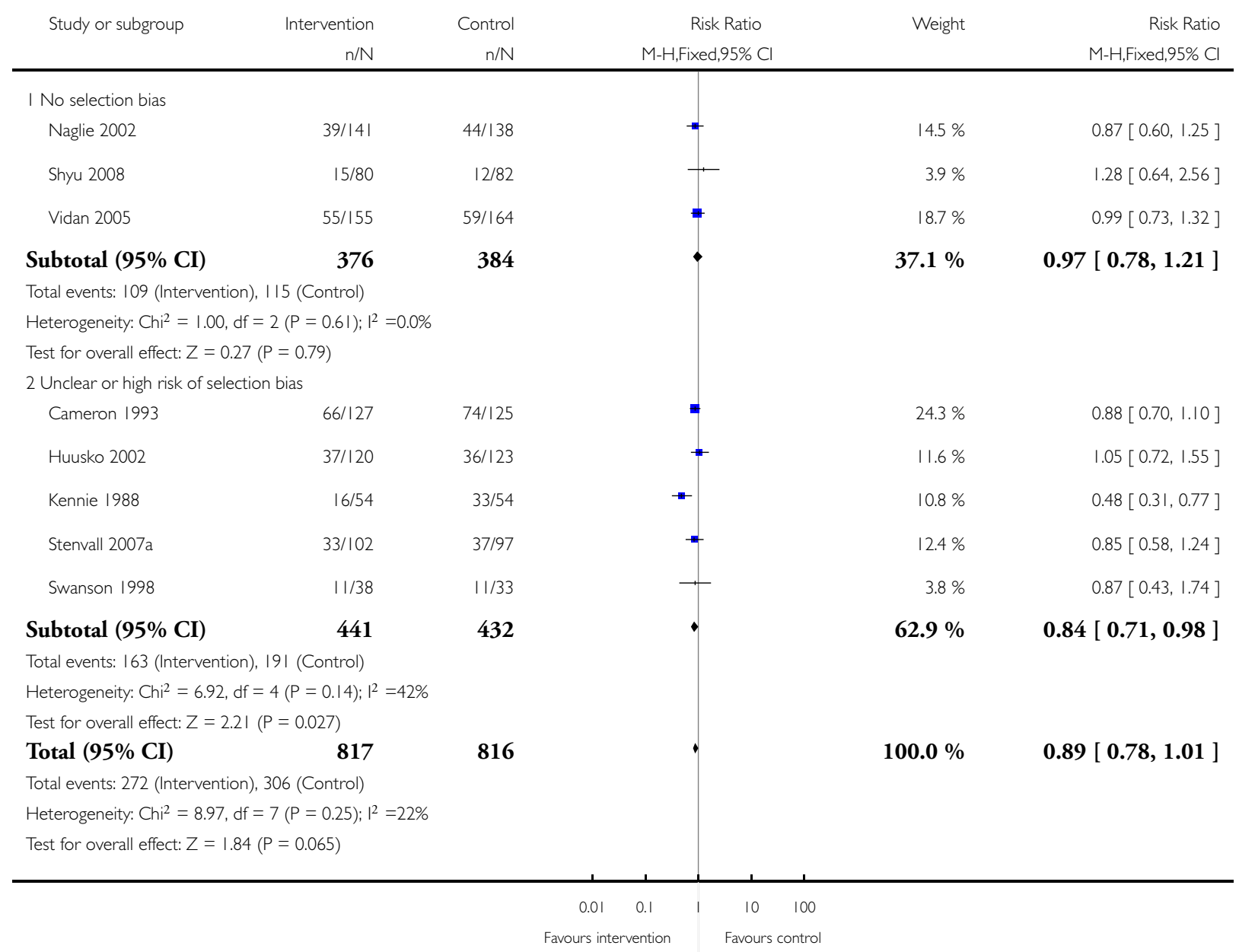


Analysis I.5. Comparison I Multidisciplinary inpatient rehabilitation versus usual care, Outcome 5 'Poor outcome' (at discharge).

Review: Multidisciplinary rehabilitation for older people with hip fractures

Comparison: I Multidisciplinary inpatient rehabilitation versus usual care

Outcome: 5 'Poor outcome' (at discharge)

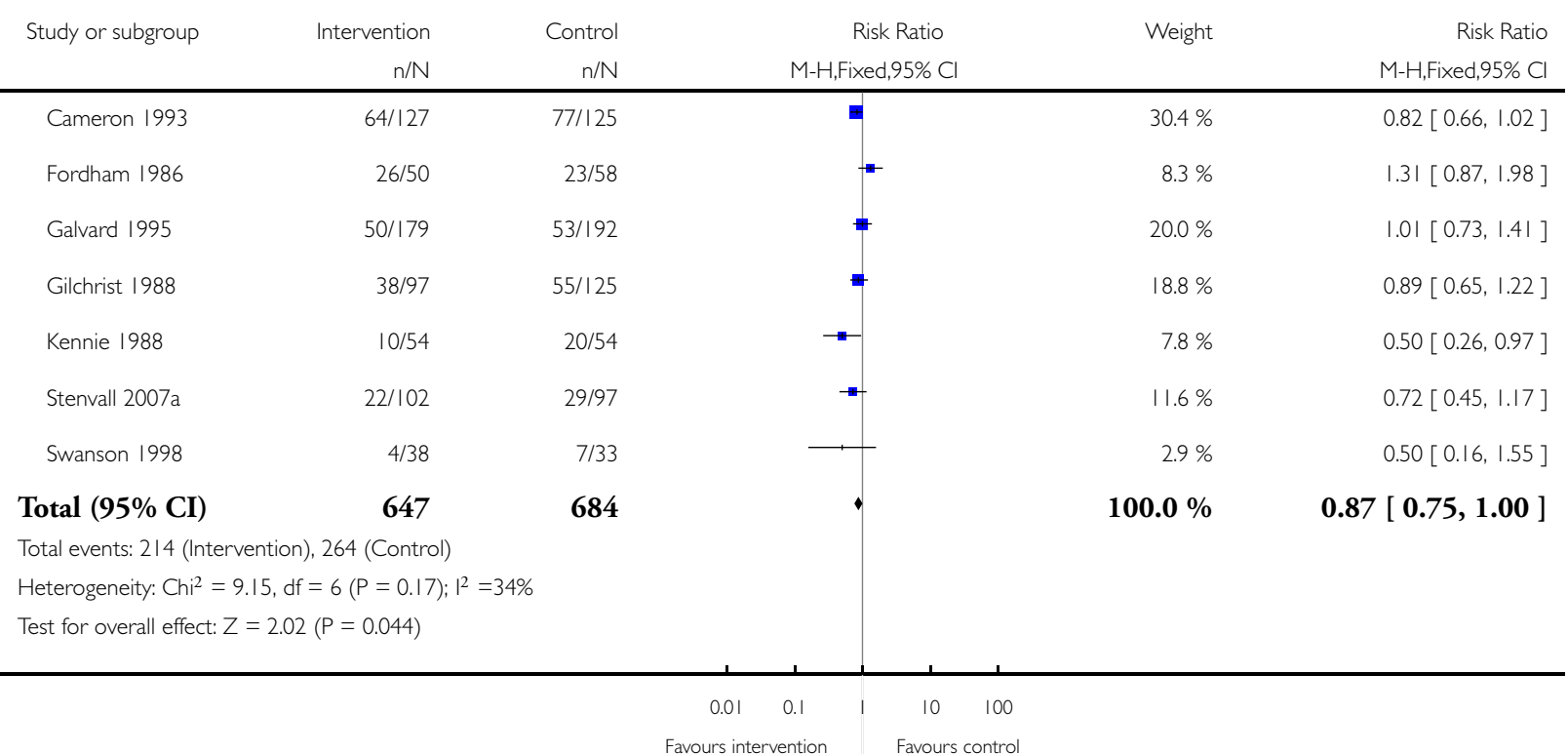


Analysis I.6. Comparison I Multidisciplinary inpatient rehabilitation versus usual care, Outcome 6 Mortality (end of scheduled follow-up).

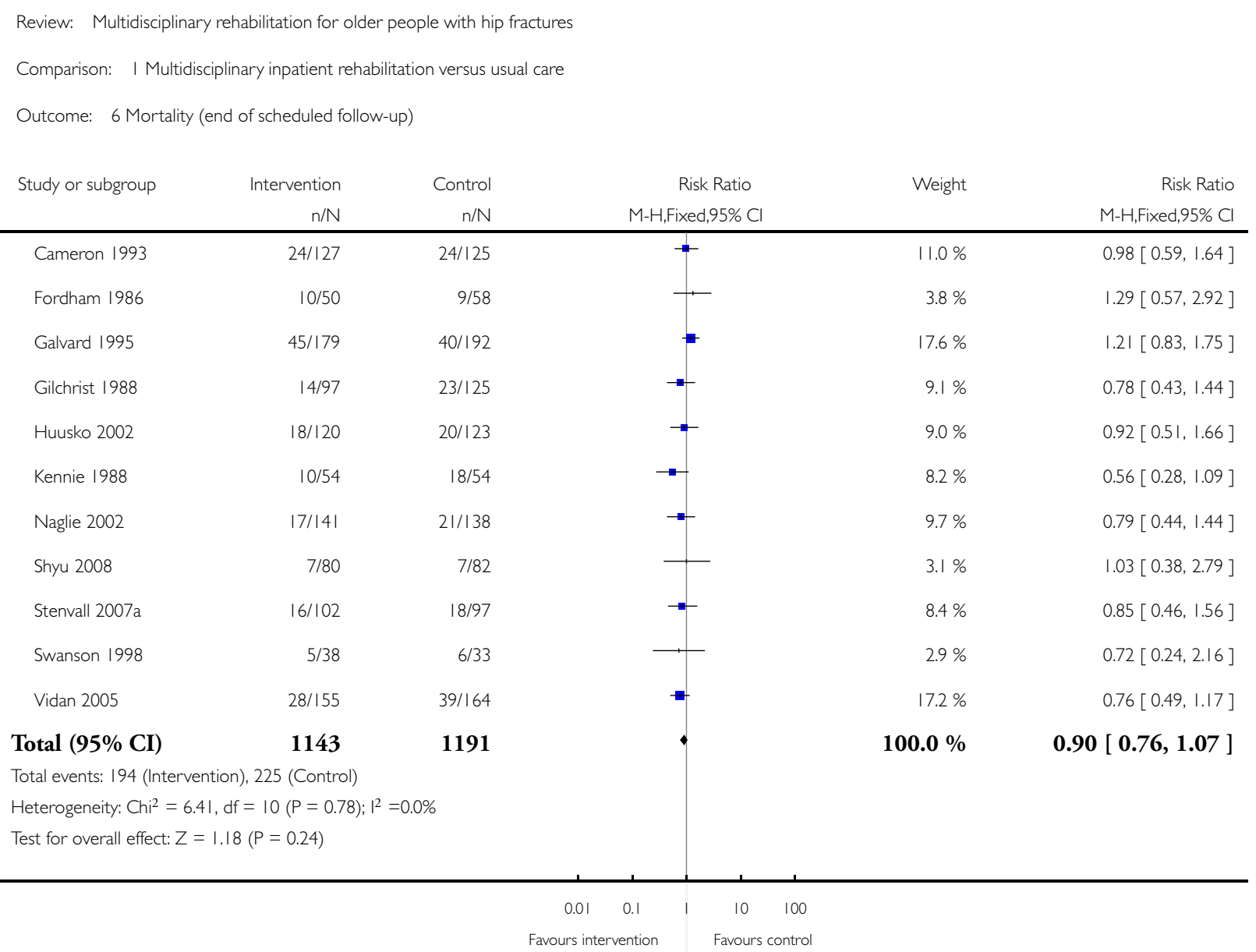


Analysis I.7. Comparison I Multidisciplinary inpatient rehabilitation versus usual care, Outcome 7 Mortality (end of scheduled follow-up) - with 12 month data for Cameron 1993.

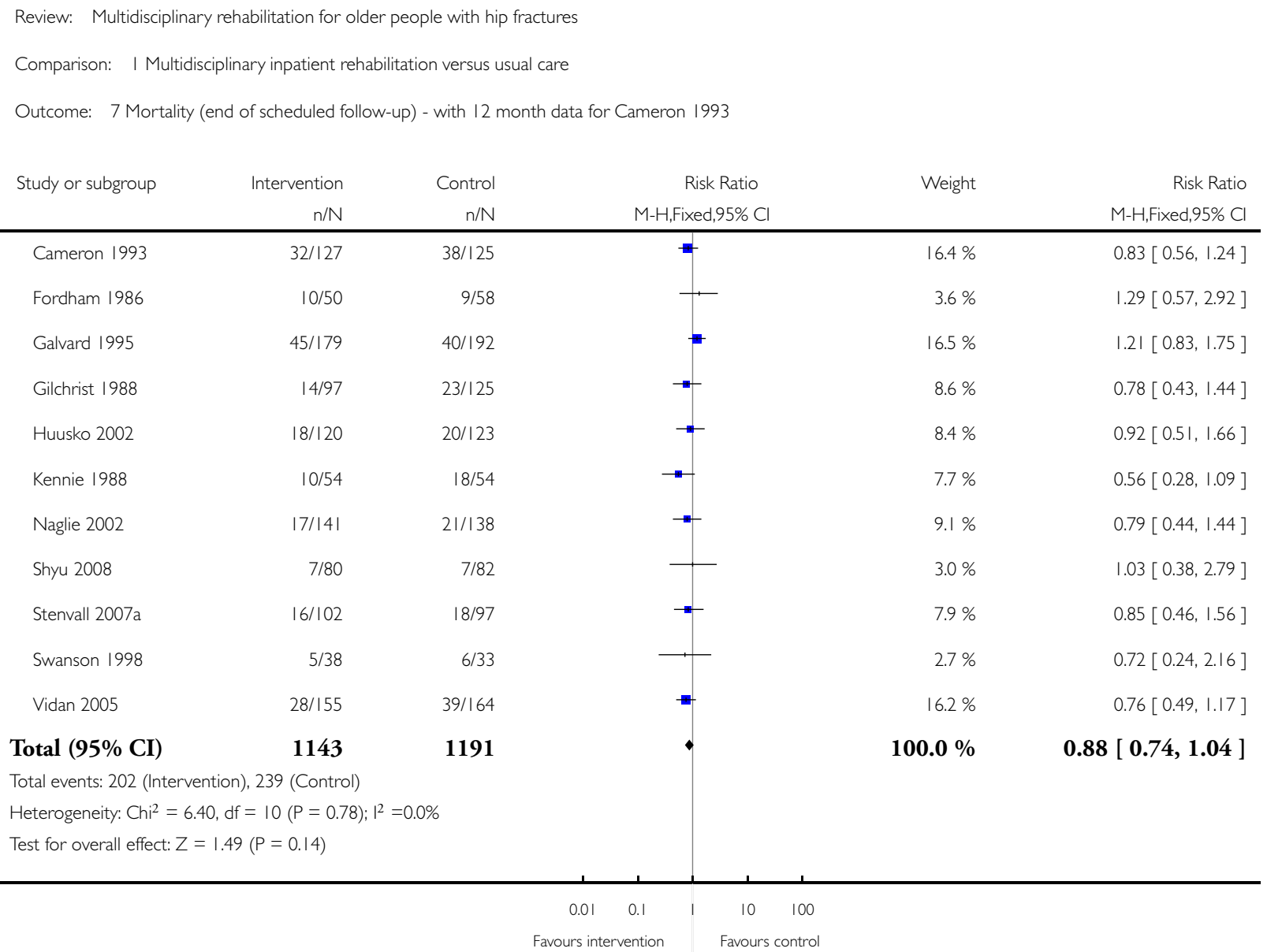


Analysis I.8. Comparison I Multidisciplinary inpatient rehabilitation versus usual care, Outcome 8 Mortality (at discharge).

Review: Multidisciplinary rehabilitation for older people with hip fractures

Comparison: I Multidisciplinary inpatient rehabilitation versus usual care

Outcome: 8 Mortality (at discharge)

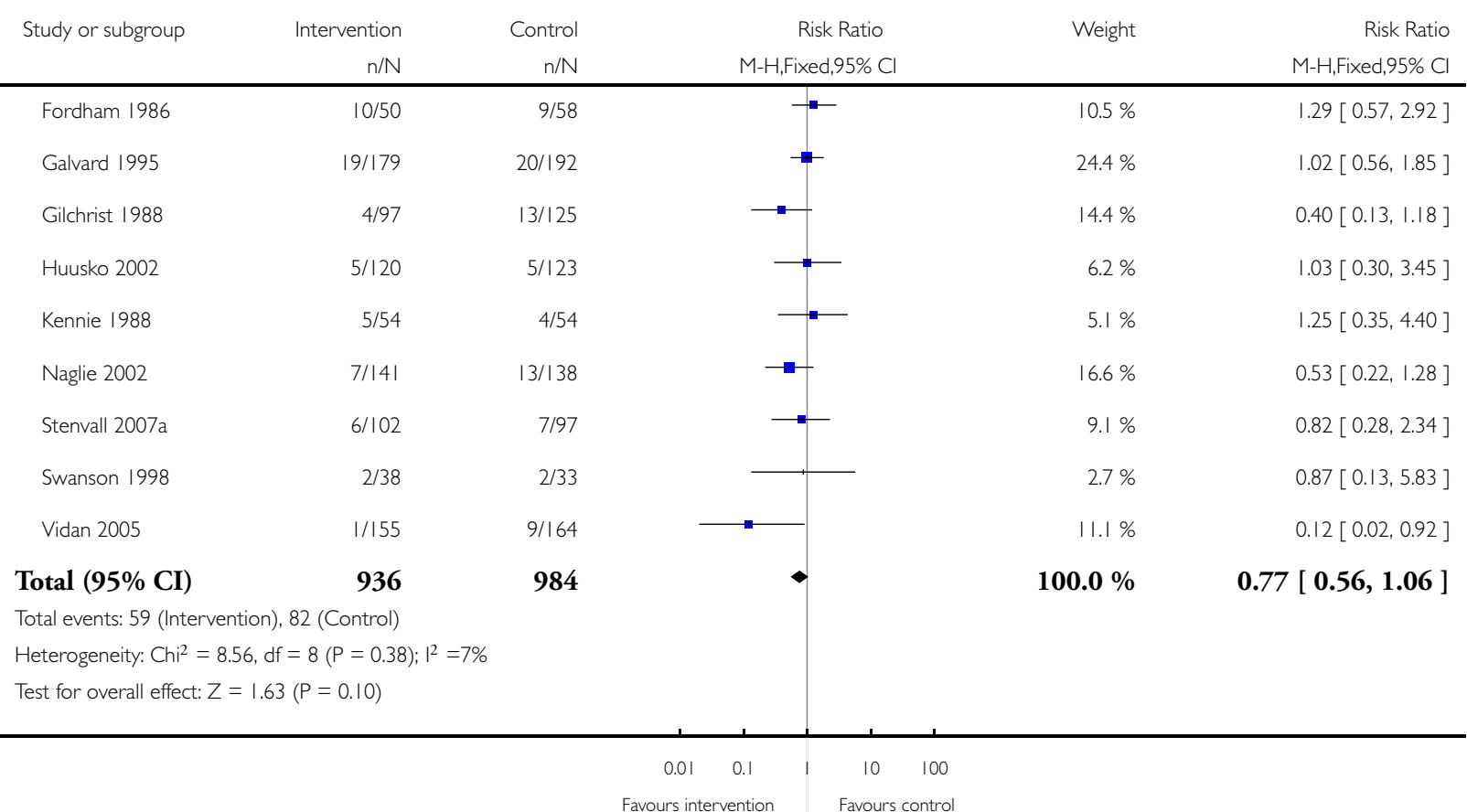


Analysis I.9. Comparison I Multidisciplinary inpatient rehabilitation versus usual care, Outcome 9 Functional outcomes.

Review: Multidisciplinary rehabilitation for older people with hip fractures

Comparison: I Multidisciplinary inpatient rehabilitation versus usual care

Outcome: 9 Functional outcomes

$\begin{array}{llll}\text { Study or subgroup } & \text { Intervention } & \text { Control } & \text { Risk Ratio Ratio }\end{array}$

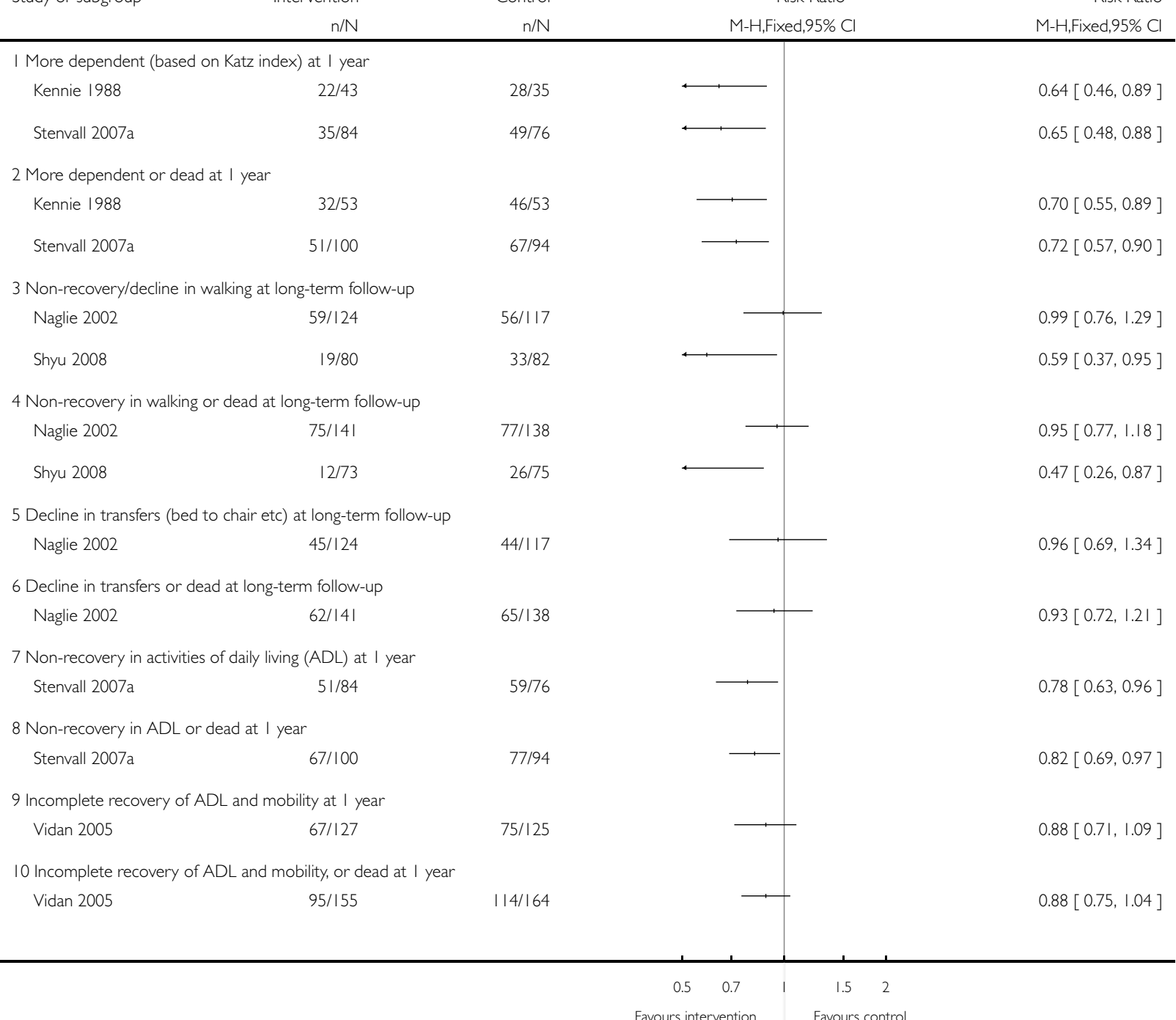


Analysis I.I0. Comparison I Multidisciplinary inpatient rehabilitation versus usual care, Outcome 10 Functional outcomes: Barthel scores at long-term follow-up.

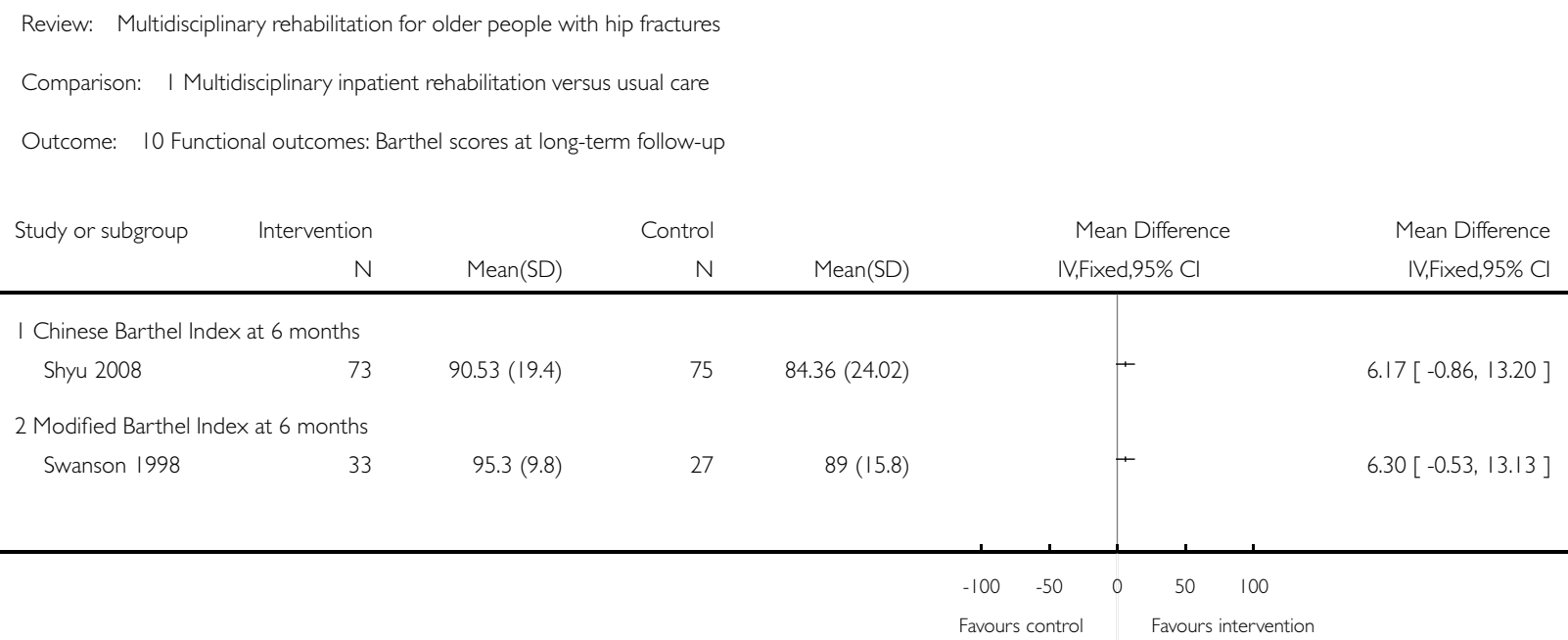

Analysis I.I I. Comparison I Multidisciplinary inpatient rehabilitation versus usual care, Outcome I I Complications.

Review: Multidisciplinary rehabilitation for older people with hip fractures

Comparison: I Multidisciplinary inpatient rehabilitation versus usual care

Outcome: II Complications

Study or subgroup

Intervention

Control

Risk Ratio

Risk Ratio

$\mathrm{n} / \mathrm{N}$

$\mathrm{n} / \mathrm{N}$

M-H,Fixed,95\% Cl

M-H,Fixed,95\% Cl

I pressure sores

Vidan 2005

$8 / 155$

$27 / 164$

$0.31[0.15,0.67]$

2 heart failure

Vidan 2005

12/155

$5 / 164$

$2.54[0.92,7.04]$

3 pneumonia

Vidan 2005

$6 / 155$

$6 / 164$

$1.06[0.35,3.21]$

4 confusion

Vidan 2005

$53 / 155$

$67 / 164$

$0.84[0.63,1.11]$

5 chest infection, cardiac problem, bedsore

Swanson 1998

$6 / 38$

$13 / 33$

$0.40[0.17,0.94]$

$\begin{array}{lllllll}0.1 & 0.2 & 0.5 & 1 & 2 & 5 & 10\end{array}$

Favours Intervention Favours Control

(Continued....) 


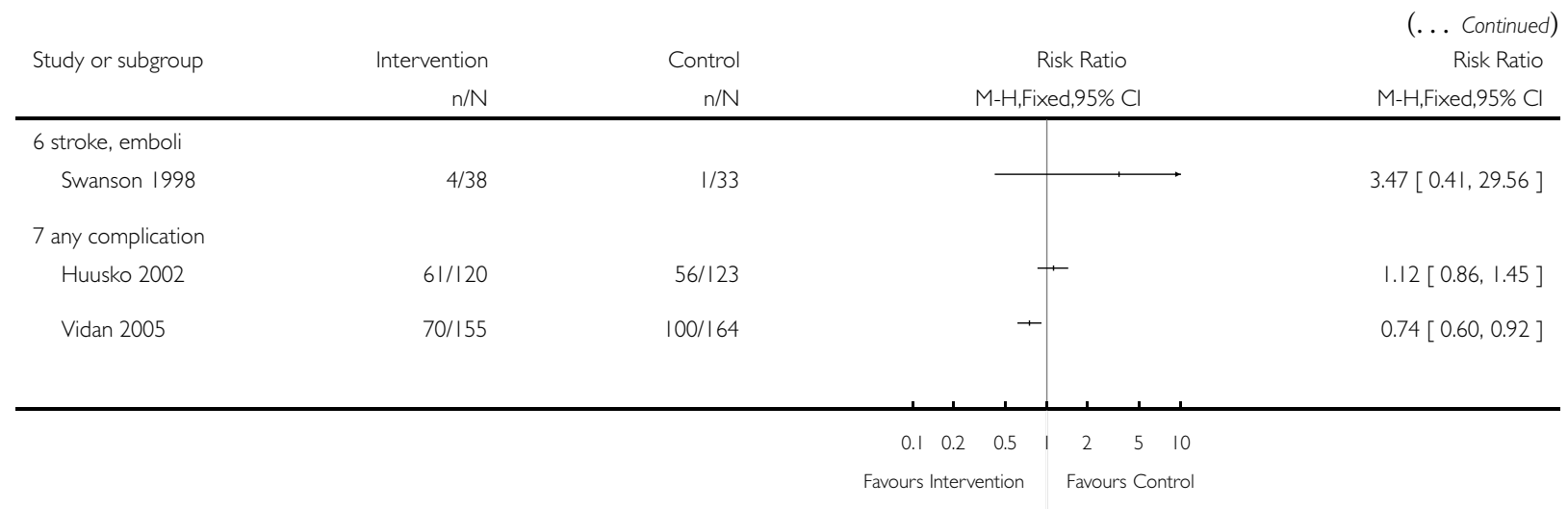

\section{Analysis I.12. Comparison I Multidisciplinary inpatient rehabilitation versus usual care, Outcome 12} Length of hospital stay.

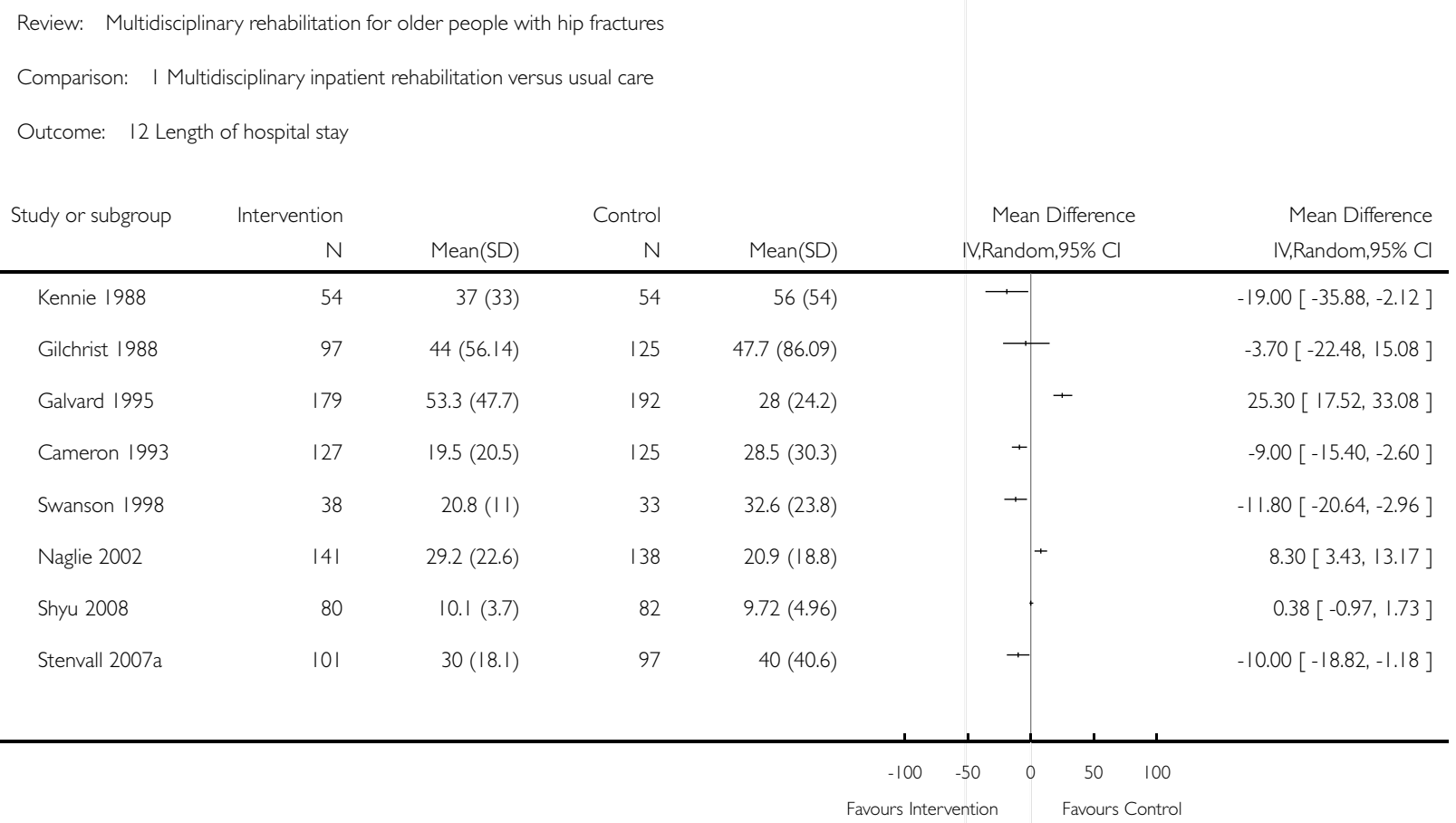


Analysis I.13. Comparison I Multidisciplinary inpatient rehabilitation versus usual care, Outcome I3 Readmitted to hospital during follow-up.

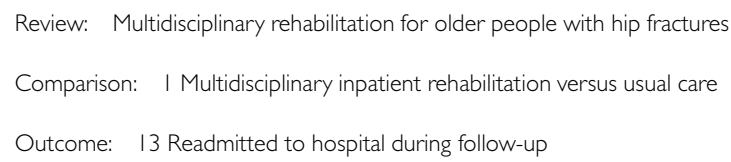

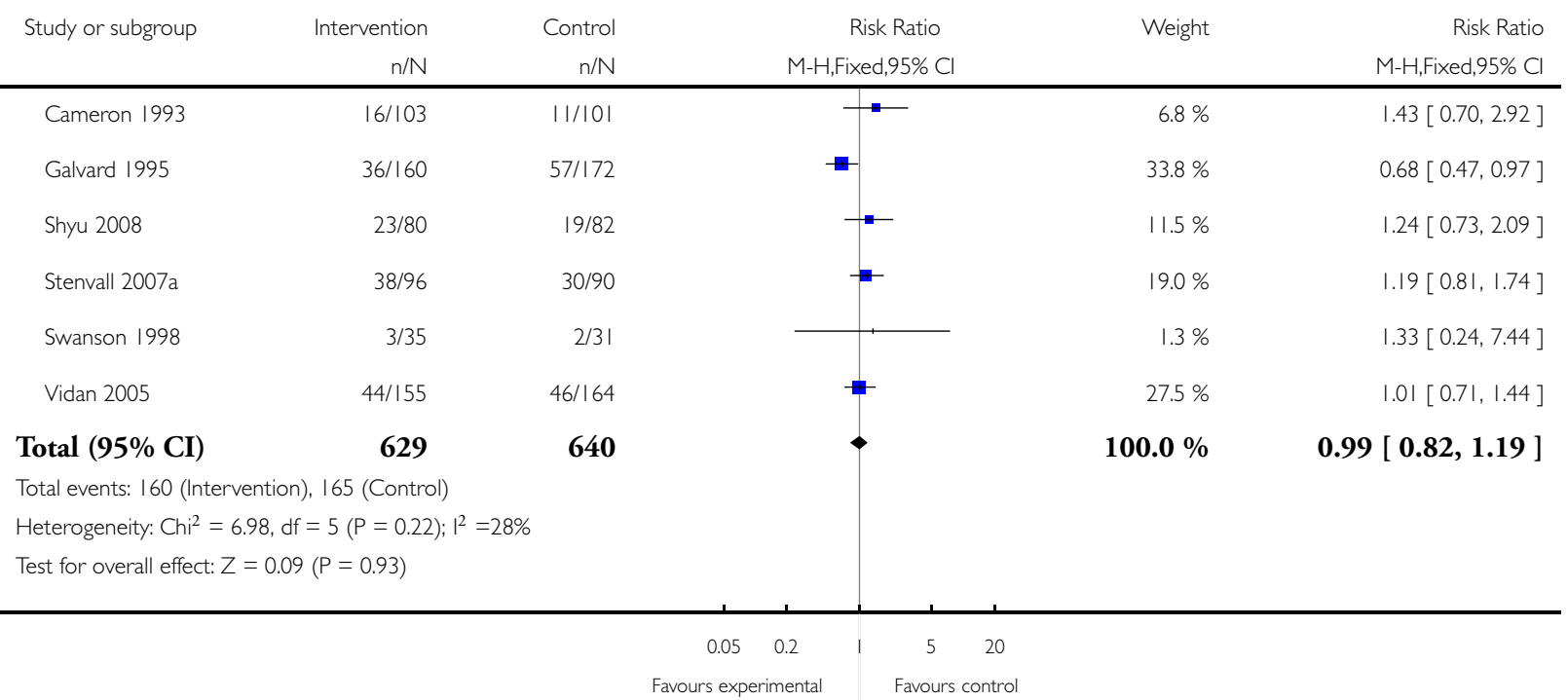


Analysis I.I4. Comparison I Multidisciplinary inpatient rehabilitation versus usual care, Outcome 14 Dead or readmitted to hospital during follow-up.

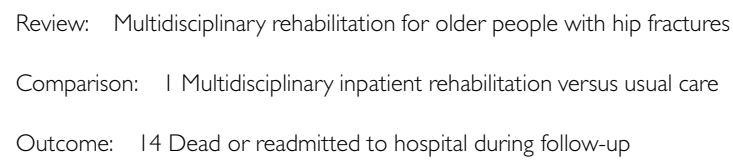

\begin{tabular}{|c|c|c|c|c|c|}
\hline \multirow[t]{2}{*}{ Study or subgroup } & Intervention & Control & Risk Ratio & Weight & Risk Ratio \\
\hline & $\mathrm{n} / \mathrm{N}$ & $\mathrm{n} / \mathrm{N}$ & M-H,Fixed,95\% Cl & & M-H,Fixed,95\% Cl \\
\hline Cameron 1993 & $40 / 127$ & $35 / 125$ & - & $17.2 \%$ & $1.12[0.77,1.65]$ \\
\hline Galvard 1995 & $55 / 182$ & $77 / 196$ & - & $36.1 \%$ & $0.77[0.58,1.02]$ \\
\hline Stenvall 2007a & $44 / 102$ & $37 / 97$ & - & $18.5 \%$ & $1.13[0.81,1.58]$ \\
\hline Swanson 1998 & $6 / 38$ & $4 / 33$ & & $2.1 \%$ & $1.30[0.40,4.22]$ \\
\hline Vidan 2005 & $45 / 157$ & $55 / 164$ & 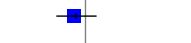 & $26.2 \%$ & $0.85[0.62,1.19]$ \\
\hline Total $(95 \%$ CI $)$ & 606 & 615 & $\bullet$ & $100.0 \%$ & $0.93[0.79,1.09]$ \\
\hline \multicolumn{6}{|c|}{ Total events: 190 (Intervention), 208 (Control) } \\
\hline \multicolumn{6}{|c|}{ Heterogeneity: $\mathrm{Chi}^{2}=4.57, \mathrm{df}=4(\mathrm{P}=0.33) ; \mathrm{I}^{2}=13 \%$} \\
\hline \multicolumn{6}{|c|}{ Test for overall effect: $Z=0.87(P=0.38)$} \\
\hline
\end{tabular}

$\begin{array}{lllllll}0.1 & 0.2 & 0.5 & 1 & 2 & 5 & 10\end{array}$

Favours Intervention Favours Control 
Analysis 2.1. Comparison 2 Accelerated discharge and multidisciplinary home-based rehabilitation versus usual inpatient rehabilitation, Outcome I 'Poor outcome', mortality, institutional care and unable to walk ( 12 months).

Review: Multidisciplinary rehabilitation for older people with hip fractures

Comparison: 2 Accelerated discharge and multidisciplinary home-based rehabilitation versus usual inpatient rehabilitation

Outcome: I 'Poor outcome', mortality, institutional care and unable to walk ( 2 months)

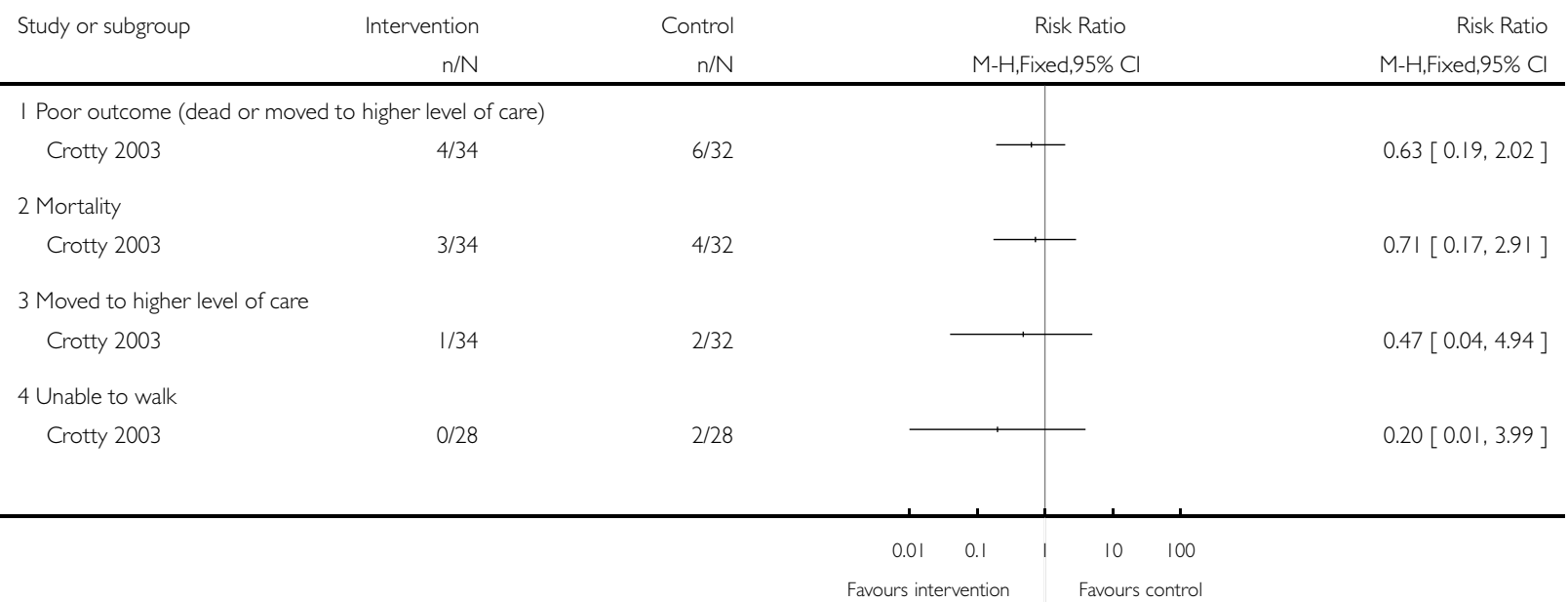

Analysis 2.2. Comparison 2 Accelerated discharge and multidisciplinary home-based rehabilitation versus usual inpatient rehabilitation, Outcome 2 SF-36 scores at 12 months (0: worst to 100: best).

Review: Multidisciplinary rehabilitation for older people with hip fractures

Comparison: 2 Accelerated discharge and multidisciplinary home-based rehabilitation versus usual inpatient rehabilitation

Outcome: 2 SF-36 scores at 12 months (0: worst to I00: best)

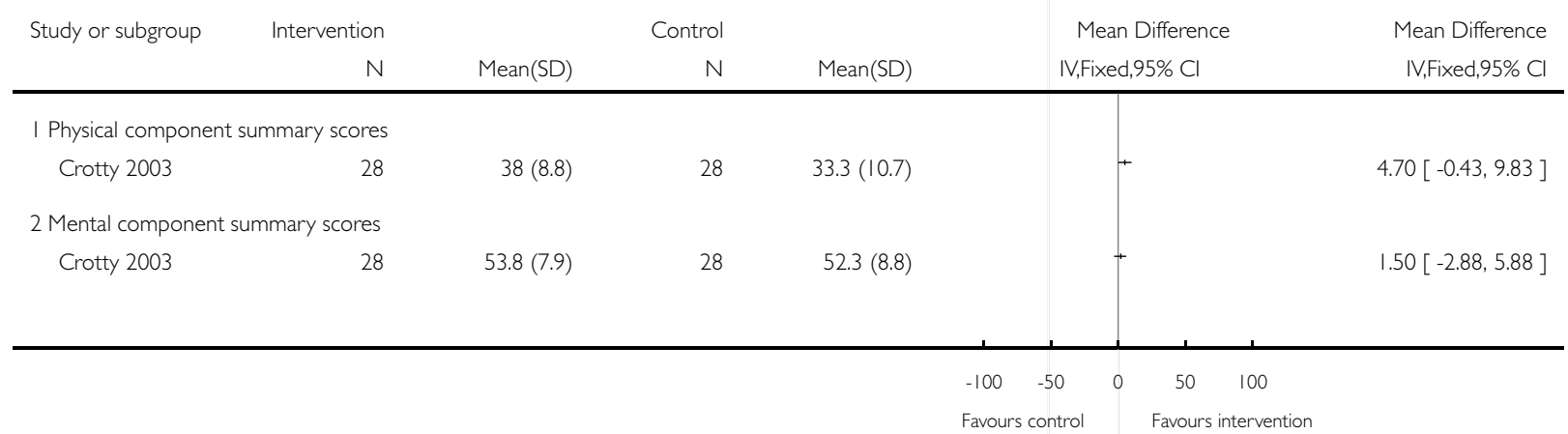


Analysis 2.3. Comparison 2 Accelerated discharge and multidisciplinary home-based rehabilitation versus usual inpatient rehabilitation, Outcome 3 Lengths of hospital or rehabilitation stays (days).

Review: Multidisciplinary rehabilitation for older people with hip fractures

Comparison: 2 Accelerated discharge and multidisciplinary home-based rehabilitation versus usual inpatient rehabilitation

Outcome: 3 Lengths of hospital or rehabilitation stays (days)

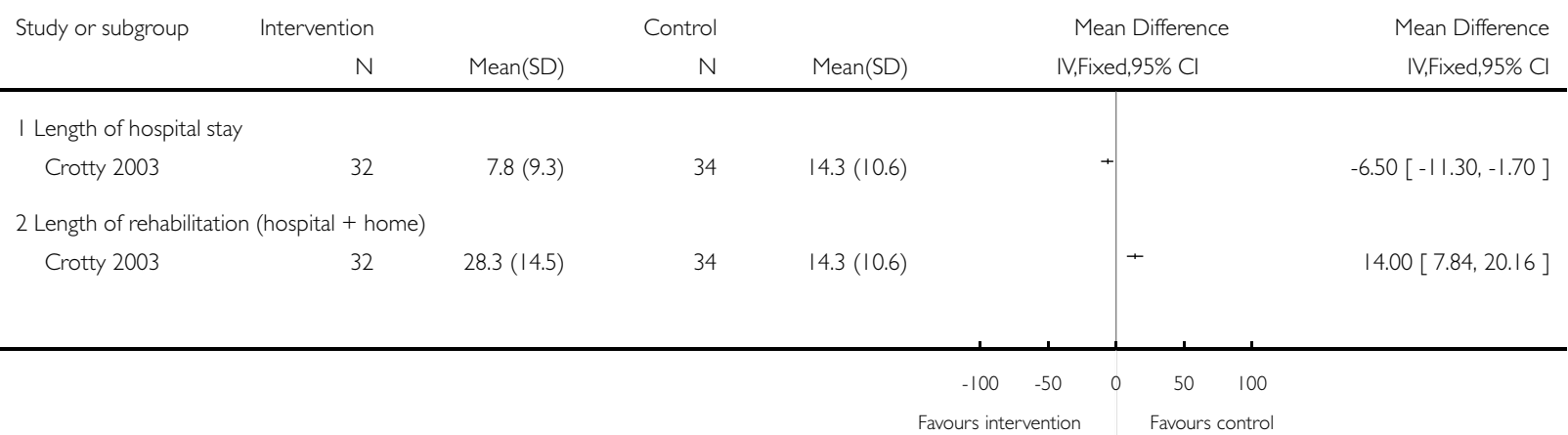

Analysis 2.4. Comparison 2 Accelerated discharge and multidisciplinary home-based rehabilitation versus usual inpatient rehabilitation, Outcome 4 Readmission to hospital during 4 months follow-up.

Review: Multidisciplinary rehabilitation for older people with hip fractures

Comparison: 2 Accelerated discharge and multidisciplinary home-based rehabilitation versus usual inpatient rehabilitation

Outcome: 4 Readmission to hospital during 4 months follow-up

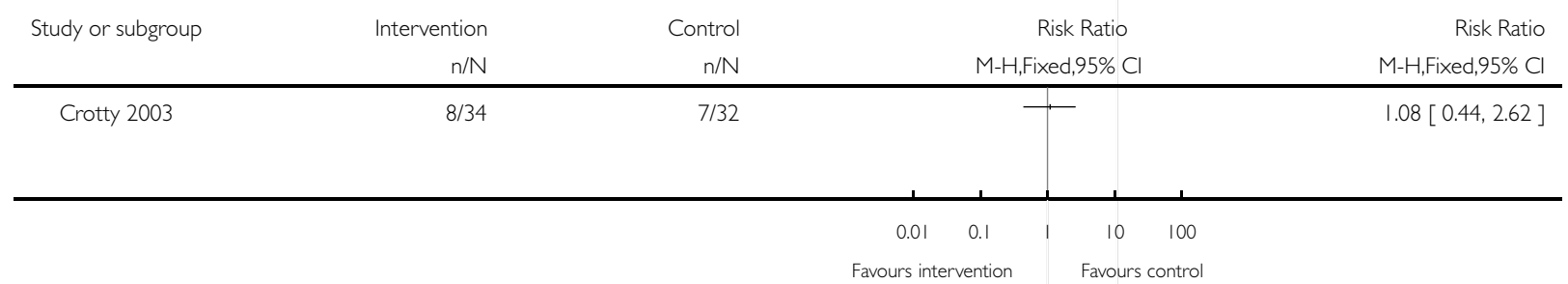


Analysis 3.I. Comparison 3 Intensive versus less intensive community rehabilitation, Outcome I 'Poor outcome', mortality and institutional care (1 2 months).

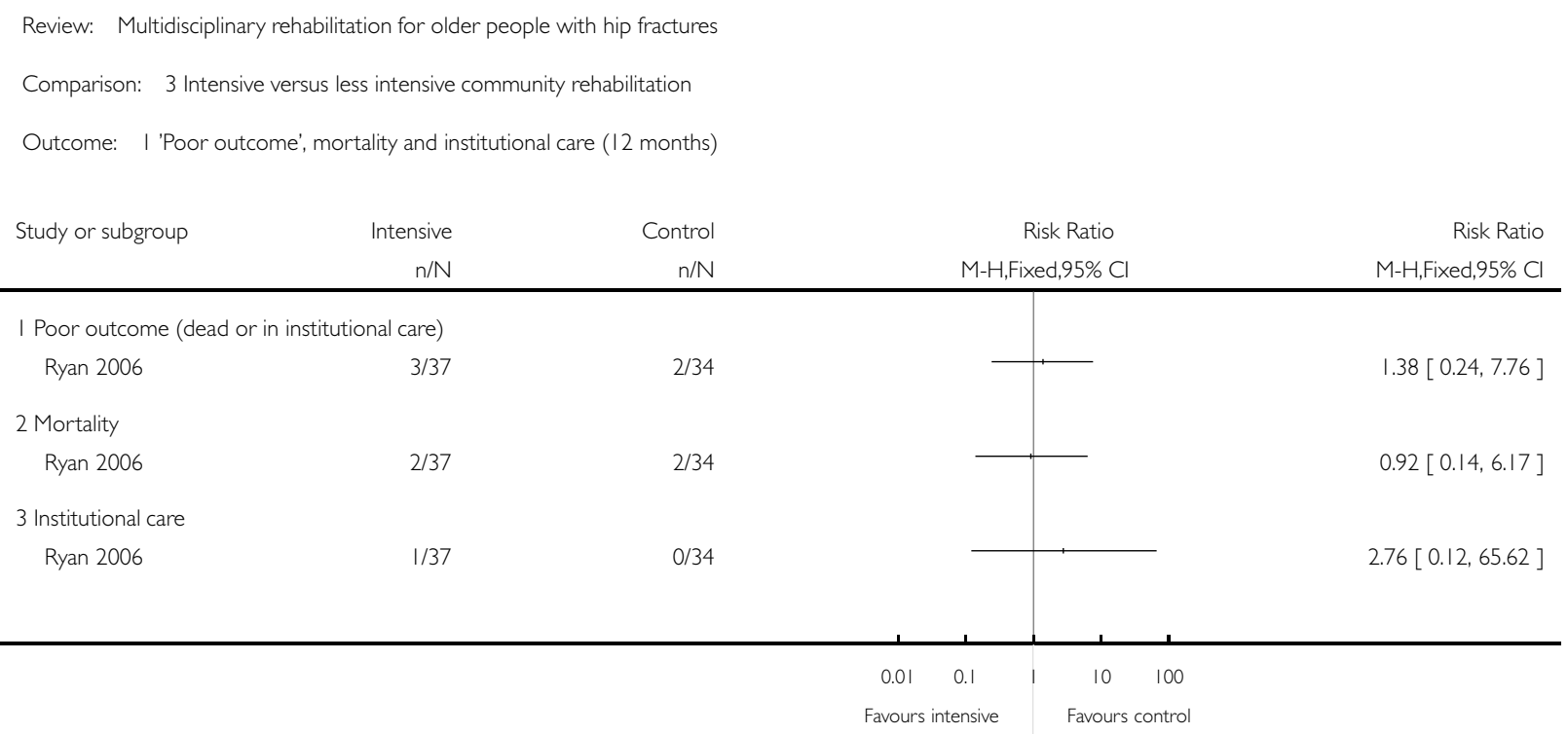

Analysis 3.2. Comparison 3 Intensive versus less intensive community rehabilitation, Outcome 2 Number of contacts over 12 weeks (for participants with hip fracture or stroke).

Review: Multidisciplinary rehabilitation for older people with hip fractures

Comparison: 3 Intensive versus less intensive community rehabilitation

Outcome: 2 Number of contacts over 12 weeks (for participants with hip fracture or stroke)

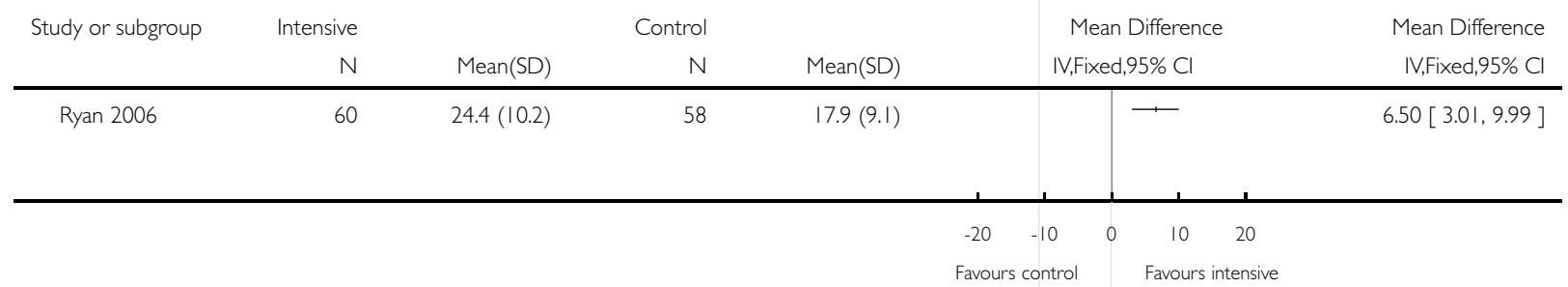


Analysis 4.I. Comparison 4 Exploratory analysis: all settings, Outcome I 'Poor outcome' (long-term followup) by intervention type + Crotty 2003.

Review: Multidisciplinary rehabilitation for older people with hip fractures

Comparison: 4 Exploratory analysis: all settings

Outcome: I 'Poor outcome' (long-term follow-up) by intervention type + Crotty 2003

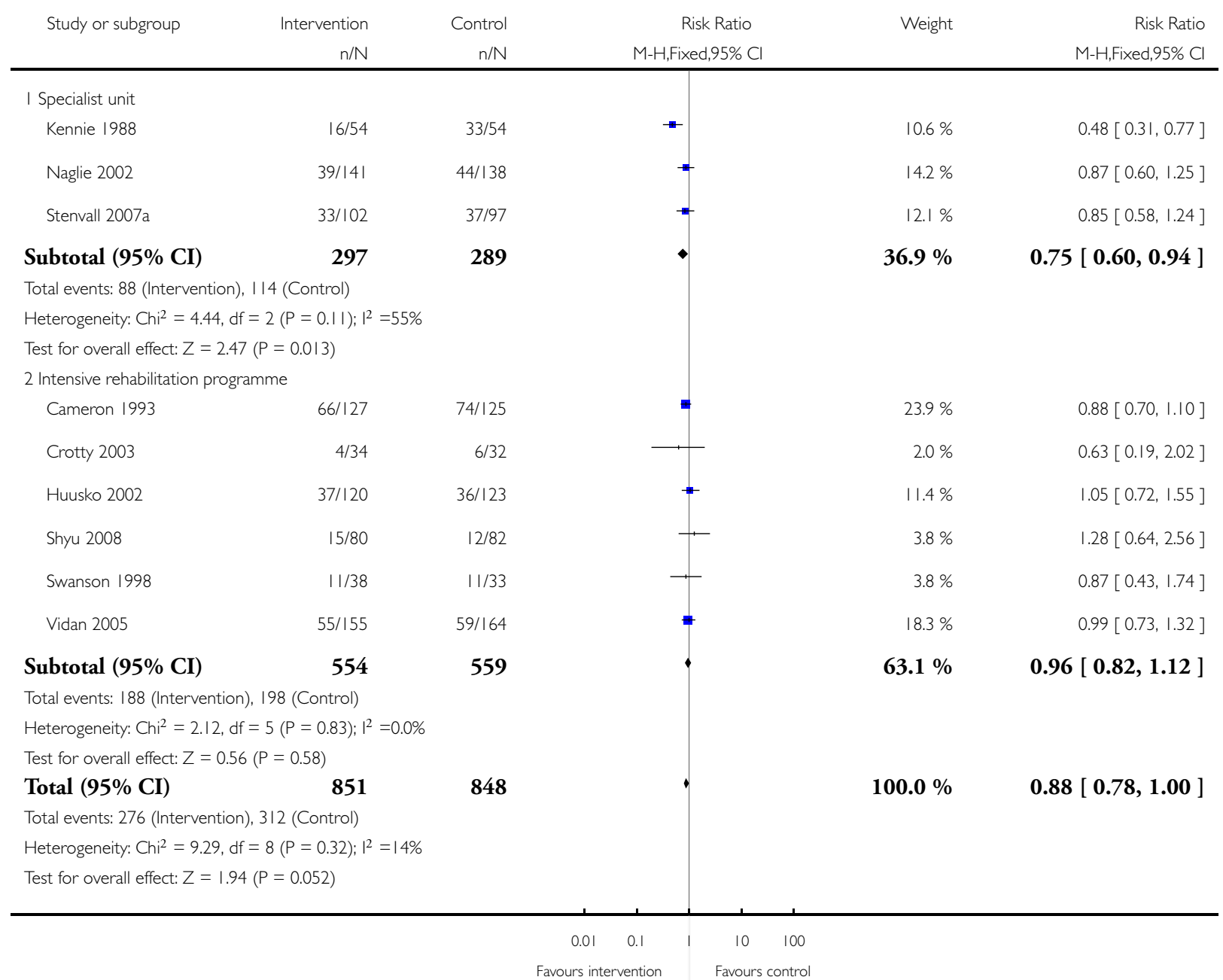




\section{A P P E N D I C E S}

\section{Appendix I. Search strategies}

\section{MEDLINE (Ovid interface) (1950 to April Week 3 2009)}

1. exp Femoral Fractures/(3691)

2. ((hip\$ or $(($ femur $\$$ or femoral\$) adj3 (neck or proximal) $))$ adj4 fracture $\$) . t w . ~(2817)$

3. or/1-2 (4577)

4. Physical Therapy Modalities/or rehabilitation/or activities of daily living/ or early ambulation/or occupational therapy/ or Critical Pathways/ or "Physical Therapy (Specialty)"/(15382)

5. Rehabilitation Nursing/ (219)

6. (rehab\$ or (early adj1 (mobil\$ or discharg\$ or ambulat\$)) or occupational therap\$ or physiotherap\$ or physical therap\$ or multidisciplin\$).tw. (27577)

7. (geriatr\$ or geriatr\$-orthop\$ or orthop?edic-geriatr\$ or ortho\$-geriatr\$ or orthogeriatr\$).tw (4138)

8. hospital at home.tw. (45)

9. exp Hospitalization/ (24901)

10. or/4-9 (63878)

11. and $/ 3,10(642)$

12. exp Aged/ (338899)

13. and/11-12 (513)

14. randomized controlled trial.pt. (64865)

15. controlled clinical trial.pt. (9265)

16. Randomized Controlled Trials/ (22270)

17. Random Allocation/ (10520)

18. Double Blind Method/ (18830)

19. Single Blind Method/ (3730)

20. or/14-19 (108232)

21. Animals/not Humans/ (414752)

22. 20 not 21 (96954)

23. clinical trial.pt. (44586)

24. exp Clinical Trials as topic/ (47885)

25. (clinic\$ adj25 trial\$).tw. (49616)

26. ((singl\$ or doubl\$ or trebl\$ or tripl\$) adj25 (blind\$ or mask\$)).tw. (19461)

27. Placebos/ (3336)

28. placebo\$.tw. (25335)

29. random\$.tw. (125956)

30. Research Design/ (14640)

31. or/23-30 (230596)

32. 31 not $21(212297)$

33. 32 not $22(131263)$

34. or/22,33 (228217)

35. and/13,34 (92)

\section{EMBASE (Ovid interface) (1980 to 2009 week 16)}

1. exp Hip Fracture/ (2144)

2. ((hip\$ or ((femur\$ or femoral\$) adj3 (neck or proximal))) adj4 fracture\$).tw. (1487)

3. or/1-2 (2438)

4. exp Randomized Controlled trial/ (29184)

5. exp Double Blind Procedure/(8887)

6. exp Single Blind Procedure/(1679)

7. exp Crossover Procedure/(2802)

8. Controlled Study/ (491098)

Multidisciplinary rehabilitation for older people with hip fractures (Review)

Copyright $\odot 2009$ The Cochrane Collaboration. Published by John Wiley \& Sons, Ltd. 
9. or/4-8 (497624)

10. ((clinical or controlled or comparative or placebo or prospective $\$$ or randomi\#ed) adj3 (trial or study)).tw. (51634)

11. (random\$ adj7 (allocat\$ or allot\$ or assign\$ or basis\$ or divid\$ or order\$)).tw. (14498)

12. ((singl\$ or doubl\$ or trebl\$ or tripl\$) adj7 (blind\$ or mask\$)).tw. (10097)

13. (cross?over\$ or (cross adj1 over\$)).tw. (4313)

14. ( (allocat $\$$ or allot $\$$ or assign $\$$ or divid $\$$ ) adj3 (condition $\$$ or experiment $\$$ or intervention $\$$ or treatment $\$$ or therap $\$$ or control $\$$ or group\$)).tw. (17007)

15. or/10-14 (76261)

16. or/9,15 (518123)

17. limit 16 to human (331869)

18. and $/ 3,17$ (921)

\section{H I S T O R Y}

Protocol first published: Issue 2, 2008

Review first published: Issue 4, 2009

\begin{tabular}{l|l|l}
\hline 7 July 2008 & Amended & Converted to new review format \\
\hline 19 February 2008 & Amended & $\begin{array}{l}\text { This protocol, published in Issue 2, 2008, precedes the update and scope expansion of a former } \\
\text { review (“Co-ordinated multidisciplinary approaches for inpatient rehabilitation of older patients } \\
\text { with proximal femoral fractures"; last updated Issue 2, 2003), which included inpatient rehabilitation } \\
\text { only. }\end{array}$ \\
\hline
\end{tabular}

\section{CONTRIBUTIONS OFAUTHORS}

The contributions of the authors to the former review ("Co-ordinated multidisciplinary approaches for rehabilitation of older patients with proximal femoral fractures"), from which this review is derived, were described in that document. Ian Cameron and Helen Handoll prepared the initial and subsequent drafts of the protocol for this review, which incorporated feedback and suggestions for rewrites from the other two co-authors, Terry Finnegan and Peter Langhorne.

Helen Handoll co-ordinated the production of the review, performed searches, located studies and contacted trialists. All four authors participated in study selection, and assessed risk of bias and extracted data from trial reports. Helen Handoll wrote the first draft and performed the primary data analyses and, with some contribution from Jenson Mak, entered trial data into RevMan. All reviewers critically reviewed subsequent drafts and commented on any re-analyses and revisions at all stages. Helen Handoll and Ian Cameron are the guarantors of the review. 


\section{DECLARATIONSOF INTEREST}

As Ian Cameron was the principal investigator of one of the included trials, this trial was assessed independently by other review authors.

\section{SOURCES OF SUPPORT}

\section{Internal sources}

- University of Teesside, Middlesbrough, UK.

- Rehabilitation Studies Unit, Faculty of Medicine, University of Sydney, Australia.

\section{External sources}

- The Cochrane Collaboration, Prioritisation Project Fund, Not specified. Funding for completion of priority review

\section{DIFFERENCES BETWEEN PROTOCOL ANDREVIEW}

We renamed 'outpatient' rehabilitation as 'ambulatory' rehabilitation because the latter term better covers the various setting: home, outpatient department or day hospital.

We clarified that supervision of multidisciplinary care, particularly in the ambulatory setting, could be by a specialist clinician other than a physician.

We assessed risk of bias using the tool outlined in the Cochrane Handbook for Systematic Reviews of Interventions.

\section{NOTES}

The title of the former review (Cameron 2001) was: "Co-ordinated multidisciplinary approaches for inpatient rehabilitation of older patients with proximal femoral fractures". The protocol for Cameron 2001 was published in Issue 2, 1995; and the first version of the review appeared in Issue 2, 1997. This was followed by two substantive updates published in Issue 4, 2000 and Issue 3, 2001 respectively, and then by two minor updates published in Issue 2, 2002 and Issue 2, 2003 respectively. 